\title{
DESENVOLVIMENTO DE DISPOSITIVO DE GERAÇÃO E ABSORÇÃO ATIVA DE ONDAS PARA TANQUE DE ENSAIOS DE ESTRUTURAS OCEÂNICAS
}

\author{
Dissertação apresentada à Escola Po- \\ litécnica da Universidade de São Paulo \\ para obtenção do Título de Mestre em \\ Engenharia.
}




\title{
DESENVOLVIMENTO DE DISPOSITIVO DE GERAÇÃO E ABSORÇÃO ATIVA DE ONDAS PARA TANQUE DE ENSAIOS DE ESTRUTURAS OCEÂNICAS
}

\author{
Dissertação apresentada à Escola Po- \\ litécnica da Universidade de São Paulo \\ para obtenção do Título de Mestre em \\ Engenharia. \\ Área de concentração: \\ Mecatrônica \\ Orientador: \\ Prof. Dr. Julio Cezar Adamowski
}


Este exemplar foi revisado e alterado em relação à versão original, sob responsabilidade única do autor e com a anuência de seu orientador.

São Paulo, 04 de dezembro de 2007.

Assinatura do autor

Assinatura do orientador

FICHA CATALOGRÁFICA

Carneiro, Mario Luis

Desenvolvimento de dispositivo de geração e absorção ativa de ondas para tanque de ensaios de estruturas oceânicas / M.L. Carneiro. -- ed.rev. -- São Paulo, 2007.

$98 \mathrm{p}$.

Dissertação (Mestrado) - Escola Politécnica da Universidade de São Paulo. Departamento de Engenharia Mecatrônica e de Sistemas Mecânicos.

1.Tanque de provas 2.Ondas (Análise) 3.Ondógrafo I.Universidade de São Paulo. Escola Politécnica. Departamento de Engenharia Mecatrônica e de Sistemas Mecânicos Il.t. 
Dedico este trabalho aos meus pais e à Patricia por me apoiarem em todos os momentos 


\section{Agradecimentos}

Ao meu orientador, Prof. Dr. Julio Cezar Adamowski, por todo o apoio, encorajamento e orientação durante o mestrado.

Ao Prof. Dr. Kazuo Nishimoto, pela idealização do presente projeto.

Ao Prof. Dr. Flávio Buiochi, pelas sugestões durante o desenvolvimento do sensor de altura de ondas por ultra-som.

À Patricia, por todo o incentivo e carinho.

Ao Heitor pela ajuda com o Linux e o LATEX.

Ao Pedro pela ajuda na montagem do protótipo, no algorítmo de reflexão de ondas e na realização dos ensaios.

Aos amigos do laboratório do Departamento de Engenharia Naval e Oceânica, Carlos, João e Marlei, pelas sugestões para a melhoria do protótipo e pela ajuda durante os ensaios.

Ao Nilson, pelas sugestões no desenvolvimento da eletrônica do sensor de altura de ondas por ultra-som.

Aos técnicos da usinagem Gilberto e Adilson, que fabricaram algumas das peças do protótipo e outros dispositivos para ensaios.

Aos amigos Davi, Eduardo, Ignácio, Luciana, Marco, Rodrigo, Sérgio, Sydnei e Sylvio pelas discussões acadêmicas e não acadêmicas.

À Petrobras pelo apoio financeiro concedida para a realização deste trabalho.

À Escola Politécnica da USP pela oportunidade na realização deste e de outros trabalhos.

E por fim, à todos os que contribuíram direta ou indiretamente para a realização deste trabalho. 


\section{Resumo}

Este trabalho trata do desenvolvimento de um gerador e absorvedor dinâmico de ondas para ensaios com modelos de estruturas oceânicas em escala reduzida, em tanques que simulam as condições de operação encontradas no mar.

Propõe-se um procedimento para o projeto de geradores absorvedores ativos de ondas do tipo placa basculante. O procedimento desenvolvido é aplicado ao projeto de um protótipo com quatro módulos geradores de ondas. O protótipo resultante foi instalado no laboratório do Departamento de Engenharia Naval e Oceânica a fim de ser utilizado pela Escola Politécnica da Universidade de São Paulo no estudo de algoritmos de geração e absorção de ondas.

Para a medição de altura de onda, foi desenvolvido um sensor por ultra-som utilizando a técnica de pulso-eco e uma guia de ondas. O sensor, fixado junto ao batedor de ondas, é utilizado para a realimentação do controlador de absorção de ondas. Foram realizados ensaios para sua caracterização e comparação com um sensor capacitivo. Nesses ensaios, o sensor por ultra-som apresentou melhor linearidade e resposta dinâmica do que o sensor capacitivo, além de não necessitar de calibração antes de cada ensaio.

Foram realizados ensaios com ondas regulares para a avaliação do desempenho do gerador de ondas e para o levantamento das funções de transferência do motor, da onda progressiva longe do atuador $H / S$ e da onda próxima ao atuador $H_{0} / S$ que considera as ondas evanescentes. Os resultados experimentais apresentaram uma boa concordância com o modelo teórico. 


\section{Abstract}

This work aims at the development of a wave generator and dynamic absorber to perform tests with models of oceanic structures in reduced scale, in tanks that simulate operating conditions found in the sea.

It is proposed a procedure to design absorbing wavemakers of the flap type. The developed procedure is then applied for the construction of an prototype with four wave generator modules. The prototype was installed in the laboratory of the Naval Architecture and Ocean Engineering Departament, to be used by the Polytechnical School of University of São Paulo in the study of wave absorption algorithms.

In order to mesure wave heights, it was developed a wave height sensor based on ultrasound, applying the pulse-echo technique and a waveguide. This sensor, attached to the flap of the wave generator, is used as part of the feedback system of the wave absorption controller. Tests for its characterization and comparison with a capacitive sensor had been carried out. In those tests, the ultrasonic sensor had presented a better linearity and dynamic response then the capacitive sensor, moreover it does not need calibration before each test.

Tests with regular waves had been carried out for the evaluation of the performance of the wave generator and the determination of the transfer functions of the servomotors, of the progessive wave far of the actuator $H / S$ and the wave next to the actuator $H_{0} / S$ that considers the evanescentes waves. The experimental results had presented a good agreement with the theoretical model. 


\section{Sumário}

\section{Lista de Figuras}

\section{Lista de Tabelas}

\section{Lista de Abreviaturas}

\section{Lista de Símbolos}

1 Introdução 1

1.1 Breve histórico . . . . . . . . . . . . . . . . . . . . . 2

1.2 Revisão Bibliográfica . . . . . . . . . . . . . . . . . . . . . . 5

1.3 Objetivos . . . . . . . . . . . . . . . . . . . . . 6

2 Ondas - Revisão teórica $\quad 8$

2.1 Teoria de ondas . . . . . . . . . . . . . . . . . . 9

2.2 Teoria linear de ondas . . . . . . . . . . . . . . . . . . . 12

2.2.1 Equação diferencial característica . . . . . . . . . . . . . . 12

2.2.2 Condições de contorno . . . . . . . . . . . . . . . . . . 13

2.2.3 Solução para onda progressiva . . . . . . . . . . . . . . . . . 14

2.2.4 Simplificações para águas rasas e profundas . . . . . . . . . . 16

2.3 Reflexão de ondas . . . . . . . . . . . . . . . . . . . . . 17

3 Desenvolvimento do gerador de ondas 19

3.1 Requisitos de projeto do gerador . . . . . . . . . . . . . . . . . . . 19

3.2 Descrição do gerador de ondas . . . . . . . . . . . . . . . 20

3.3 Modelo hidrodinâmico do gerador de ondas . . . . . . . . . . . . . 20 
3.4 Máxima altura de onda f . . . . . . . . . . . . . . . . . . . . . 22

3.5 Dimensionamento do flap . . . . . . . . . . . . . . . . . 23

3.6 Dimensionamento do gerador de ondas . . . . . . . . . . . . . . 27

3.7 Dimensionamento e seleção do servomotor e do fuso de esferas recirculantes ................................ 31

3.8 Mecanismo do gerador de ondas ............... . . . 35

$\begin{array}{lll}4 & \text { Sensor de altura de ondas } & 37\end{array}$

4.1 Sensor resistivo . . . . . . . . . . . . . . . . . . . . 37

4.2 Sensor capacitivo . . . . . . . . . . . . . . . . . . . . . . . . 38

4.3 Sensor por ultra-som . . . . . . . . . . . . . . . . . . . . . . . 39

4.3 .1 Revisão teórica . . . . . . . . . . . . . . . . . . . . . . 39

4.3.2 Descrição da eletrônica . . . . . . . . . . . . . . . . . . 49

4.3.3 Descrição do software . . . . . . . . . . . . . . . 50

4.3.4 Ensaios preliminares . . . . . . . . . . . . . 51

4.4 Caracterização dos sensores de altura de onda capacitivo e por ultra-som 53

4.4.1 Calibração estática . . . . . . . . . . . . . . . . . 53

4.4.2 Calibração dinâmica . . . . . . . . . . . . . . . 55

5 Arquitetura de controle $\quad 61$

5.1 Sistema eletrônico . . . . . . . . . . . . . . . . . . . . 62

5.1.1 Malha de controle de posição . . . . . . . . . . . . 63

5.1 .2 Sistema de proteção elétrica . . . . . . . . . . . . 65

5.2 Software de controle . . . . . . . . . . . . . . . . . 66

6 Análise de desempenho do gerador de ondas 69

6.1 Procedimento experimental . . . . . . . . . . . . . . . . . . 69

6.2 Resultados preliminares . . . . . . . . . . . . . . . . . 72

6.3 Análise dos dados . . . . . . . . . . . . . . . . . . . . 75

6.3.1 Função de transferência do motor . . . . . . . . . . . . . 76 
6.3.2 Função de transferência $H / S \ldots$. . . . . . . . . . 76

6.3.3 Função de transferência $H_{0} / S \ldots$. . . . . . . . . . 78

6.3.4 Detecção de ondas refletidas . . . . . . . . . . . . . . . 80

7 Conclusões e recomendações $\quad 84$

7.1 Recomendações para futuras pesquisas . . . . . . . . . . . . . . 86

$\begin{array}{lr}\text { Referências } & \mathbf{8 8}\end{array}$

Apêndice A - Método experimental para estudo da reflexão

Apêndice B - Dados obtidos no ensaio de caracterização do gerador de ondas 


\section{Lista de Figuras}

1.1 Ilustração da evolução do tanque de ensaios. . . . . . . . . . . . . 3

1.2 Tanque AMOEBA da Universidade de Osaka. Reproduzido de NAOE (2000) . . . . . . . . . . . . . . . . . . . . 4

1.3 Tanque Deep Sea Basin do NMRI. Reproduzido de Tamura (2006). . 4

1.4 Ilustração da concepção do Calibrador Hidrodinâmico do TPN da Universidade de São Paulo.

2.1 Ilustração da formação de ondas em uma certa região como resultado dos processos de interações e superposições. Reproduzido de Martins (2003).

2.2 Distribuição da energia da agitação marítima em função dos fenômenos atuantes. Reproduzido de Martins (2003). . . . . . . . . . . . . . . 9

2.3 Formato dos principais tipos de ondas de gravidade. Adaptado de CEM (2002) . . . . . . . . . . . . . . . . . . . . . . 11

2.4 Aplicabilidade das teorias de ondas. Adaptado de CEM (2002). . . . 11

2.5 Sistema de coordenadas e nomenclatura da onda. . . . . . . . . . 12

2.6 Condições de contorno para ondas regulares. . . . . . . . . . . . . . 13

2.7 Trajetória das partículas de água de ondas progressivas em diferentes profundidades. Adaptado de Dean e Dalrymple (1984) (a) Águas rasas; (b)Águas intermediárias; (c)Águas profundas. . . . . . . . . . 17

3.1 Esquema do mecanismo do gerador de ondas. . . . . . . . . . . . . . 20

3.2 Função de transferência $H / S \ldots$. . . . . . . . . . . . . . . . . 23

3.3 Limites de altura de onda. . . . . . . . . . . . . . . . . . . . . . 24

3.4 Dimensões básicas do flap. . . . . . . . . . . . . . . . . . . . . . . . . 24

3.5 Modelo de viga biapoiada em vibração natural não amortecida ( $1^{\circ}$ modo). 25

3.6 Modelo discretizado do flap. . . . . . . . . . . . . . . . . . . . 26 
3.7 Modos de vibração do flap. . . . . . . . . . . . . . . . . . . 26

3.8 Curso máximo do atuador. . . . . . . . . . . . . . . . . . . . . . . 27

3.9 Velocidade linear máxima do acionamento. . . . . . . . . . . . . . . 28

3.10 Aceleração linear máxima do acionamento. . . . . . . . . . . . . . . 28

3.11 Rotação máxima do fuso. . . . . . . . . . . . . . . . . . . . . . . . . 29

3.12 Aceleração angular máxima do fuso. . . . . . . . . . . . . . . . . . . . 29

3.13 Momento máximo de acionamento no ponto de pivotamento do flap. 31

3.14 Força máxima de acionamento. . . . . . . . . . . . . . . . . . . 31

3.15 Torque de acionamento. . . . . . . . . . . . . . . . . . . . . 32

3.16 Potência de acionamento. . . . . . . . . . . . . . . . . . . . 33

3.17 Inércia de acionamento. . . . . . . . . . . . . . . . . . . 33

3.18 Detalhe do sistema de acionamento. . . . . . . . . . . . . . . . 35

3.19 Desenho do gerador de ondas. . . . . . . . . . . . . . . . 35

3.20 Foto do gerador de ondas. . . . . . . . . . . . . . . . . . . . . 36

4.1 llustração do sensor de altura de onda resistivo. . . . . . . . . . . . . 38

4.2 Deslocamento das partículas em uma onda acústica: (a) posição de equilíbrio; (b) onda de cisalhamento; (c) onda longitudinal. . . . . . 40

4.3 Reflexão e transmissão de uma onda acústica. . . . . . . . . . . . . . . 41

4.4 Reflexão e transmissão de uma onda acústica com incidência oblíqua. 43

4.5 Típica construção de um transdutor de ultra-som de banda larga. Adaptado de Andrade (2006).

4.6 Campo acústico de um transdutor de ultra-som (a)Seção longitudinal; (b)Variação de intensidade de pressão ao longo do eixo do transdutor. Reproduzido de Costa et al. (2004).

4.7 Formato dos lóbulos de pressão para um transdutor circular com $k \boldsymbol{a}=10$. Reproduzido de Kinsler et al. (1982). . . . . . . . . . . . . . . . . . 45

4.8 Técnica de pulso-eco para medição de nível. . . . . . . . . . . . . . 45

4.9 Ilustração da perda de sinal do sensor por ultra-som para uma superfície inclinada. 
4.10 Ilustração do sensor por ultra-som com guia de ondas.

4.11 Propagação de uma onda de ultra-som por um caminho de ziguezague. 47

4.12 Velocidades de fase e de grupo em uma guia de ondas, onde $p$ é a distribuição de pressão, $C$ é a velocidade de fase, $C_{g}$ é a velocidade de grupo e $c$ é a velocidade em um meio infinito. . . . . . . . . . . 47

4.13 Guia de ondas tipo lâmina. . . . . . . . . . . . . . . . . . . . . . . 48

4.14 Eletrônica do sensor de ultra-som. . . . . . . . . . . . . . . . . . . . 49

4.15 Janela de tempo de detecção de eco. . . . . . . . . . . . . . . . . . . 51

4.16 Guia de ondas do sensor de ultra-som. . . . . . . . . . . . . . . . 52

4.17 Foto do ensaio do sensor de altura de ondas por ultra-som. . . . . . 52

4.18 Exemplos de sinais obtidos no ensaio do sensor de altura de ondas. . 53

4.19 Superfície perfurada modificada da guia de onda. . . . . . . . . . . . 54

4.20 Calibração estática do sensor de altura de onda capacitivo. . . . . . . . 54

4.21 Calibração estática do sensor de altura por ultra-som. . . . . . . . . 55

4.22 Perturbação da superfície da água durante o ensaio de caracterização dos sensores de altura de onda. . . . . . . . . . . . . . . . . 56

4.23 Configuração do ensaio de caracterização dos sensores de altura de onda.

4.24 Exemplo de série temporal do ensaio dinâmico do sensor capacitivo. Freqüência de $1,0 \mathrm{~Hz}$ e $14 \%$ de declividade . . . . . . . . . . . . . 58

4.25 Resposta dinâmica do sensor de altura de ondas por ultra-som. . . . 58

4.26 Resposta dinâmica do sensor de altura de ondas capacitivo. . . . . . 59

5.1 Arquitetura do sistema de controle. . . . . . . . . . . . . . . . . 61

5.2 Placas desenvolvidas para o sistema de controle. . . . . . . . . . . 62

5.3 Foto do rack. . . . . . . . . . . . . . . . . 63

5.4 Diagrama do controle de posição do driver do servomotor. . . . . . . 64

5.5 Esquema do sistema de proteção. . . . . . . . . . . . . . . . . 65

5.6 Fluxograma da rotina de geração de ondas. . . . . . . . . . . . . . 67

5.7 Ilustração do funcionamento do algoritmo de Bresenham. . . . . . . 68 
6.1 Configuração do ensaio para levantamento da função de transferência do protótipo (medidas em metros). . . . . . . . . . . . . . 70

6.2 Fluxo de água entre a parede do tanque e o flap. . . . . . . . . . . 72

6.3 Vedações instaladas no gerador de ondas. . . . . . . . . . . . . . 72

6.4 Onda gerada após a instalação das vedações. . . . . . . . . . . . . 73

6.5 Absorvedor poroso instalado atrás do gerador de ondas. . . . . . . . 74

6.6 Efeito de ressonância lateral do tanque. . . . . . . . . . . . . . . . . 74

6.7 Exemplo de série temporal do ensaio para determinação do desempenho do gerador de ondas. Freqüência de $1,25 \mathrm{~Hz}$ e $1 \%$ de declividade. 75

6.8 Função de transferência experimental do motor. . . . . . . . . . . . 76

6.9 Função de transferência $H / S$ experimental. . . . . . . . . . . . . . . 77

6.10 Comparação entre as formas de onda para as declividades de $1 \%$ e $8 \%$ (freqüência $0,75 \mathrm{~Hz}$ ). . . . . . . . . . . . . . . . . . . . . . . 78

6.11 Função de transferência $H_{0} / S$ experimental. . . . . . . . . . . . . . 80

6.12 Exemplo da detecção de reflexão de ondas. Declividade 4\% e freqüência $2,25 \mathrm{~Hz}$.

6.13 Comparação entre as alturas de onda incidente calculadas pelo algoritmo de reflexão e pela densidade espectral de potência. . . . . . . . . 82

6.14 Coeficiente de reflexão da praia. . . . . . . . . . . . . . . . . 83

A.1 Arranjo experimental para medição de reflexão de ondas. . . . . . . . 91 


\section{Lista de Tabelas}

1.1 Principais características dos tanque AMOEBA, Deep Sea Basin e Calibrador Hidrodinâmico. . . . . . . . . . . . . . . . . . . . . . 5

2.1 Formas assintóticas das funções hiperbólicas. . . . . . . . . . . . . 17

3.1 Freqüência natural do flap em função da largura da aba $b$ (modelo de viga). . . . . . . . . . . . . . . . . . . . . . . 25

3.2 Análise de sensibilidade do $\operatorname{MEF}(b=30 \mathrm{~mm}) \ldots \ldots 26$

3.3 Dados obtidos no dimensionamento do gerador de ondas. . . . . . 34

3.4 Principais componentes do sistema de acionamento. . . . . . . . . . 34

3.5 Principais características do servomotor selecionado. . . . . . . . . . 34

3.6 Principais características do fuso selecionado. . . . . . . . . . . . . . . 34

4.1 Sensores de altura de onda mais utilizados entre os membros do ITTC (1999). . . . . . . . . . . . . . . . . . . 37

4.2 Coeficientes da equação 4.4 . . . . . . . . . . . . . . . . . . . . . . 40

4.3 Coeficientes de calibração estática dos sensores de altura de onda para uma curva de segunda ordem $\left(f(x)=A x^{2}+B x+C\right) \ldots \ldots 5$

4.4 Freqüência de corte dos sensores de altura de onda . . . . . . . . . . 60

5.1 Sinais digitais de controle do motor . . . . . . . . . . . . . . . . . 64

6.1 Dados do ensaio para determinação do desempenho do gerador de ondas.

B.1 Ensaio para determinação do desempenho do gerador de ondas. Módulo dos sensores capacitivos. . . . . . . . . . . . . . . . . . . . . 96

B.2 Ensaio para determinação do desempenho do gerador de ondas. Módulo e fase dos sensores por ultra-som.

B.3 Ensaio para determinação do desempenho do gerador de ondas. Módulo e fase dos motores. 


\title{
Lista de Abreviaturas
}

\author{
AMOEBA Advanced Multiple Organized Experimental Basin \\ CCF condição de contorno do fundo \\ CCLP condição de contorno lateral periódica \\ CCDSL condição de contorno dinâmica da superfície livre \\ CCCSL condição de contorno cinemática na superfície livre \\ IPT Instituto de Pesquisas Tecnológicas do Estado de São Paulo \\ LENO Laboratório de Engenharia Naval e Oceânica da Escola Politécnica da USP \\ MEF método de elementos finitos \\ NAE nível de água estático \\ NMRI National Maritime Research Institute \\ TPN Tanque de Provas Numérico \\ USP Universidade de São Paulo
}




\section{Lista de Símbolos}

Os seguintes símbolos serão utilizados:

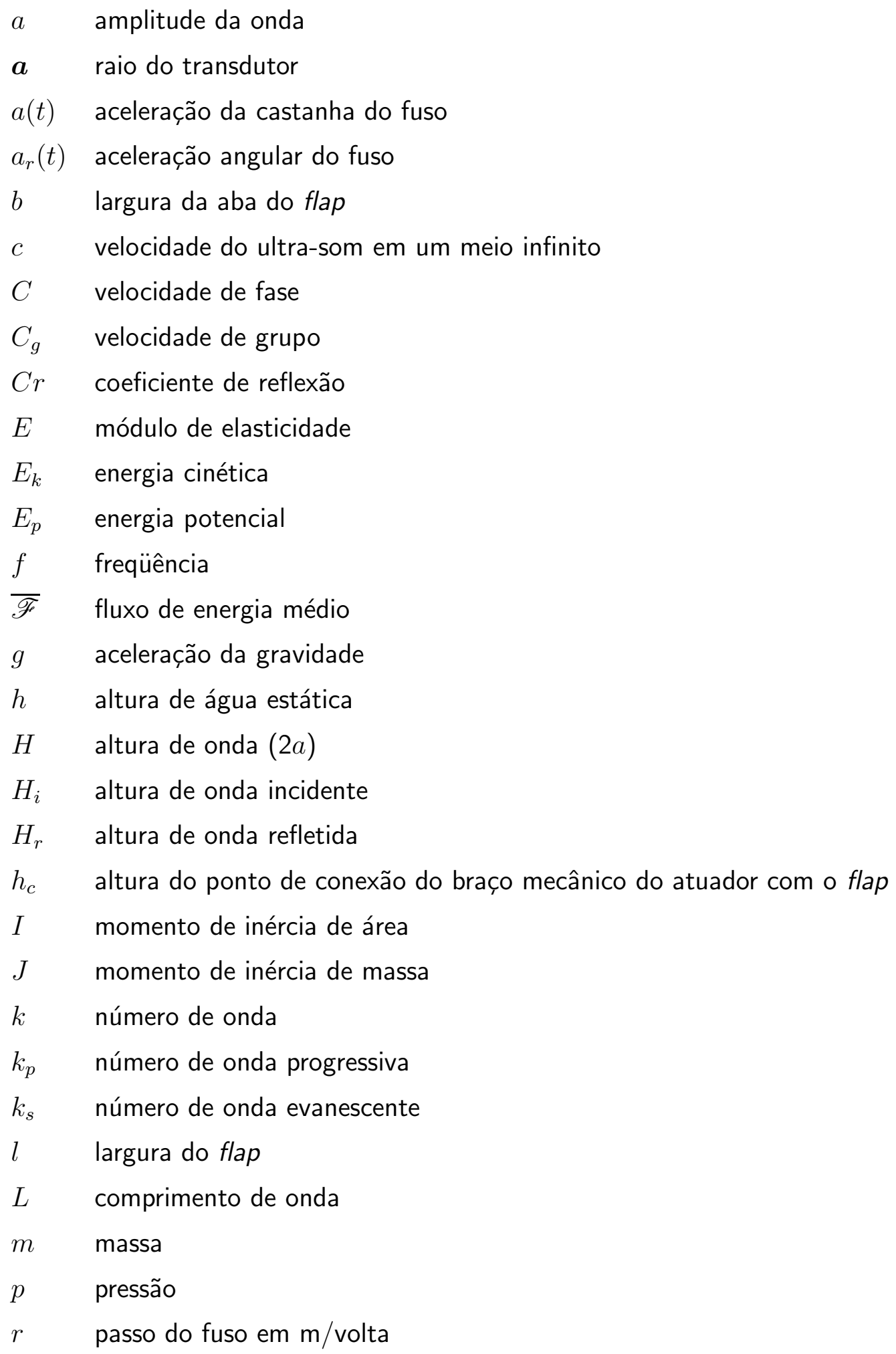




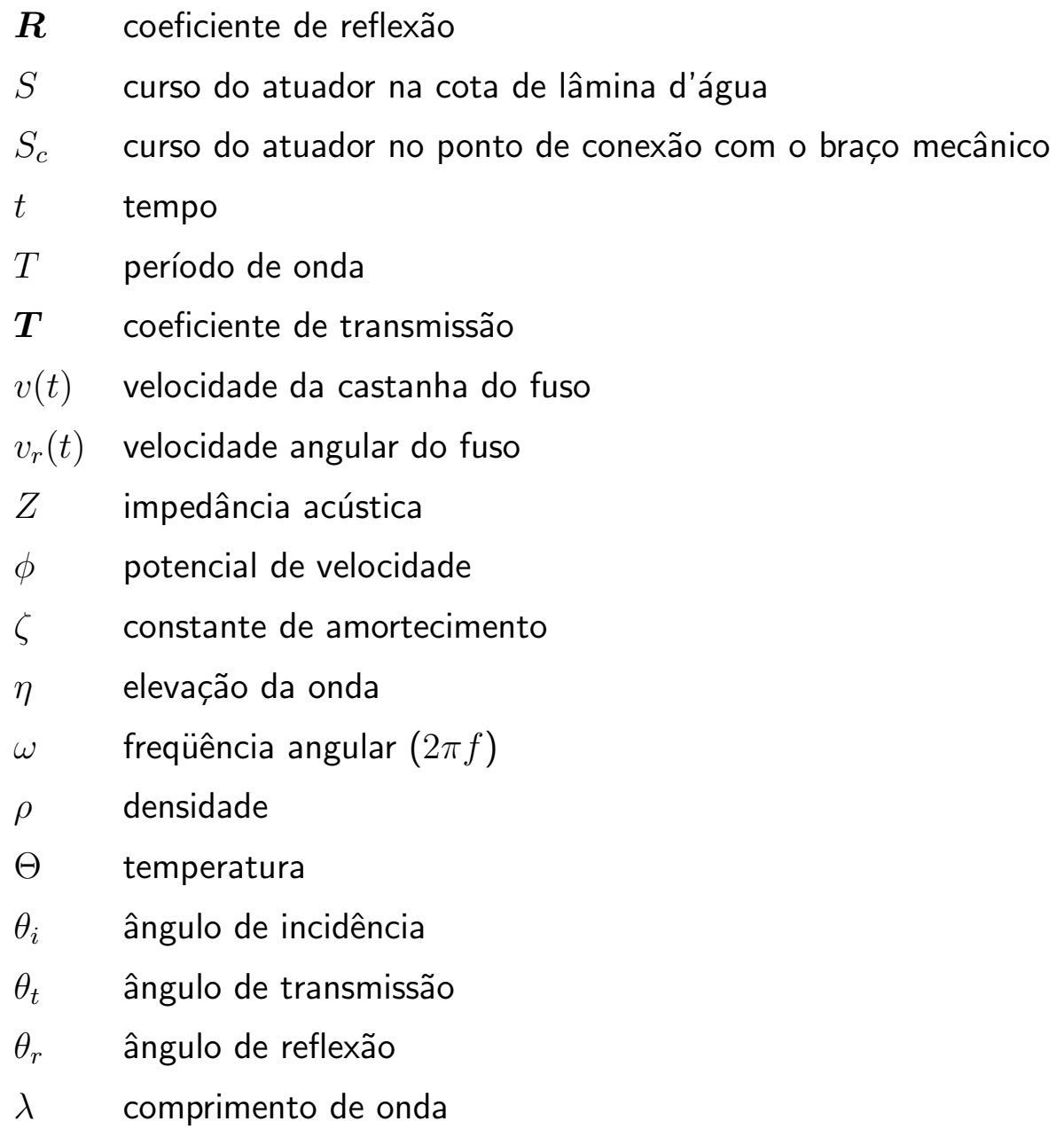




\section{Introdução}

A construção de estruturas oceânicas, como embarcações e plataformas de exploração de petróleo, envolve muita responsabilidade devido a aspectos da segurança, confiabilidade e ao seu desempenho na realização das tarefas para as quais foram projetadas. No seu desenvolvimento existem muitos fatores ligados ao ambiente de operação que devem ser levados em consideração, porém uma boa previsão do seu comportamento em condições naturais combinadas é difícil de se realizar com base apenas em modelos teóricos.

Desta forma, uma etapa essencial no desenvolvimento de sistemas oceânicos é a realização de ensaios com modelos em escala reduzida em tanques que simulam algumas das condições ambientais de trabalho, como ondas, vento e correnteza.

Nos experimentos realizados com ondas, o problema das ondas refletidas na parede do tanque de ensaios é muito sério, tornando difícil a realização da simulação do movimento real do oceano. Para evitar esse problema existe a necessidade de tanques com grandes dimensões e absorvedores passivos. Outra possibilidade que vem sendo explorada é a utilização de um sistema gerador de ondas, que pode gerá-las e absorvê-las simultaneamente em todo o contorno do tanque.

A capacidade de absorver as ondas na parede do tanque permite que suas dimensões sejam bastante reduzidas em comparação com os tanques de ensaios tradicionais, pois desta forma se consegue simular um mar infinito num tanque de dimensões finitas.

No desenvolvimento de um sistema de absorção ativa de ondas são necessárias diversas disciplinas em engenharia: os aspectos estruturais e dinâmicos do mecanismo do gerador de ondas; hidrodinâmica, provendo a teoria para a geração e absorção de ondas; teoria de controle, necessária para prover estabilidade e eficiência tanto para o movimento do acionamento do gerador de ondas quanto a correção deste movimento para se realizar a absorção; eletrônica e microprocessadores para a implementação prática da realimentação do controle, incluindo seu sistema de sensoriamento (SCHäFFER; KLOPMAN, 2000). 
O foco principal deste trabalho é projeto mecânico do gerador de ondas, o desenvolvimento de sua arquitetura de controle e a implementação de um sensor de altura de ondas por ultra-som.

\subsection{Breve histórico}

Desde longa data, trabalhos experimentais de Engenharia Oceânica e Arquitetura Naval tem usado tanques, pode-se citar o Dr. William Froude (1810-1879) que realizou ensaios de resistência ao avanço com modelos de embarcações em escala reduzida em tanque sem ondas.

Com o aumento da demanda do conhecimento da performance de embarcações em ondas, gradualmente os tanques foram equipados com um gerador de ondas. Como a reflexão das ondas deveria ser evitada, tanques cada vez maiores foram construídos e foi adicionado um absorvedor de ondas passivo do tipo praia na parede oposta à do gerador, de forma a permitir ensaios com maior duração.

Os geradores de ondas evoluiram de uma única peça para muitos segmentos, tornando possível gerar ondas com direções variadas no tanque, podendo simular mares irregulares em quase qualquer local no tanque, usando também reflexões da onda na parede lateral. Para simular condições de mar real com melhor performance os tanques foram equipados com geradores de ondas em dois lados.

Desenvolvimentos recentes trouxeram o gerador de ondas ativo que pode gerar e absorver ondas simultaneamente em todo o contorno do tanque, eliminando reflexões que causam interferências no campo de ondas especificado. A forma do tanque não precisa necessariamente ser retangular, como analisaram Naito et al. (1996).

Na figura 1.1 pode-se ver uma ilustração das etapas da evolução dos tanques de ensaios.

A bibliografia consultada mostra que existem atualmente no mundo apenas dois tanques com todo o seu contorno constituído por geradores ativos de onda, ambos localizados no Japão.

O primeiro tanque com essa nova configuração foi construído na Universidade de Osaka e tem sido testado há mais de 12 anos. Denominado Advanced Multiple Organized Experimental Basin (AMOEBA), o tanque possui pequenas dimensões (tabela 1.1), necessitando de modelos em escala muito pequena, fora dos padrões usuais. Desta forma, o AMOEBA é utilizado principalmente no desenvolvimento e validação de modelos de geração e absorção de ondas. Outra característica que se 


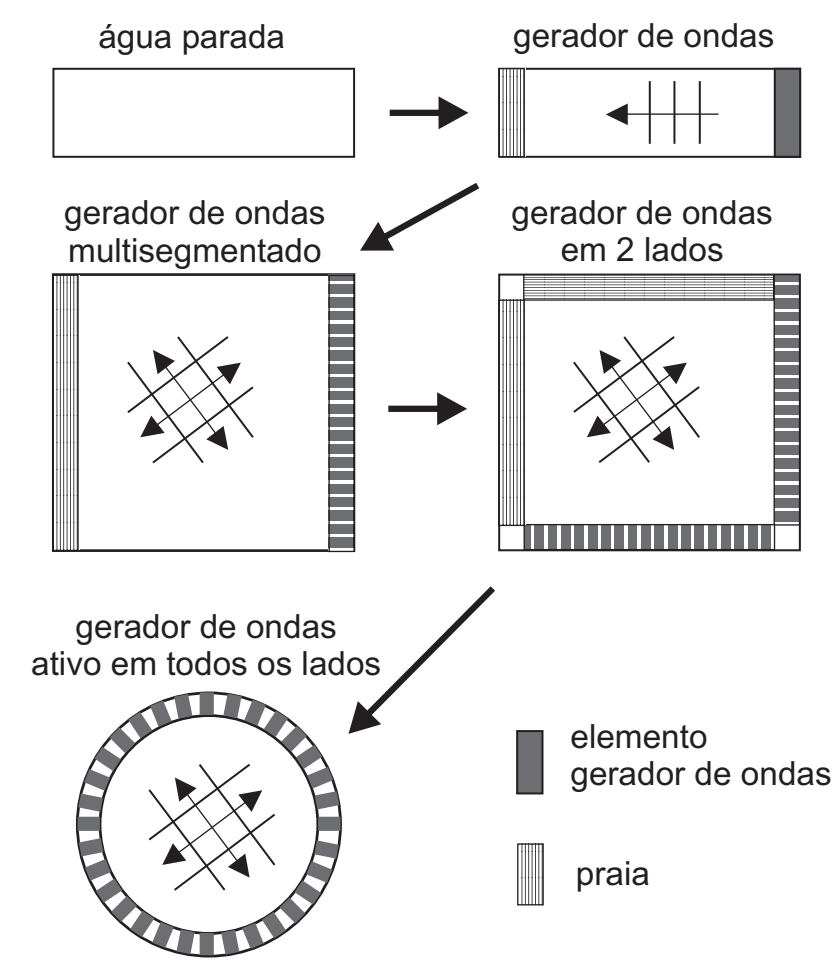

Figura 1.1: Ilustração da evolução do tanque de ensaios.

destaca é a flexibilidade do posicionamento dos módulos geradores de onda do tipo cunha, permitindo a mudança da configuração do tanque em formato circular, elíptico ou outra geometria formada por um polígono convexo (NAITO, 2006).

O outro tanque, construído em escala real, foi inaugurado em 2002 no National Maritime Research Institute (NMRI), possui configuração circular e é cercado por geradores de onda do tipo flap. O Deep Sea Basin, foi desenvolvido para simular o comportamento do mar em águas profundas. Possuindo um poço central com $35 \mathrm{~m}$ de profundidade, pode trabalhar com modelos em escala 1:100 simulando condições de águas profundas até $3500 \mathrm{~m}$. O tanque possui ainda um sistema de geração de correntes em seu poço central (TAMURA, 2006).

As figuras 1.2 e 1.3 apresentam respectivamente fotos do AMOEBA da Universidade de Osaka e do Deep Sea Basin do NMRI.

A Escola Politécnica da Universidade de São Paulo está desenvolvendo um tanque de provas para estudos de estruturas offshore. Os ensaios de tais estruturas servem para calibração de modelos numéricos computacionais do Tanque de Provas Numérico (TPN) (TPN, 2004). A figura 1.4 apresenta uma ilustração do estado atual da concepção do projeto do tanque. Na tabela 1.1 foi feita uma comparação entre os dois tanques do Japão e o previsto para o calibrador hidrodinâmico. 


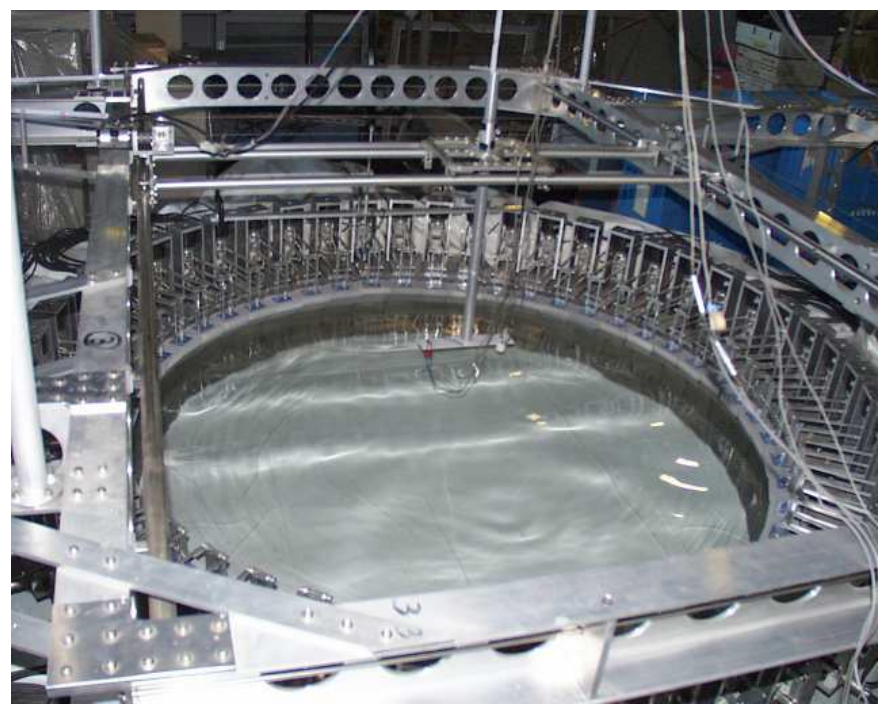

Figura 1.2: Tanque AMOEBA da Universidade de Osaka. Reproduzido de NAOE (2000)

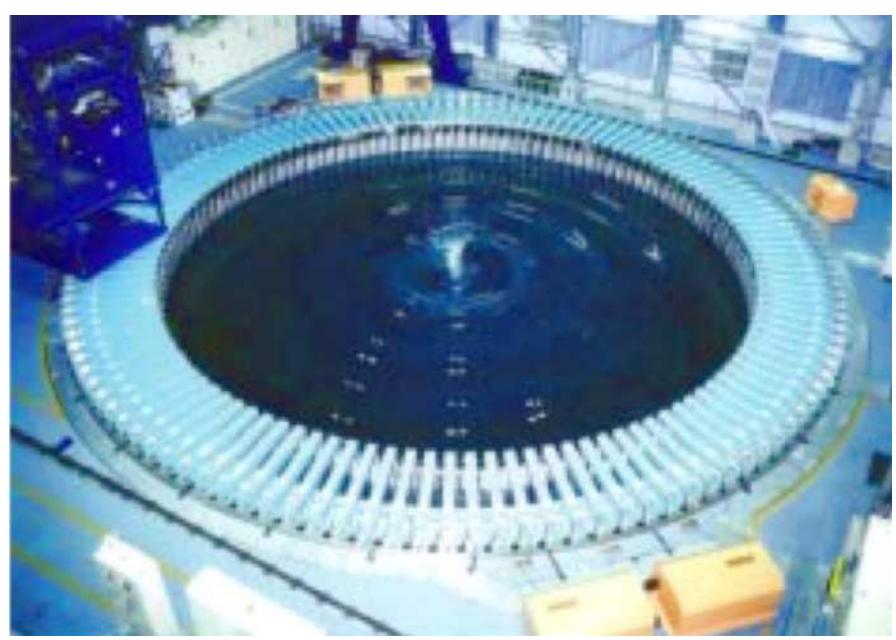

Figura 1.3: Tanque Deep Sea Basin do NMRI. Reproduzido de Tamura (2006).

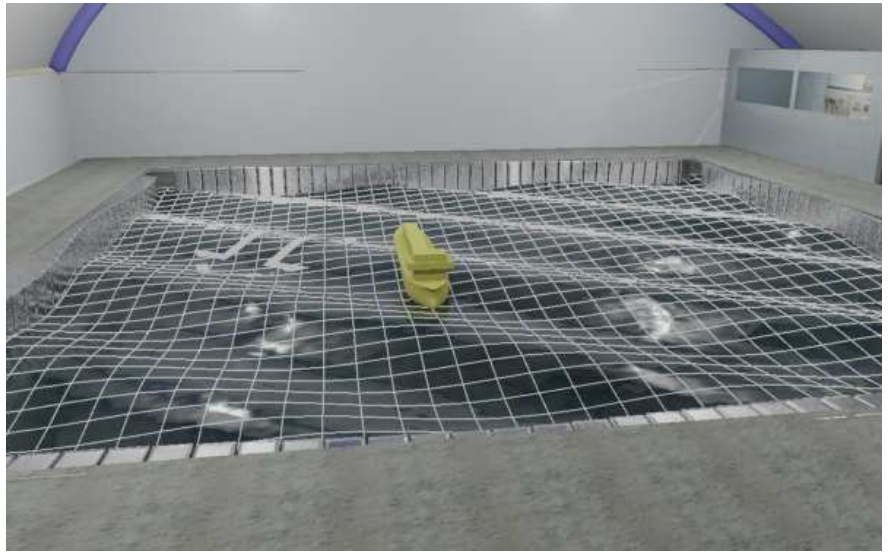

Figura 1.4: Ilustração da concepção do Calibrador Hidrodinâmico do TPN da Universidade de São Paulo. 
Tabela 1.1: Principais características dos tanque AMOEBA, Deep Sea Basin e Calibrador Hidrodinâmico.

\begin{tabular}{lccc}
\hline Tanque & AMOEBA & Deep Sea Basin & $\begin{array}{c}\text { Calibrador } \\
\text { hidrodinâmico }\end{array}$ \\
\hline Geometria & Flexível & Circular & Quadrada \\
Dimensões & $\varnothing 1,6 \mathrm{~m}$ & $\varnothing 14 \mathrm{~m}$ & $14 \mathrm{~m} \times 14 \mathrm{~m}$ \\
Profundidade & $0,3 \mathrm{~m}$ & $5 \mathrm{~m}$ & $4 \mathrm{~m}$ \\
Tipo do gerador & Cunha & Flap & Flap \\
Quantidade de atuadores & 50 & 128 & 148 \\
Dimensões do atuador & $0,1 \mathrm{~m} \times 0,12 \mathrm{~m}$ & $0,33 \mathrm{~m} \times 2,7 \mathrm{~m}$ & $0,36 \mathrm{~m} \times 1,75 \mathrm{~m}$ \\
Acionamento & Motor de bobina & Servomotor & Servomotor \\
Curso & magnética & $0,8 \mathrm{~kW}$ & $0,75 \mathrm{~kW}$ \\
Máxima altura de onda & $20 \mathrm{~mm}$ & $\sim 1,5 \mathrm{~m}$ & $0,8 \mathrm{~m}$ \\
& $0,02 \mathrm{~m}$ & $0,5 \mathrm{~m}$ & $0,4 \mathrm{~m}$ \\
\hline
\end{tabular}

\subsection{Revisão Bibliográfica}

Devido à característica multidisciplinar do trabalho, diversas fontes foram consultadas, dentre as quais as referências citadas a seguir se apresentaram relevantes na compreensão dos fenômenos estudados e deram base para o desenvolvimento do trabalho.

O projeto de um gerador de ondas para tanque de ensaios requer o estudo da física de ondas oceânicas, Dean e Dalrymple (1984), LeMéhauté (1976) e CEM (2002) abrangem amplamente a física básica das ondas, desde a teoria linear de ondas que foi utilizada neste trabalho, assim como teorias mais avançadas que representam determinados fenômenos não lineares.

Souza e Morishita (2003) apresentam um modelo para o cálculo dos esforços necessários para a geração de ondas, o qual foi a base para a metodologia do projeto do gerador deste trabalho.

Nohara, Yamamoto e Matsuura (1996) examinam os geradores de ondas multidirecionais e a tecnologia de geração de ondas oceânicas nesses tanques. Enquanto que Nohara (2000) apresenta a estrutura hierárquica do sistema de controle para geradores multisegmentados.

Naito et al. (1996), NAOE (2000), Maeda et al. (2004) e Tamura (2006) apresentaram um novo conceito em tanque de ensaios de dimensões reduzidas, com geradores ativos em toda a volta e levantam a discussão de que o tanque não precisa ser necessariamente retangular.

Schäffer e Klopman (2000) fazem uma extensa revisão sobre os métodos de absorção de ondas e as possíveis configurações para os sensores de realimentação do 
seu sistema de controle.

Mello (2006) e Isaacson (2000) discutem técnicas com a utilização de sensores de altura de onda na análise de ondas refletidas em um canal, método que pode ser utilizado na avaliação do algoritmo de absorção de ondas de um gerador de ondas.

Wilner (1960) apresenta o princípio de funcionamento e as características de um sensor de altura de ondas capacitivo. Não foram encontrados trabalhos mais recentes sobre o sensor de altura de ondas capacitivo, porém considera-se que o princípio de funcionamento se manteve o mesmo nos sensores atuais.

A utilização de sensores de ultra-som em diversas aplicações na indústria é avaliada por Gallego-Juarez (1989) e também por Hauptmann, Hoppe e Püttmer (2002). Porém, não foi encontrado nenhum trabalho a respeito da utilização de ultra-som para se medir a altura de onda, os trabalhos encontrados tratavam apenas para a medição de nível estático.

Kinsler et al. (1982) e Costa et al. (2004) abrangem desde a teoria da física de ondas de ultra-som até a características construtivas de transdutores, conceitos que foram utilizados no desenvolvimento de um sensor de altura de ondas por ultra-som.

Ondas guiadas se tornaram uma técnica importante do sensor de altura de ondas por ultra-som desenvolvido neste trabalho, sua modelagem é apresentada em Harris, Hill e Tuner (1995) e Redwood (1963).

\subsection{Objetivos}

Este trabalho tem por objetivo estudar o estado da arte de geração de ondas em tanques de ensaios hidrodinâmicos de estruturas oceânicas, com o intuito de desenvolver um procedimento de projeto para geradores absorvedores de onda. $\mathrm{O}$ foco é dado ao gerador de ondas do tipo placa basculante, comumente conhecido na área como gerador do tipo flap.

O segundo objetivo é o desenvolvimento e construção de um protótipo de um gerador de ondas multisegmentado, de forma a prover um ambiente de desenvolvimento para futuros estudos de algoritmos de geração e absorção de ondas, que serão utilizados no desenvolvimento do Calibrador Hidrodinâmico do TPN. E também, a realização ensaios para a caracterização do protótipo e comparação de seu desempenho com a teoria.

Este trabalho também tem por objetivo o desenvolvimento do sistema de sensoriamento para a realimentação da malha de controle de absorção de ondas. Neste 
intuito, é estudada a viabilidade da implementação de um sensor de altura de ondas por ultra-som, com a implementação de protótipos desses sensores e a realização de ensaios para sua caracterização no gerador de ondas. 


\section{Ondas - Revisão teórica}

Onda é o fenômeno pelo qual uma perturbação de energia se propaga. Ondas mecânicas necessitam de um meio físico para se propagarem. As ondas de interesse neste trabalho são as ondas que se propagam na interface entre a água e $\mathrm{o}$ ar, conhecidas como ondas gravitacionais.

A descrição das ondas no oceano é de grande complexidade, uma vez que elas são produto de diversas interações e superposições. A figura 2.1 ilustra esse fenômeno. Os principais fatores que influenciam na agitação marítima são as ondas gravitacionais, as marés, os ventos, as correntes, as tempestades e os deslocamentos de gelo ou de terra.

As ondas gravitacionais são responsáveis pela maior parte da energia da agitação marítima, conforme podemos observar na figura 2.2. Essas ondas são formadas principalmente pela transferência de energia dos ventos para o oceano e a força restauradora é a gravidade.
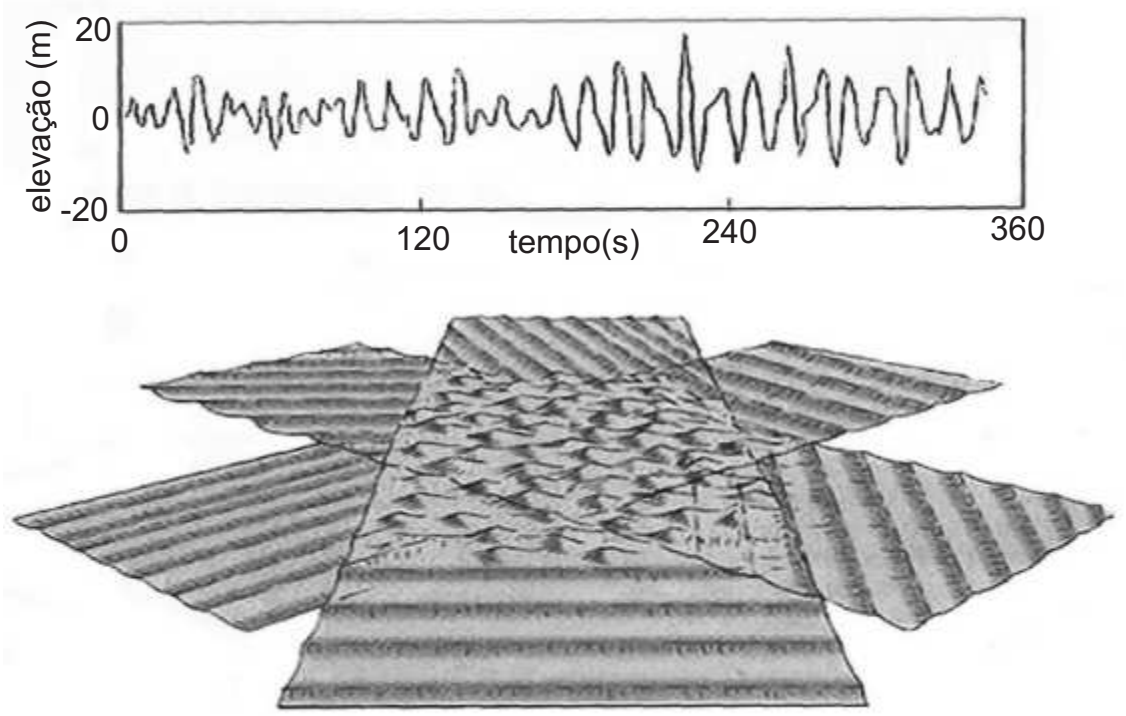

Figura 2.1: Ilustração da formação de ondas em uma certa região como resultado dos processos de interações e superposições. Reproduzido de Martins (2003). 


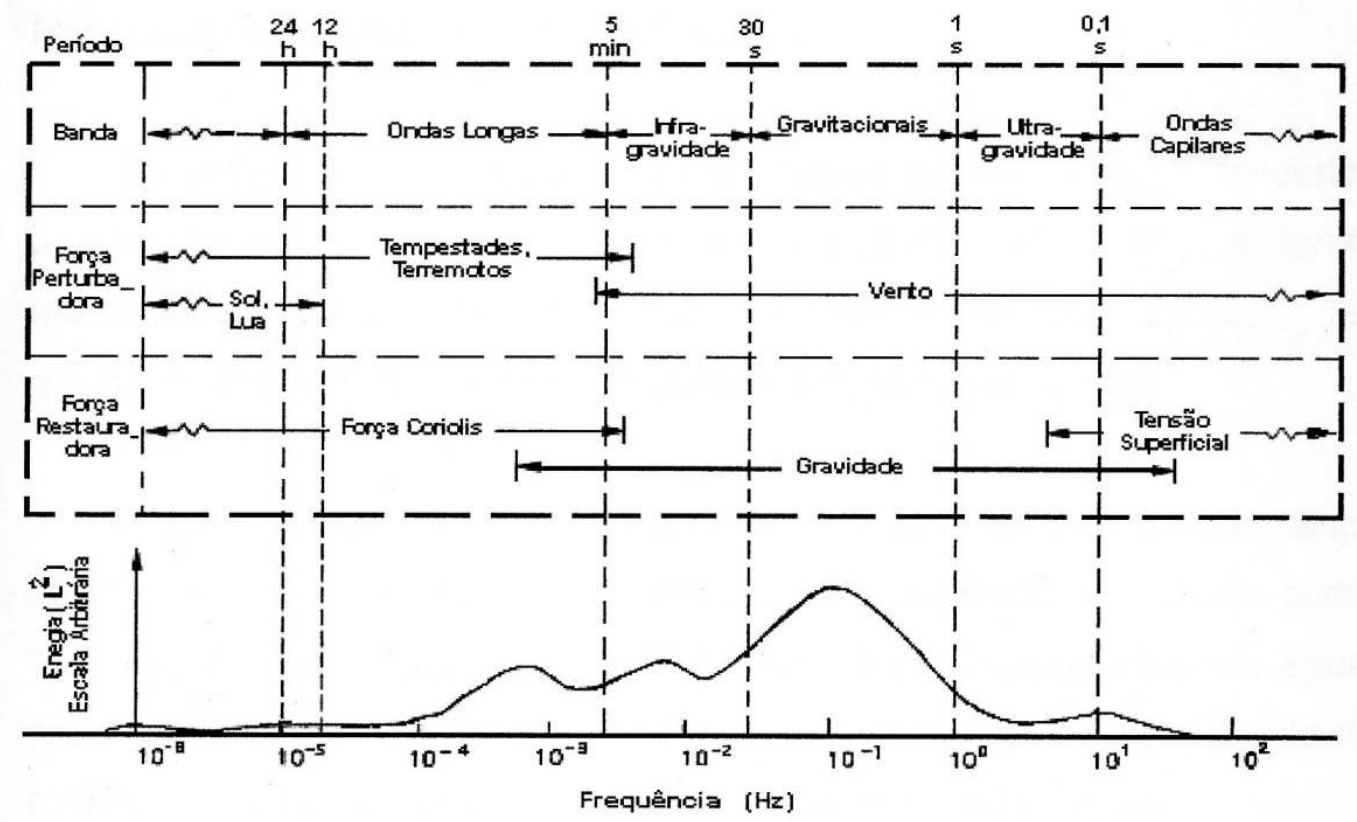

Figura 2.2: Distribuição da energia da agitação marítima em função dos fenômenos atuantes. Reproduzido de Martins (2003).

\subsection{Teoria de ondas}

Um grande número de teorias de ondas foram desenvolvidas, as quais podem ser aplicadas para diferentes casos dependendo das condições ambientais. Os principais fatores que devem ser levados em consideração para a determinação da teoria a ser aplicada são a altura de onda $H$, o comprimento de onda $L$ e a profundidade da água $h$ (LEMéHAUTé, 1976, p. 202). Esses fatores são comumente compostos nos seguintes parâmetros adimensionais:

- declividade $(H / L)$

- profundidade relativa $(h / L)$

- altura de onda relativa $(H / h)$

- número de Ursell $\left(U_{R}=L^{2} H / h^{3}\right)$

Nos critérios para a determinação da região de aplicação de cada teoria, o comprimento de onda $L$ pode ser substituído pelo período da onda $T$, uma vez que, o comprimento de onda pode ser obtido em função da profundidade e do período.

A teoria de ondas mais simples é a teoria linear de ondas, também conhecida como teoria de Airy. Essa teoria é válida quando a declividade, a profundidade relativa e a 
altura de onda relativa são pequenas, ou seja, ondas de pequena amplitude e pequeno comprimento em grandes profundidades.

Teorias não lineares conseguem obter uma representação mais próxima das ondas reais, permitindo a análise de ondas mais altas e em profundidades mais rasas.

A teoria de Stokes se aplica para alturas de onda maiores em águas relativamente profundas. Nesta teoria o potencial de velocidades é obtido através de uma série de potências usando o termo $\varepsilon=k a$, assim:

$$
\phi=\varepsilon \phi_{1}+\varepsilon^{2} \phi_{2}+\varepsilon^{3} \phi_{3}+\ldots
$$

A solução contendo o termo de primeira ordem $\phi_{1}$ é a teoria linear de Airy. A expansão até o segundo termo $\phi_{2}$ representa a teoria de Stokes de segunda ordem, e assim por diante.

A partir da teoria de segunda ordem aparecem componentes super-harmônicas, isto é, componentes de freqüência mais altas em 2, 3, etc. vezes a freqüência fundamental, o que acarreta em cristas mais altas e cavados mais achatados. Outro fenômeno que aparece é o transporte de massa na direção de propagação da onda, uma vez que a solução não apresenta mais o caminho das partículas como uma órbita fechada. Na figura 2.3 podemos comparar o formato de alguns tipos ondas de gravidade.

A solução de Stokes é formalmente válida para $k h<1$ e $H / L \ll 1$ (CEM, 2002). Em termos do número de Ursell o limite de aplicação é para $U_{R}<26$ (DEAN; DALRYMPLE, 1984)

A teoria Cnoidal é definida em termos da integral elíptica Jacobiana, cn $(u)$, da qual deriva seu nome. As ondas Cnoidais possuem crista fina separadas por um largo e achatado cavado. A teoria é utilizada para águas rasas, ela é valida para valores $h / L<1 / 8$ quando $U_{R}>20$ (CEM, 2002). Quando o comprimento da onda se torna longo, se aproximando de um valor infinito, a teoria de ondas Cnoidal se reduz à teoria de ondas solitárias, que são ondas não periódicas que não possuem cavado, ou seja, seu contorno fica inteiro sobre a linha de água estática.

A teoria de função de corrente (stream function theory) se assemelha com a teoria de Stokes de grande ordem, uma vez que ambas utilizam uma expansão de funções em senos e cossenos para satisfazer a equação de Laplace, porém utiliza mínimos quadrados para determinar os coeficientes de cada termo da série, ocasionando um melhor ajuste da condição de contorno dinâmica na superfície livre. Além disso, a 
teoria de função de corrente consegue satisfazer exatamente a condição de contorno cinemática na superfície livre. Esta teoria pode ser aplicada para alturas de onda próxima à altura de quebra (CEM, 2002).

As teorias de onda não lineares não serão abordadas neste trabalho, mais detalhes podem ser encontrados em CEM (2002) e em Dean e Dalrymple (1984).

Como regra geral, pode se utilizar o gráfico da figura 2.4 para selecionar qual teoria de ondas deve ser aplicada em função dos parâmetros $h, H$ e $T$.

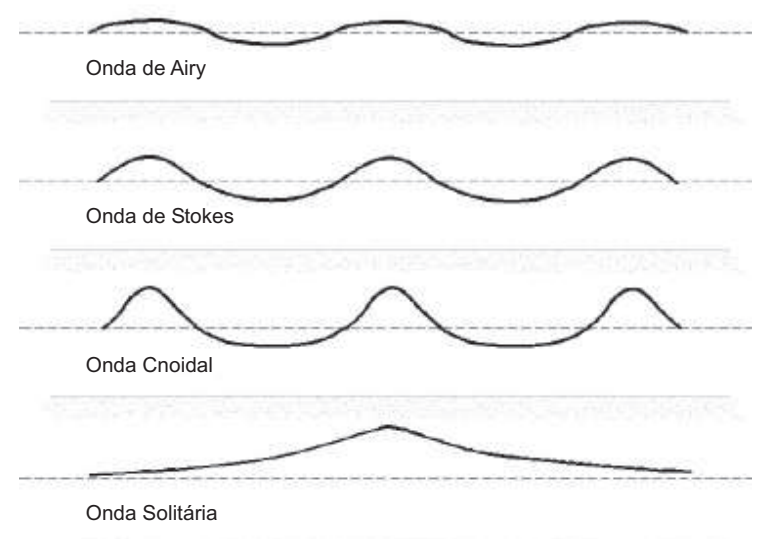

Figura 2.3: Formato dos principais tipos de ondas de gravidade. Adaptado de CEM (2002).

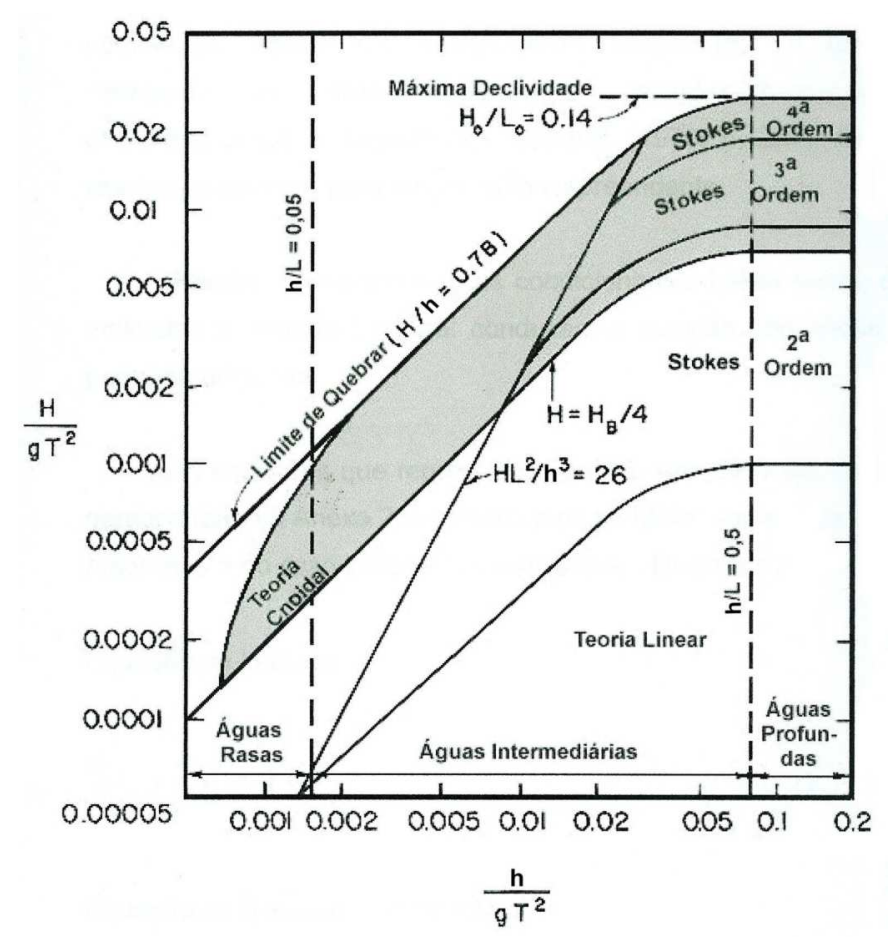

Figura 2.4: Aplicabilidade das teorias de ondas. Adaptado de CEM (2002). 


\subsection{Teoria linear de ondas}

Conforme vimos anteriormente, a teoria linear de ondas é a mais simples de todas as teorias, e pode ser aplicada a um conjunto muito particular de ondas que não existem na natureza, porém esse modelo é util para a compreensão de muitos fenômenos e na solução de um grande número de problemas reais.

A seguir são apresentadas as hipóteses e principais resultados da teoria de Airy. Neste ponto é importante ressaltar que neste trabalho são privilegiadas as interpretações físicas em detrimento das demonstrações matemáticas, que podem ser consultadas em Dean e Dalrymple (1984).

Para obter o modelo matemático da onda adota-se o sistema de coordenadas $O_{x y z}$, no qual a origem se situa no nível de água estático (NAE) e o eixo $z$ aponta para cima. O símbolo $\eta$ representa o deslocamento da superfície da água em relação ao NAE em função do tempo e da coordenada $x$ (figura 2.5 ).

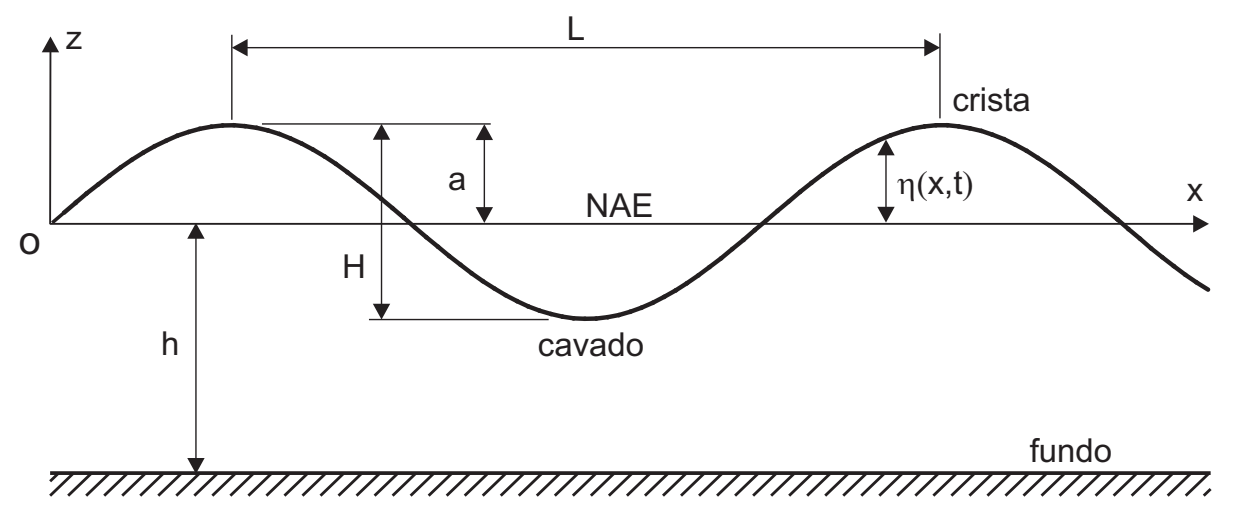

Figura 2.5: Sistema de coordenadas e nomenclatura da onda.

\subsubsection{Equação diferencial característica}

O princípio da conservação de massa estabelece que a massa não pode ser criada nem destruída. O que resulta na equação de continuidade:

$$
\frac{1}{\rho} \frac{\mathrm{D} \rho}{\mathrm{D} t}+\nabla \bullet \mathbf{v}=0
$$

onde $\mathbf{v}(u, w)$ é o vetor velocidade das partículas, sendo $u$ a velocidade horizontal e $v$ a velocidade vertical e $\rho$ a massa específica do fluido.

Como a água pode ser considerada incompressível a equação 2.2 se reduz a: 


$$
\nabla \bullet \mathbf{v}=0
$$

A suposição de movimento irrotacional do fluido, resulta na existência de um potêncial de velocidades que satifaz a equação de continuidade, que nos conduz à equação de Laplace:

$$
\nabla^{2} \phi=0
$$

onde $\phi$ é o potencial de velocidades.

\subsubsection{Condições de contorno}

A partir da equação de Laplace podem existir inúmeras soluções, desta forma devemos utilizar condições de contorno do problema estudado para a determinação do potencial de velocidades. Na figura 2.6 são indicadas as condições de contorno no caso de ondas de gravidade.

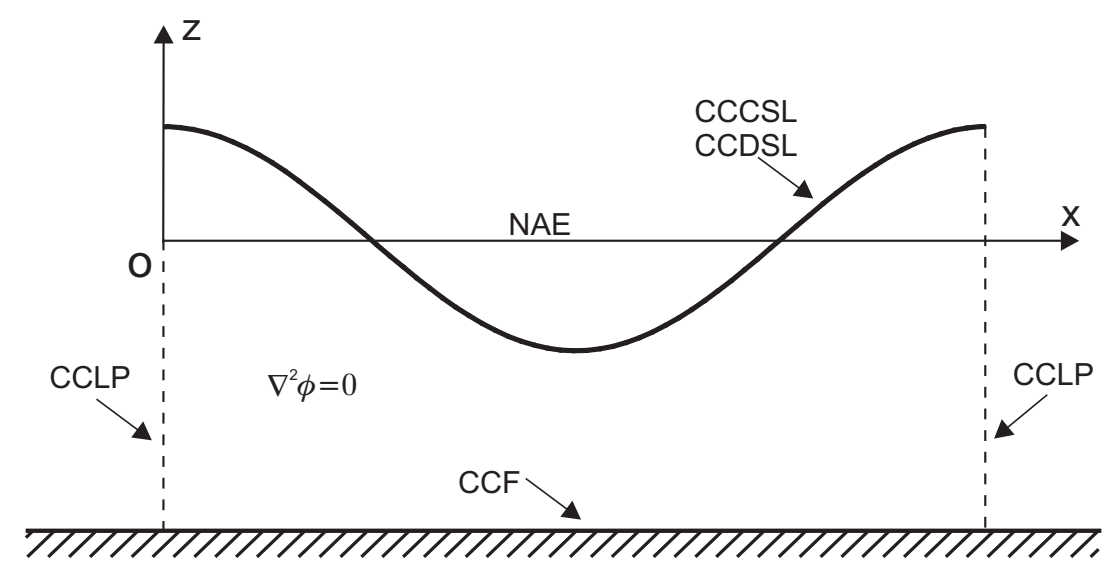

Figura 2.6: Condições de contorno para ondas regulares.

No fundo, considerado horizontal e impermeável, aplica-se a condição de contorno do fundo (CCF), na qual a velocidade vertical é nula:

$$
\frac{\partial \phi}{\partial z}=0 \quad \text { em } \quad z=-h
$$

A condição de contorno cinemática na superfície livre (CCCSL) impõe que a componente normal da velocidade das partículas da superfície é a mesma da velocidade da componente normal do contorno do fluido:

$$
-\frac{\partial \phi}{\partial z}=\frac{\partial \eta}{\partial t}-\frac{\partial \phi}{\partial x} \frac{\partial \eta}{\partial x} \quad \text { em } \quad z=\eta(x, t)
$$


Já a condição de contorno dinâmica da superfície livre (CCDSL) diz que na superfície livre a pressão relativa é constante, dessa forma:

$$
-\frac{\partial \phi}{\partial t}+\frac{1}{2}\left[\left(\frac{\partial \phi}{\partial x}\right)^{2}+\left(\frac{\partial \phi}{\partial z}\right)^{2}\right]+g \eta=f(t) \quad \text { em } \quad z=\eta(x, t)
$$

que é a integral da equação de Euler. Expandindo essa equação em $z=0$ por série de Taylor e considerando apenas a parcela linear, uma vez que a onda é considerada de pequena amplitude, a condição de contorno acima pode ser expressa por:

$$
\eta=\frac{1}{g}\left[\frac{\partial \phi}{\partial t}\right]_{z=0}
$$

Por último, temos a condição de contorno lateral periódica (CCLP) tanto espacial quanto temporal, ou seja, periodicidade do escoamento:

$$
\begin{aligned}
& \phi(x, t)=\phi(x+L, t) \\
& \phi(x, t)=\phi(x, t+T)
\end{aligned}
$$

\subsubsection{Solução para onda progressiva}

O problema apresentado é não linear. Assumindo que as ondas são de pequenas amplitudes, o problema pode ser linearizada para um domínio com profundidade constante. Na solução proposta por Airy (DEAN; DALRYMPLE, 1984) o potencial de velocidades para ondas progressivas pode ser descrito por:

$$
\phi(x, z, t)=-\frac{H}{2} \frac{g}{\omega} \frac{\cosh [k(h+z)]}{\cosh (k h)} \operatorname{sen}(k x-\omega t)
$$

E o movimento da superfície livre é obtido substituindo o potencial de velocidades na equação 2.8:

$$
\eta(x, t)=\frac{H}{2} \cos (k x-\omega t)
$$

onde $k$ e $\omega$ são respectivamente o número de onda (equação 2.12) e a freqüência 
angular (equação 2.13).

$$
\begin{aligned}
& k=\frac{2 \pi}{L} \\
& \omega=\frac{2 \pi}{T}
\end{aligned}
$$

A dependência entre a freqüência e o comprimento de onda é dada pela relação de dispersão:

$$
\omega^{2}=g k \tanh (k h)
$$

A velocidade de fase da onda, ou celeridade, é dada por:

$$
C=\frac{\omega}{k}=\frac{L}{T}=\sqrt{\frac{g}{k} \tanh (k h)}
$$

Combinando a equação 2.14 com as equações 2.12 e 2.13 obtemos o comprimento de onda:

$$
L=\frac{g}{2 \pi} T^{2} \tanh \left(\frac{2 \pi h}{L}\right)
$$

As velocidades horizontal $u$ e vertical $w$ das partículas podem ser obtidas derivando o potencial de velocidades:

$$
\begin{aligned}
& u=\frac{\partial \phi}{\partial x}=\frac{H}{2} \omega \frac{\cosh [k(h+z)]}{\operatorname{senh}(k h)} \cos (k x-\omega t) \\
& w=\frac{\partial \phi}{\partial z}=\frac{H}{2} \omega \frac{\operatorname{senh}[k(h+z)]}{\operatorname{senh}(k h)} \operatorname{sen}(k x-\omega t)
\end{aligned}
$$

Derivando as velocidades no tempo temos as acelerações das partículas:

$$
\begin{aligned}
& a_{x}=\frac{\partial u}{\partial t}=\frac{H}{2} \omega^{2} \frac{\cosh [k(h+z)]}{\operatorname{senh}(k h)} \operatorname{sen}(k x-\omega t) \\
& a_{z}=\frac{\partial w}{\partial t}=-\frac{H}{2} \omega^{2} \frac{\operatorname{senh}[k(h+z)]}{\operatorname{senh}(k h)} \cos (k x-\omega t)
\end{aligned}
$$


Também pode-se definir, para pequenos deslocamentos, a amplitude do movimento horizontal $(\zeta)$ e vertical $(\xi)$ das partículas em torno de um ponto arbitrário $\left(x_{1}, z_{1}\right)$ :

$$
\begin{aligned}
& \zeta=-\frac{H}{2} \frac{\cosh \left[k\left(h+z_{1}\right)\right]}{\operatorname{senh}(k h)} \operatorname{sen}\left(k x_{1}-\omega t\right) \\
& \xi=\frac{H}{2} \frac{\operatorname{senh}\left[k\left(h+z_{1}\right)\right]}{\operatorname{senh}(k h)} \cos \left(k x_{1}-\omega t\right)
\end{aligned}
$$

A energia total de uma onda é a soma de suas energias cinética e potencial. A energia cinética é a parte da energia correspondente à velocidade das partículas associada ao movimento das ondas. Já a energia potencial é o resultado do deslocamento de massa de sua posição de equilíbrio contra o campo gravitacional. As energias potencial e cinemática são iguais e a energia total em um comprimento de ondas por unidade de largura é dada por:

$$
E=E_{k}+E_{p}=\frac{\rho g H^{2}}{16}+\frac{\rho g H^{2}}{16}=\frac{\rho g H^{2}}{8}
$$

A propagação de energia ocorre em uma velocidade diferente da velocidade de fase, chamada de velocidade de grupo $C_{g}$ (equação 2.24). Em águas profundas a energia é transmitida na metade da velocidade de fase e varia conforme a profundidade relativa diminui, chegando a se igualar a velocidade de fase em águas rasas.

$$
C_{g}=n C=\frac{1}{2}\left(1+\frac{2 k h}{\sinh (2 k h)}\right) \frac{\omega}{k}
$$

A taxa com que a energia é transferida numa seção transversal da onda é chamada de fluxo de energia $\mathscr{F}$. O fluxo de energia médio é obtido tirando-se uma média sobre um período de onda e é dado por:

$$
\overline{\mathscr{F}}=E C_{g}
$$

\subsubsection{Simplificações para águas rasas e profundas}

As funções hiperbólicas podem ser simplificadas conforme a profundidade relativa. Na literatura são comumente encontrados três conjuntos de soluções definidas para as regiões chamadas de águas rasas, intermediárias e profundas. 
A teoria apresentada na seção anterior pode sofrer simplificações quanto as suas funções hiperbólicas, para dar origem às soluções para águas rasas e profundas. Em águas intermediárias, existe a necessidade de se aplicar a teoria completa, sem simplificações. A tabela 2.1 apresenta as simplificações das funções hiperbólicas e as regiões em que estas podem ser aplicadas.

Tabela 2.1: Formas assintóticas das funções hiperbólicas.

\begin{tabular}{lccc}
\hline Grandeza & Águas rasas & Águas intermediárias & Águas profundas \\
\hline$h / L$ & 0 a $1 / 20$ & $1 / 20 \mathrm{a} 1 / 2$ & $1 / 2$ a $\infty$ \\
$k h$ & 0 a $\pi / 10$ & $\pi / 10 \mathrm{a} \pi$ & $\pi$ a $\infty$ \\
$\cosh (k h)$ & 1 & $\cosh (k h)$ & $e^{k h} / 2$ \\
$\operatorname{senh}(k h)$ & $k h$ & $\operatorname{senh}(k h)$ & $e^{k h} / 2$ \\
$\tanh (k h)$ & $k h$ & $\tanh (k h)$ & 1 \\
\hline
\end{tabular}

O movimento das partículas em águas rasas produz uma trajetória elíptica, no qual seu deslocamento horizontal não varia com a profundidade e o deslocamento vertical aumenta linearmente a partir do fundo. Já em águas profundas a trajetória é circular e seu raio decai exponencialmente com a profundidade. Em águas intermediárias existe a superposição dos outros dois casos, como pode ser observado na figura 2.7.

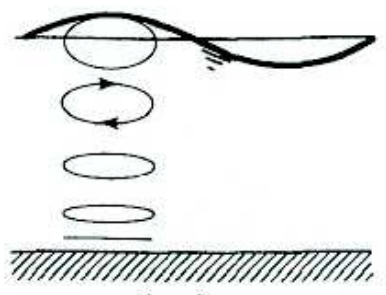

(a)

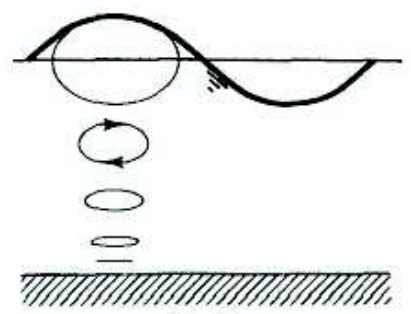

(b)

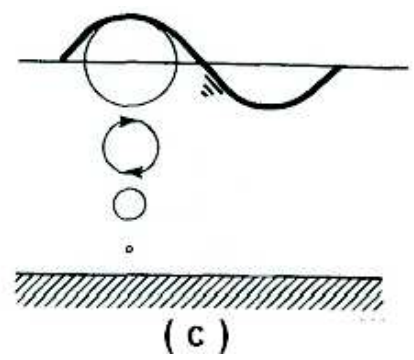

(c)

Figura 2.7: Trajetória das partículas de água de ondas progressivas em diferentes profundidades. Adaptado de Dean e Dalrymple (1984) (a) Águas rasas; (b)Águas intermediárias; (c)Águas profundas.

Neste trabalho foi adotada a solução da teoria linear de ondas na forma mais completa, uma vez que a região de interesse se encontra desde a região de águas profundas até parte da região águas intermediárias.

\subsection{Reflexão de ondas}

Quando uma onda regular atinge um obstáculo, uma parte de sua energia é refletida, uma outra parte é absorvida pelo obstáculo e outra é transmitida além do obstáculo. A onda regular refletida se propaga na direção oposta e com mesmo 
período da onda incidente. A superfície livre resultante pode ser descrita como a superposição das duas ondas:

$$
\eta=\frac{H_{i}}{2} \cos (k x-\omega t)+\frac{H_{r}}{2} \cos (k x+\omega t)
$$

onde $H_{i}$ e $H_{r}$ são respectivamente as alturas de onda incidente e refletida.

Reescrevendo $\eta$ usando propriedades trigonométricas:

$$
\eta=\frac{H_{i}+H_{r}}{2} \cos (k x) \cos (\omega t)+\frac{H_{i}-H_{r}}{2} \operatorname{sen}(k x) \operatorname{sen}(\omega t)
$$

Podemos observar que, ocorrem máximos na altura da envoltória da superfície livre quando $k x=0, \pi, 2 \pi, 3 \pi, \ldots$, de altura $H_{\max }=H_{i}+H_{r}$. Assim como ocorrem mínimos quando $k x=0, \frac{\pi}{2}, \frac{3 \pi}{2}, \frac{5 \pi}{2}, \ldots$, de altura $H_{\text {min }}=H_{i}-H_{r}$. Desta forma, máximos e mínimos ocorrem a uma distância de meio comprimento de onda.

Reescrevendo as alturas de onda incidente e refletida, em função da máxima e mínima altura da envoltória, tem-se:

$$
\begin{aligned}
H_{i} & =\frac{H_{\max }+H_{\min }}{2} \\
H_{r} & =\frac{H_{\max }-H_{\min }}{2}
\end{aligned}
$$

O coeficiente de reflexão $C r$ é definido como a relação entre as alturas de onda incidente e refletida. Este pode variar entre zero (absorção total) e um (reflexão total):

$$
C r=\frac{H_{r}}{H_{i}}=\frac{H_{\max }-H_{\min }}{H_{\max }+H_{\min }}
$$

O coeficiente de reflexão é uma medida importante, para se realizar a comparação entre diversos aparatos de absorção de ondas utilizados em tanques de ensaios. 


\section{Desenvolvimento do gerador de ondas}

Foram utilizadas as dependências do Laboratório de Engenharia Naval e Oceânica da Escola Politécnica da USP (LENO) para a instalação de um protótipo com alguns módulos gerador absorvedor de ondas, que são utilizados para a validação dos modelos teóricos e no desenvolvimento do controle do flap.

O tanque do LENO possui nível de água estático de $0,8 \mathrm{~m}$, largura de $1 \mathrm{~m}$ e comprimento de $25 \mathrm{~m}$, comportando desta forma 4 módulos com largura de aproximadamente $0,25 \mathrm{~m}$. O sistema de gerador de ondas atualmente instalado no tanque, do tipo cunha, é capaz de gerar ondas na faixa entre 0,5 e $3 \mathrm{~Hz}$, este critério foi seguido no desenvolvimento do protótipo.

\subsection{Requisitos de projeto do gerador}

Os requisitos que devem ser ponderados no projeto do gerador de ondas são:

- Rigidez: as deformações que ocorrerem no sistema não deverão alterar o resultado da geração de ondas;

- Inércia: esta deve ter o menor valor possível para melhorar a resposta dinâmica do sistema e deve ser modelada sempre que possível.

- Estabilidade: o sistema deve ser estável na faixa de operação submetida, ou seja, as freqüências naturais do mecanismo devem estar acima das freqüências das ondas geradas e de outras fontes de vibração;

- Resistência: nas piores situações de operação, previstas ou não, os componentes do sistema não podem colapsar;

- Durabilidade: os componentes do sistema têm que ter durabilidade mínima acima da vida útil esperada para o sistema, de forma que deve ser feita uma análise de fadiga dos componentes mais solicitados; 
- Modularização: o gerador deve ser projetado de forma a propiciar uma fácil reprodução em série minimizando os custos e facilitando a manutenção;

- Custo: devido à grande quantidade de módulos geradores de onda prevista no Calibrador Hidrodinâmico do TPN, os custos devem ser reduzidos. Para isto, os componentes têm que ser, sempre que possível, modelos de linha de produção. Desta forma o custo de obtenção e manutenção pode ser minimizado.

\subsection{Descrição do gerador de ondas}

O módulo gerador absorvedor de ondas é do tipo flap, o acionamento é realizado por um servomotor acoplado a um fuso de esferas que por sua vez é conectado através de um braço mecânico ao flap (figura 3.1).

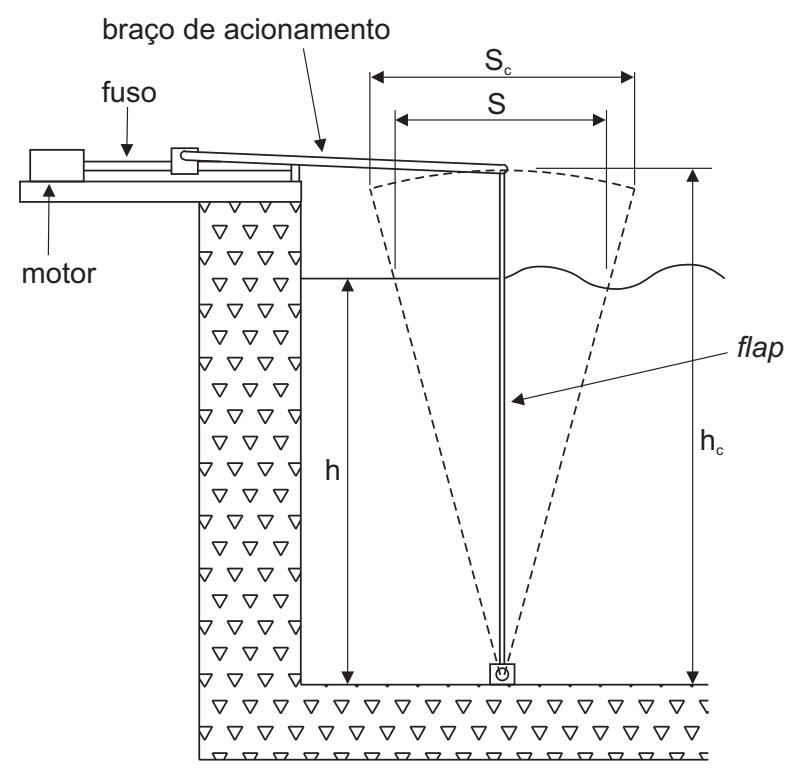

Figura 3.1: Esquema do mecanismo do gerador de ondas.

\subsection{Modelo hidrodinâmico do gerador de ondas}

Dean e Dalrymple (1984) apresentam o modelo hidrodinâmico de um gerador de ondas do tipo flap. O desenvolvimento do modelo hidrodinâmico segue diretamente o procedimento utilizado na solução da teoria linear de ondas.

A única condição que muda é a condição de contorno lateral. Em $x=0$ a condição cinemática deve satisfazer o movimento do gerador de ondas. O movimento horizontal do gerador de ondas pode ser descrito por: 


$$
x=\frac{S(z)}{2} \operatorname{sen}(\omega t)
$$

Com este novo conjunto de condições de contorno o potencial de velocidades é descrito por:

$$
\phi=A_{p} \cosh \left[k_{p}(h+z)\right] \operatorname{sen}\left(k_{p} x-\omega t\right)+\sum_{m=1}^{\infty} C_{m} e^{-k_{s}(m) x} \cos \left[k_{s}(m)(h+z)\right] \cos (\omega t)
$$

A primeira parte da equação representa a onda progressiva gerada enquanto que a segunda parte é uma série de ondas estacionárias, chamadas de ondas evanescentes, cuja altura decai conforme aumenta a distância com o gerador. As ondas evanescentes podem ser desprezadas a uma distância do gerador de duas ou três vezes a profundidade $h$.

O número de onda $k_{p}$ está relacionado com a onda progressiva e sua dependência com a freqüência do gerador é obtida através da relação de dispersão (equação 3.3) e é semelhante à relação obtida na teoria linear. Já o número de onda $k_{s}$ está relacionado as ondas evanescentes e possui infinitas soluções.

$$
\begin{gathered}
\omega^{2}=g k_{p} \tanh \left(k_{p} h\right) \\
\omega^{2}=g k_{s} \tan \left(k_{s} h\right)
\end{gathered}
$$

Os parâmetros $A_{p}$ e $C_{m}$ são obtidos através das integrais a seguir:

$$
\begin{aligned}
A_{p} & =\frac{-\int_{-h}^{0} \frac{S(z)}{2} \omega \cosh \left[k_{p}(h+z)\right] \mathrm{d} z}{k_{p} \int_{-h}^{0} \cosh ^{2}\left[k_{p}(h+z)\right] \mathrm{d} z} \\
C_{m} & =\frac{\int_{-h}^{0} \frac{S(z)}{2} \omega \cos \left[k_{s}(m)(h+z)\right] \mathrm{d} z}{k_{s}(m) \int_{-h}^{0} \cos ^{2}\left[k_{s}(m)(h+z)\right] \mathrm{d} z}
\end{aligned}
$$

onde $S(z)$ é o movimento do flap:

$$
S(z)=S_{0}\left(1+\frac{z}{h}\right)
$$


Resolvendo as integrais das equações 3.5 e 3.6 para o movimento do flap (SOUZA; MORISHITA, 2003), tem-se:

$$
\begin{gathered}
A_{p}=\frac{S_{0} \omega}{2 k_{p}^{2}} \frac{\operatorname{senh}\left(k_{p} h\right)+\frac{\left[1-\cosh \left(k_{p} h\right)\right]}{k_{p} h}}{\frac{\operatorname{senh}\left(2 k_{p} h\right)}{4 k_{p}}+\frac{h}{2}} \\
C_{m}(m)=\frac{S_{0} \omega}{2 k_{s}^{2}(m)} \frac{\operatorname{sen}\left(k_{s}(m) h\right)+\frac{\left[\cos \left(k_{s}(m) h\right)-1\right]}{k_{s}(m) h}}{\frac{\operatorname{sen}\left(2 k_{s}(m) h\right)}{4 k_{s}(m)}+\frac{h}{2}}
\end{gathered}
$$

O movimento da superfície livre é obtido com o mesmo procedimento da teoria linear. Considerando-se a altura de onda num ponto longe do gerador de ondas podemos desprezar a parcela referente às ondas evanescentes, desta forma:

$$
\eta=-\frac{A_{p} \omega}{g} \cosh \left(k_{p} h\right) \cos \left(k_{p} x-\omega t\right)
$$

A onda desejada é dada por:

$$
\eta=\frac{H}{2} \cos \left(k_{p} x-\omega t\right)
$$

Combinando as equações 3.10 e 3.11 e substituindo $A_{p}$ obtem-se a função de transferência $H / S$ em função da freqüência da onda (equação 3.12). A figura 3.2 apresenta a função de transferência, assumindo que o ponto de pivotamento do flap se encontra no fundo do tanque.

$$
\frac{H}{S}=4\left(\frac{\operatorname{senh}\left(k_{p} h\right)}{k_{p} h}\right) \frac{k_{p} h \operatorname{senh}\left(k_{p} h\right)-\cosh \left(k_{p} h\right)-1}{\operatorname{senh}\left(2 k_{p} h\right)+2 k_{p} h}
$$

\subsection{Máxima altura de onda}

O primeiro passo no projeto do gerador de ondas constitui na determinação das dimensões principais do flap, ou seja, a sua altura, largura e o curso do atuador (stroke) que sejam capazes de gerar as máximas alturas de onda requeridas nos ensaios.

A máxima altura de onda é limitada pelos seguintes fatores:

- Limite de declividade da onda $(L / H)$ antes da onda quebrar; 


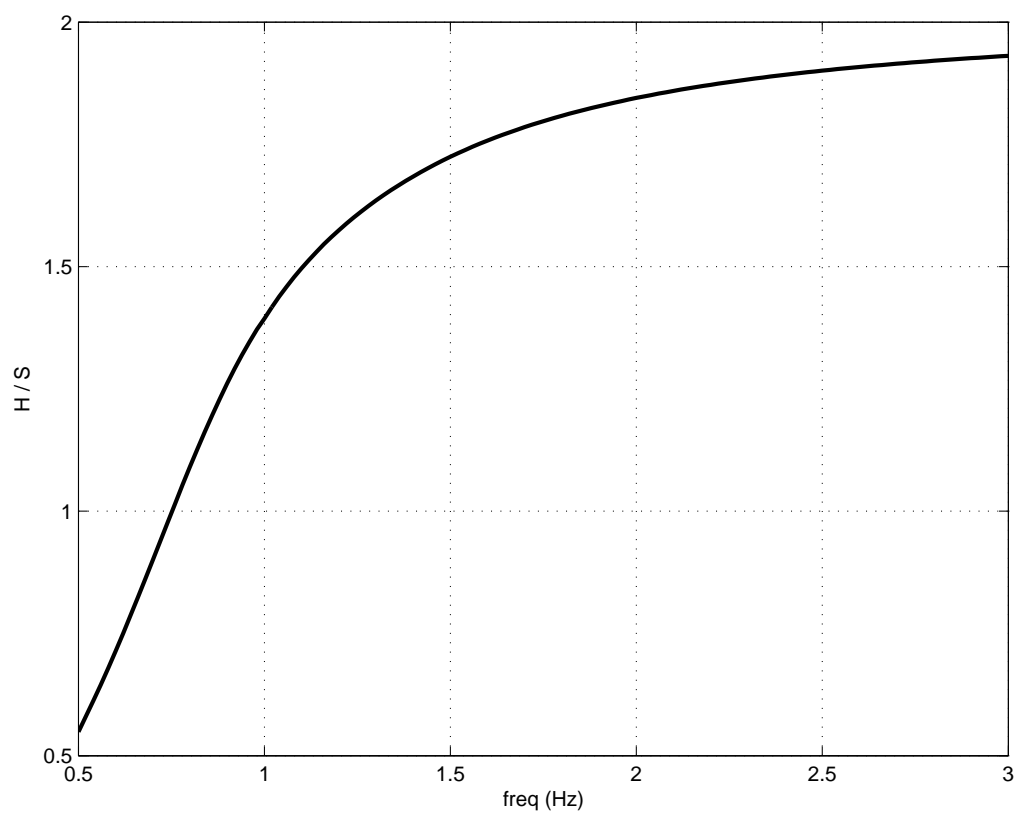

Figura 3.2: Função de transferência $H / S$.

- Máxima altura de onda que o tanque comporta;

- Maior altura de onda que o gerador de ondas consegue produzir para um determinado curso do atuador.

Lembrando que a altura do ponto de conexão do braço mecânico do atuador com o flap difere da altura onde é medido o curso do atuador, devemos fazer uma correção do curso máximo no cálculo da máxima altura de onda:

$$
S=S_{c} \frac{h}{h_{c}}
$$

A figura 3.3 mostra as curvas calculadas com curso máximo de 0,3 m. A área útil de trabalho é a que fica inferior às 3 curvas.

\subsection{Dimensionamento do flap}

Como a força de acionamento é pequena, conforme será visto mais adiante, o fator crítico durante o dimensionamento do flap é a sua freqüencia natural. Esta deve ser algumas vezes maior que a freqüência máxima da onda a ser gerada para não deformá-la e também para não deixar o mecanismo sujeito a esforços que levariam à falha por fadiga.

O flap foi construído a partir de uma chapa de alumínio dobrada. No meio do flap tem-se um canal onde é instalado o sensor de altura de ondas por ultra-som. A 


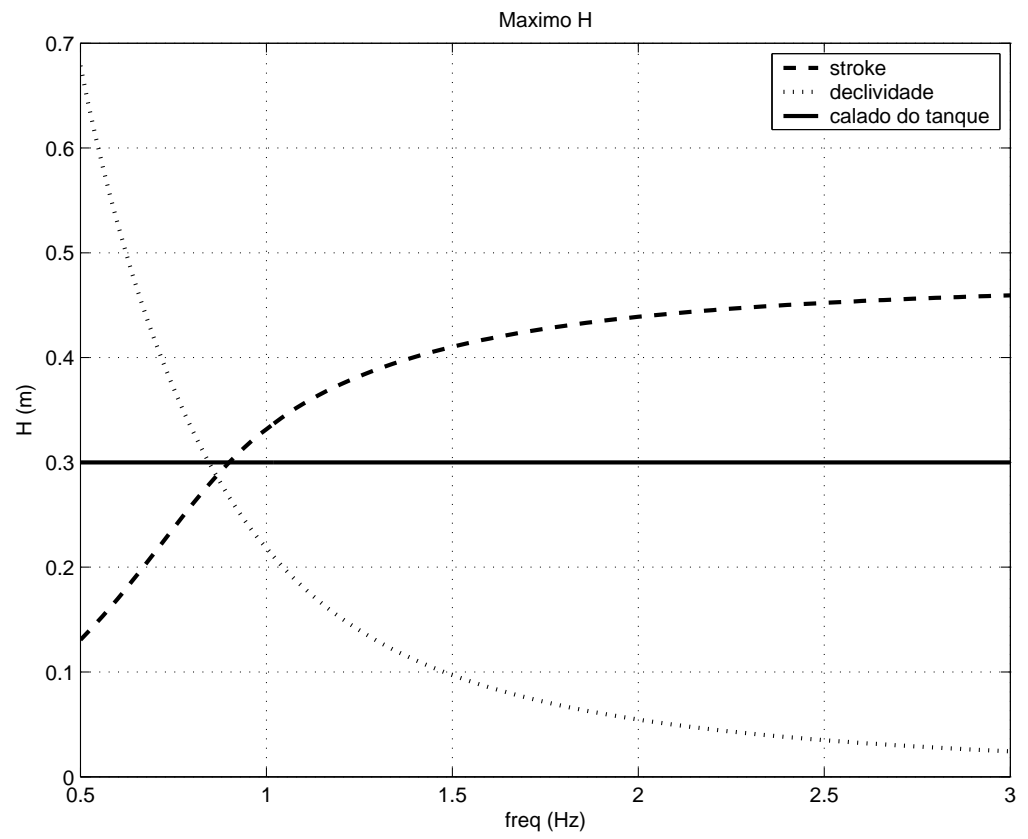

Figura 3.3: Limites de altura de onda.

figura 3.4 apresenta as dimensões básicas do flap, a aba de largura $b$ foi otimizada para ajustar a freqüência natural do flap.

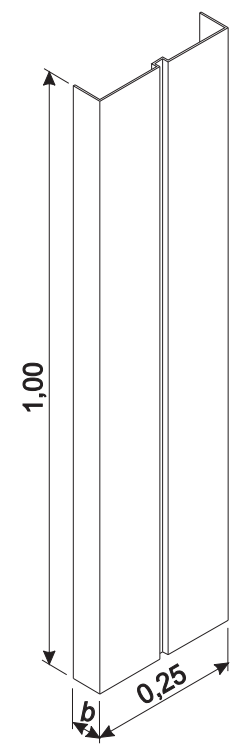

Figura 3.4: Dimensões básicas do flap.

Inicialmente foi analisada a influência da largura da aba do flap na freqüência natural, utilizando um modelo simplificado de viga biapoiada, conforme mostra a figura 3.5. Neste modelo, a primeira freqüência natural é obtida através da equação 3.14 (THOMSON, 1993). Neste trabalho foi adotado que a freqüência do primeiro modo de vibração deve ser maior que $30 \mathrm{~Hz}$, ou seja, 10 vezes a maior freqüência de operação. 


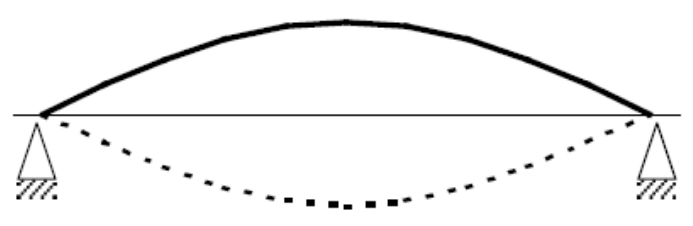

Figura 3.5: Modelo de viga biapoiada em vibração natural não amortecida (1 $1^{\circ}$ modo).

$$
f_{1}=\frac{\pi}{2} \sqrt{\frac{E I}{m d^{3}}}
$$

onde $m$ é a massa do flap, $d$ é a distância entre os apoios, $E=70 \cdot 10^{9} \mathrm{~N} / \mathrm{m}^{2}$ é o módulo de elasticidade do alumínio e $I$ é o momento de inércia da seção transversal.

Na tabela 3.1 são apresentados os resultados da equação 3.14 para várias larguras da aba e pode-se observar que $b=20 \mathrm{~mm}$ já atenderia o critério de freqüência natural.

Tabela 3.1: Freqüência natural do flap em função da largura da aba $b$ (modelo de viga).

\begin{tabular}{cc}
\hline Largura da aba $b(\mathrm{~mm})$ & $1^{\text {a }}$ freqüência natural $(\mathrm{Hz})$ \\
\hline 10 & 18,41 \\
20 & 36,96 \\
30 & 62,78 \\
40 & 92,57 \\
\hline
\end{tabular}

A seguir foi realizada uma simulação mais próxima do real utilizando método de elementos finitos (MEF) utilizando o software de análise Ansys. A figura 3.6 mostra o modelo utilizado. Diferentemente do modelo de viga, este possui alguns vínculos a mais. No apoio inferior foram utilizadas restrições de movimento nas direções $x, y \mathrm{e}$ $z$ e restrições de rotação nos eixos $y$ e $z$ distribuídos em dois pontos que simulam os mancais do eixo inferior. Já na parte superior foi utilizada restrição de movimento na direção $z$ e de rotação nos eixos $y$ e $z$.

O modelo foi discretizado utilizando um elemento quadrilátero de superfície (shell63). Foi realizada uma análise de sensibilidade do MEF em função da largura do elemento (tabela 3.2), esta análise não apresentou grandes variações nas freqüências naturais com o aumento da largura dos elementos, desta forma foi adotada a discretização com elementos de maior largura, ou seja, $30 \mathrm{~mm}$.

A freqüência de ressonância obtida pelo modelo de MEF foi menor que o obtido com o modelo simplificado de viga, havendo necessidade de se aumentar a dimensão 


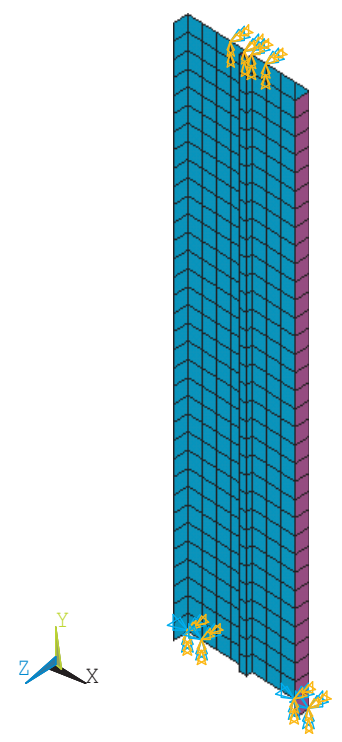

Figura 3.6: Modelo discretizado do flap.

Tabela 3.2: Análise de sensibilidade do $\operatorname{MEF}(b=30 \mathrm{~mm})$.

\begin{tabular}{cccc}
\hline Largura do elemento & \multicolumn{3}{c}{ Freqüências de ressonância $(\mathrm{Hz})$} \\
$(\mathrm{mm})$ & $1^{\circ}$ modo & $2^{\circ}$ modo & $3^{\circ}$ modo \\
\hline 10 & 44,95 & 57,30 & 128,73 \\
20 & 44,51 & 55,91 & 126,98 \\
30 & 44,37 & 55,44 & 126,39 \\
\hline
\end{tabular}

mínima da aba para $b=30 \mathrm{~mm}$. A figura 3.7 apresenta os deslocamentos para os 3 primeiros modos de vibração, as freqüências correspondentes são as encontradas na última linha da tabela 3.2 .

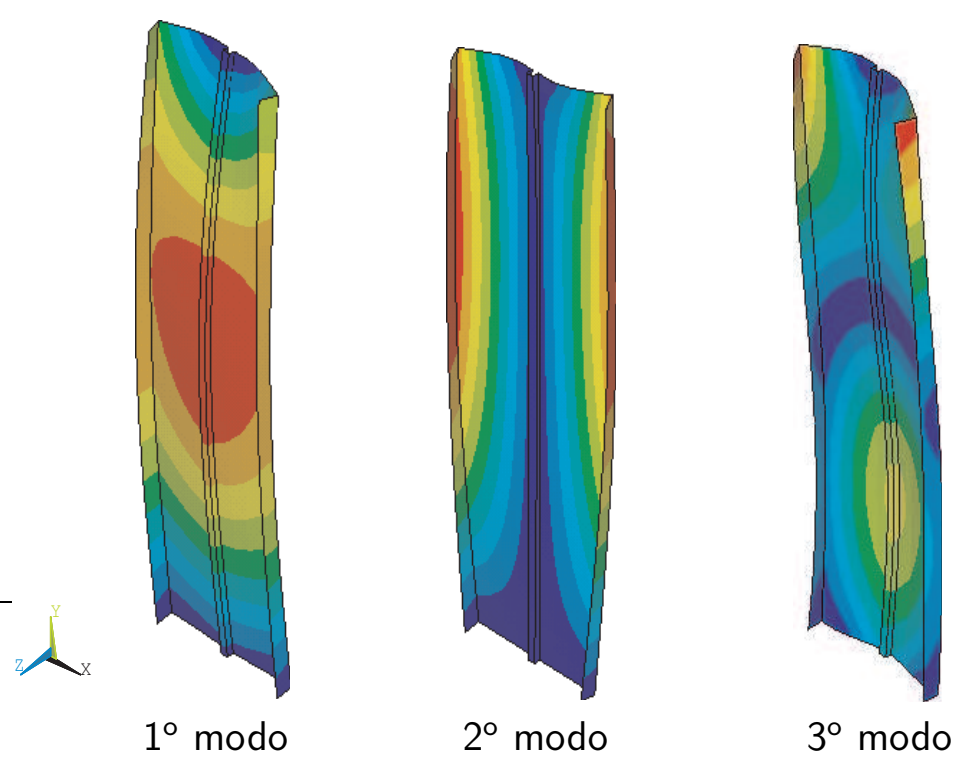

Figura 3.7: Modos de vibração do flap. 


\subsection{Dimensionamento do gerador de ondas}

A partir do gráfico da figura 3.3 pode-se obter o máximo curso do atuador, tanto para $z=0$ quanto para o ponto de conexão com o braço mecânico em função da freqüência (figura 3.8).

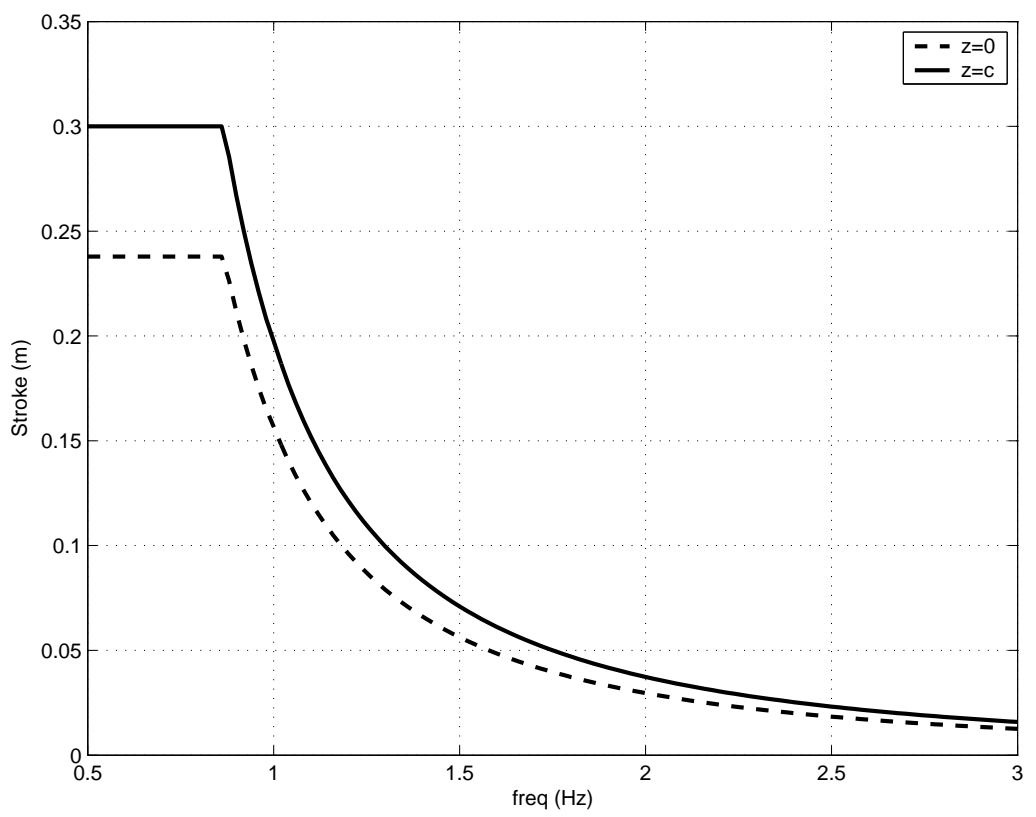

Figura 3.8: Curso máximo do atuador.

A seguir determinam-se a velocidade e a aceleração lineares máximas no fuso considerando um movimento senoidal do flap:

$$
\begin{aligned}
& S(t)=\frac{S_{c}}{2} \operatorname{sen}(\omega t) \\
& v(t)=\frac{S_{c}}{2} \omega \cos (\omega t) \\
& a(t)=-\frac{S_{c}}{2} \omega^{2} \operatorname{sen}(\omega t)
\end{aligned}
$$

As figuras 3.9, 3.10 apresentam respectivamente a velocidade linear e a aceleração linear em função da freqüência da onda.

Uma vez que o ângulo do movimento do flap é pequeno, a trajetória de movimento do ponto de conexão do braço mecânico com o flap, que descreve um arco de circunferência, foi simplificado por um segmento de reta e desta forma, idêntico ao movimento do ponto de conexão do braço mecânico com o fuso. Assim, podem ser calculadas a velocidade e a aceleração angulares do fuso através das equações 3.18 e 3.19 (figuras 3.11 e 3.12 ): 


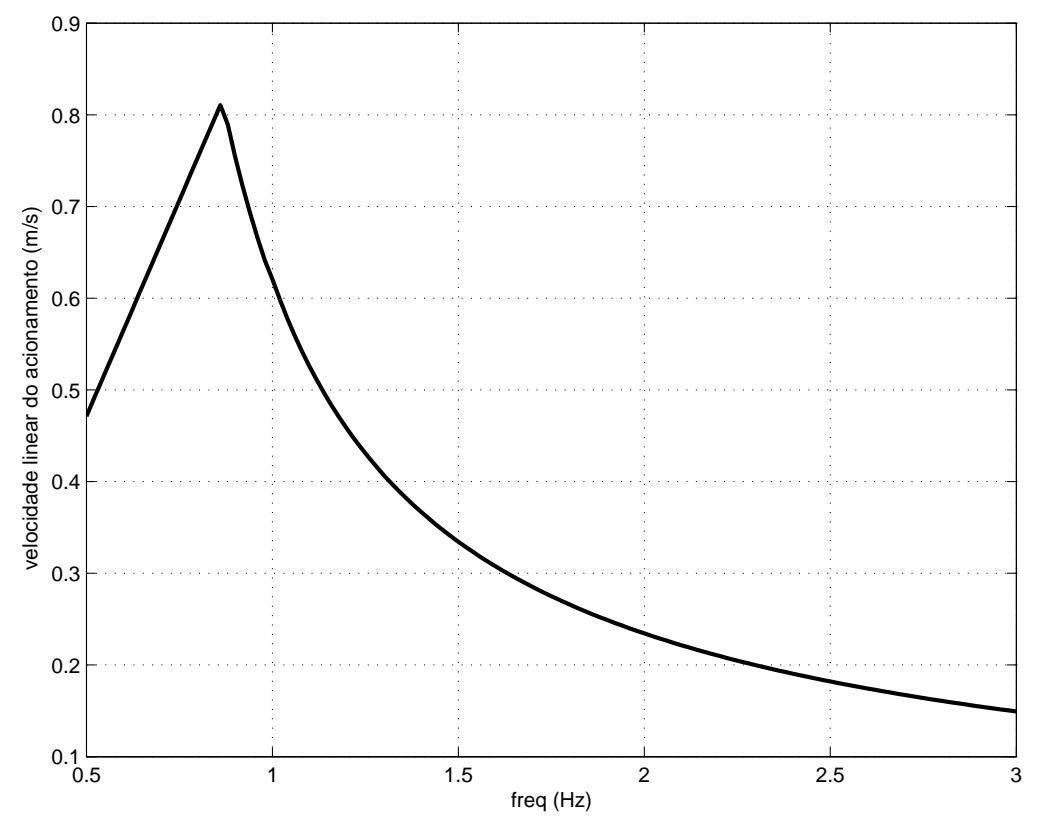

Figura 3.9: Velocidade linear máxima do acionamento.

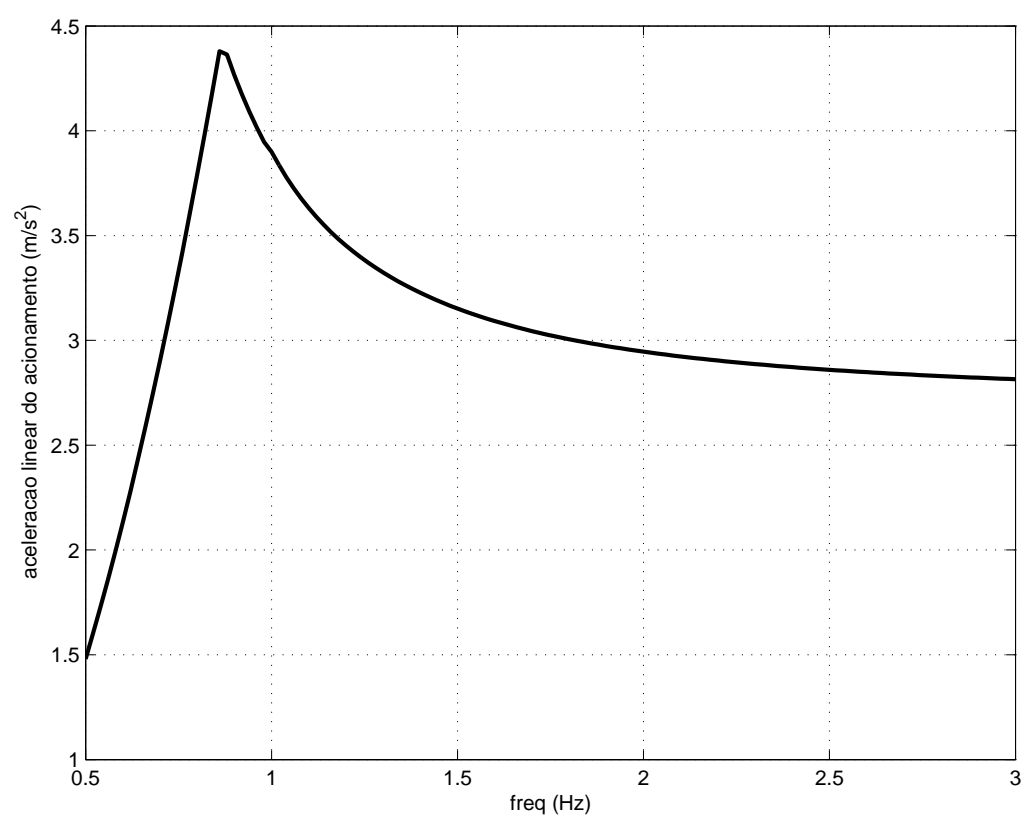

Figura 3.10: Aceleração linear máxima do acionamento.

$$
\begin{array}{ll}
v_{r}(t)=\frac{S_{c}}{2} \omega \frac{60}{r} \cos (\omega t) & {[\mathrm{rpm}]} \\
a_{r}(t)=-\frac{S_{c}}{2} \omega^{2} \frac{2 \pi}{r} \operatorname{sen}(\omega t) & {\left[\mathrm{rad} / \mathrm{s}^{2}\right]}
\end{array}
$$

Segundo Souza e Morishita (2003) a força de acionamento é composta pela reação hidrodinâmica, inércia do flap e o momento devido ao seu peso. A parcela 


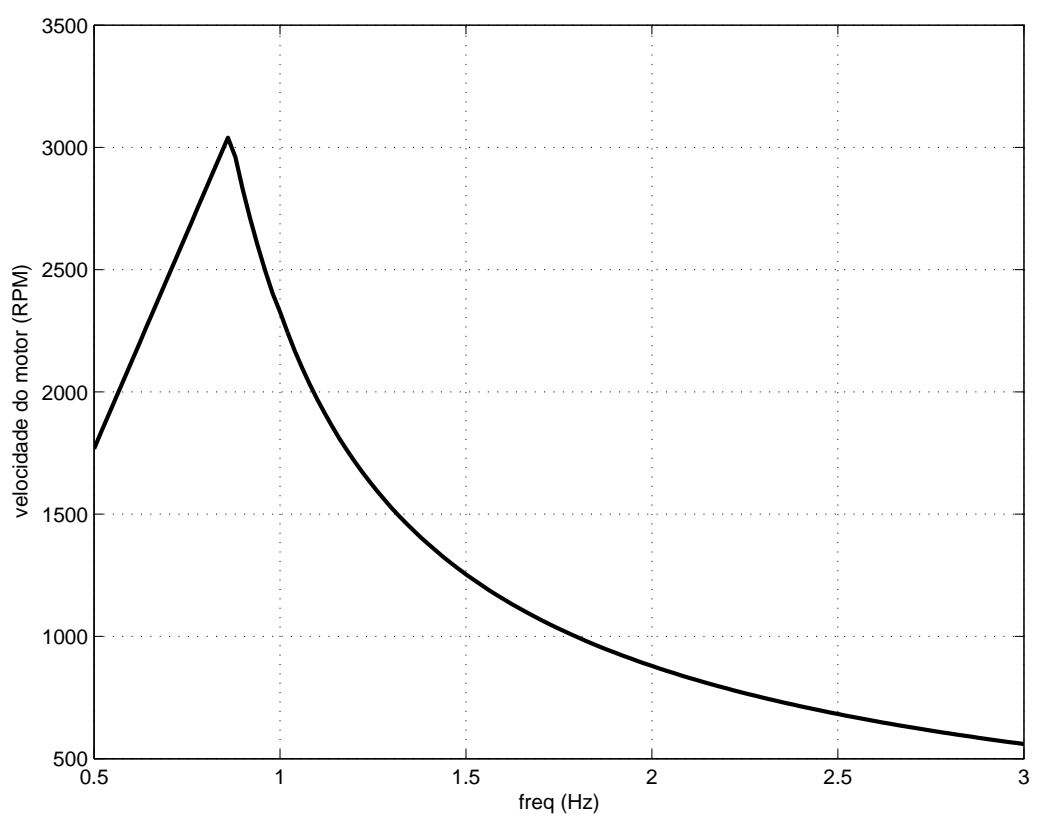

Figura 3.11: Rotação máxima do fuso.

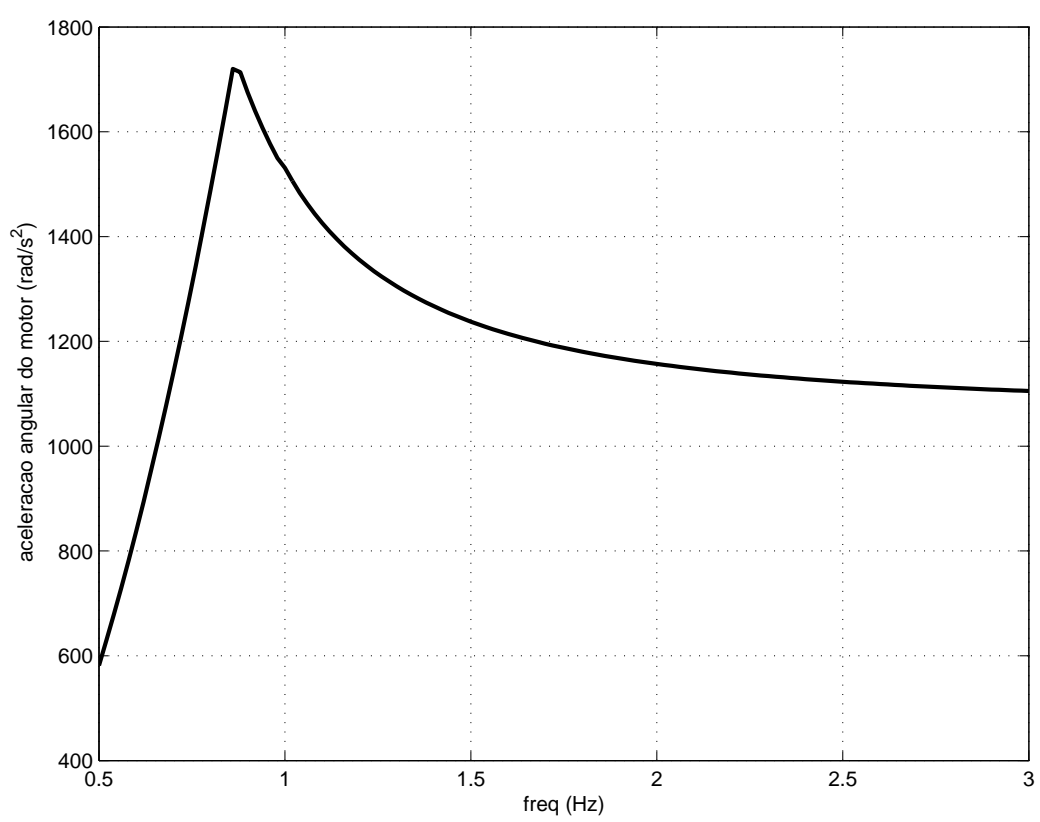

Figura 3.12: Aceleração angular máxima do fuso.

respectiva à reação hidrodinâmica é obtida através da integral da pressão em ambos os lados do flap:

$$
M_{h}=\int_{A}(h+z) p \mathrm{~d} A=2 l \int_{-h}^{0}(h+z) \rho\left[\frac{\partial \phi}{\partial t}\right]_{x=0} \mathrm{~d} z
$$

onde $A$ é a área total e $l$ é a largura do flap. Resolvendo a integral tem-se: 


$$
\begin{aligned}
M_{h} & =a_{1} \cos (\omega t)+a_{2} \sin (\omega t) \\
a_{1} & =-\frac{2 \omega l \rho A_{p}}{k_{p}}\left(h \sinh \left(k_{p} h\right)+\frac{1-\cosh \left(k_{p} h\right)}{k_{p}}\right) \\
a_{2} & =-2 \omega l \rho \sum_{m=1}^{\infty} \frac{C_{m}(m)}{k_{s}(m)}\left(h \sin \left[k_{s}(m) h\right]+\frac{\cos \left[k_{s}(m) h\right]-1}{k_{s}(m)}\right)
\end{aligned}
$$

O termo inercial depende da aceleração angular do flap, assumindo que o movimento angular do flap pode ser descrito por:

$$
\theta=\theta_{0} \operatorname{sen}(\omega t)=\arctan \left(\frac{S}{2 h}\right) \operatorname{sen}(\omega t)
$$

Desta forma o momento devido à inércia é:

$$
M_{i}=J \frac{\mathrm{d}^{2} \theta}{\mathrm{d} t^{2}}=J \omega^{2} \arctan \left(\frac{S}{2 h}\right) \operatorname{sen}(\omega t)
$$

onde $J$ é o momento inercial do flap com relação ao seu eixo de rotação no ponto de pivotamento.

O termo correspondente ao peso é dado por:

$$
M_{g}=m g x_{g}
$$

onde $m$ é a massa do flap, $g$ é a aceleração da gravidade e $x_{g}$ é a distância entre o centro de gravidade do flap e o eixo vertical $(z)$, dado por:

$$
x_{g}=x_{g 0}+h_{g} \theta_{0} \operatorname{sen}(\omega t)
$$

onde $x_{g 0}$ é a distância do centro de gravidade do flap em $\theta=0$ e o eixo vertical $(z)$ e $h_{g}$ é a altura do centro de gravidade.

O momento total de acionamento aplicado no ponto de pivotamento é a somatória dos três termos apresentados (equação 3.26) e pode ser observado na figura 3.13.

$$
M=M_{h}+M_{i}+M_{g}
$$




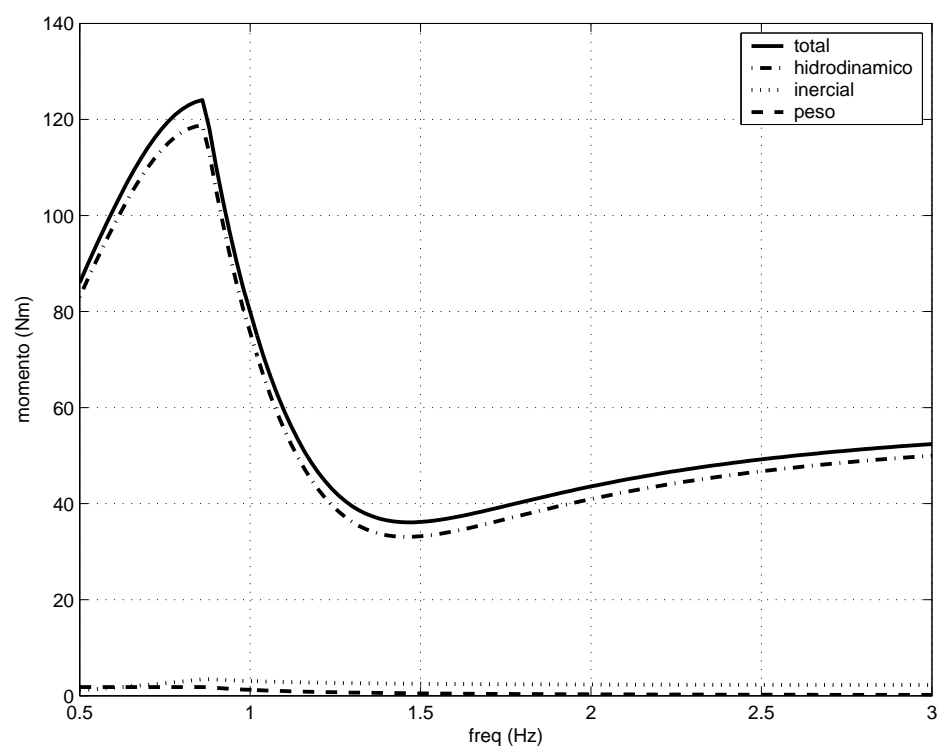

Figura 3.13: Momento máximo de acionamento no ponto de pivotamento do flap.

Desta forma, calcula-se a força de acionamento aplicada na castanha do fuso (figura 3.14):

$$
F=\frac{M}{h_{c}}
$$

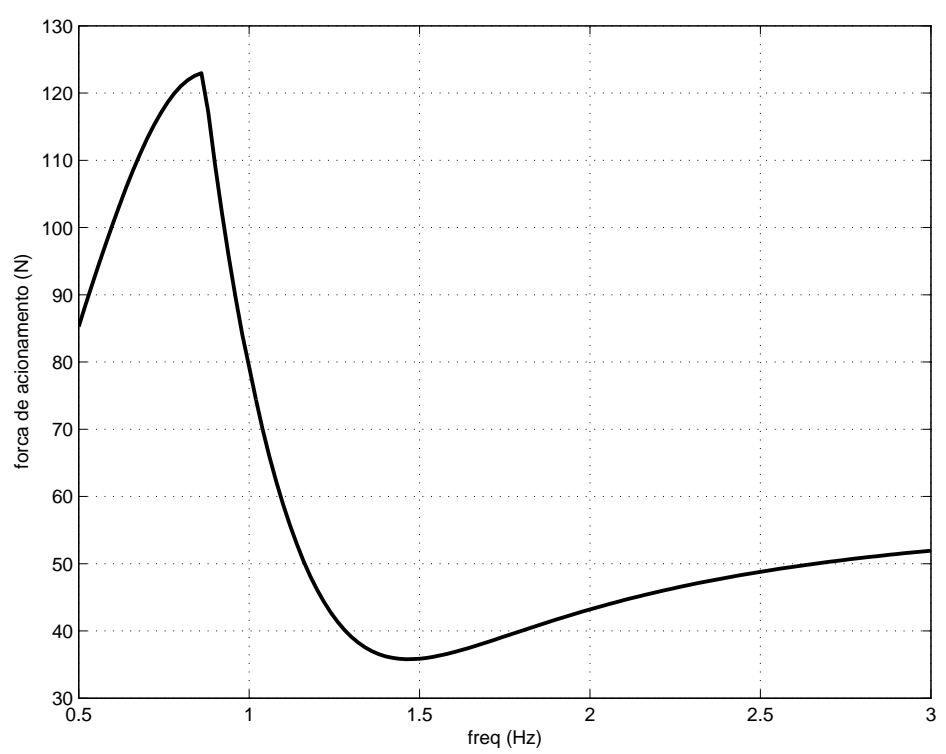

Figura 3.14: Força máxima de acionamento.

\subsection{Dimensionamento e seleção do servomotor e do fuso de esferas recirculantes}

Com os esforços de geração de ondas bem definidos, foram selecionados os principais componentes do acionamento, ou seja, o servomotor, o fuso de esferas recir- 
culantes e a guia linear. O torque do motor é calculado através da equação 3.28 (figura 3.15).

$$
T=T_{c}+\left(J_{f}+J_{m}\right) a_{r}
$$

onde $J_{f}$ é a inércia do fuso, $J_{m}$ é a inércia do rotor do motor e $T_{c}$ é o torque da carga, obtido através da equação 3.29 :

$$
T_{c}=\frac{r}{2 \pi} F
$$

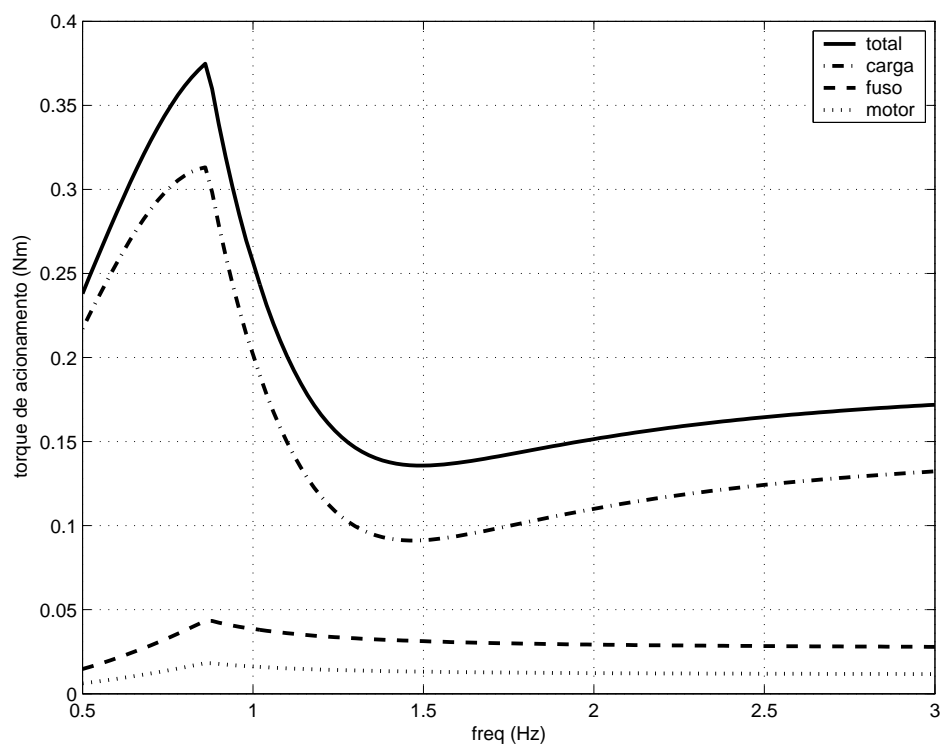

Figura 3.15: Torque de acionamento.

As potências da carga e total de acionamento são calculadas respectivamente pelas equações 3.30 e 3.31 (figura 3.16):

$$
\begin{aligned}
P_{c} & =F v \\
P & =T v_{r} \frac{2 \pi}{60}
\end{aligned}
$$

A inércia total da carga também deve ser analisada, uma vez que a carga é majoritariamente inercial. Ela é dada pela equação 3.32 (figura 3.17): 


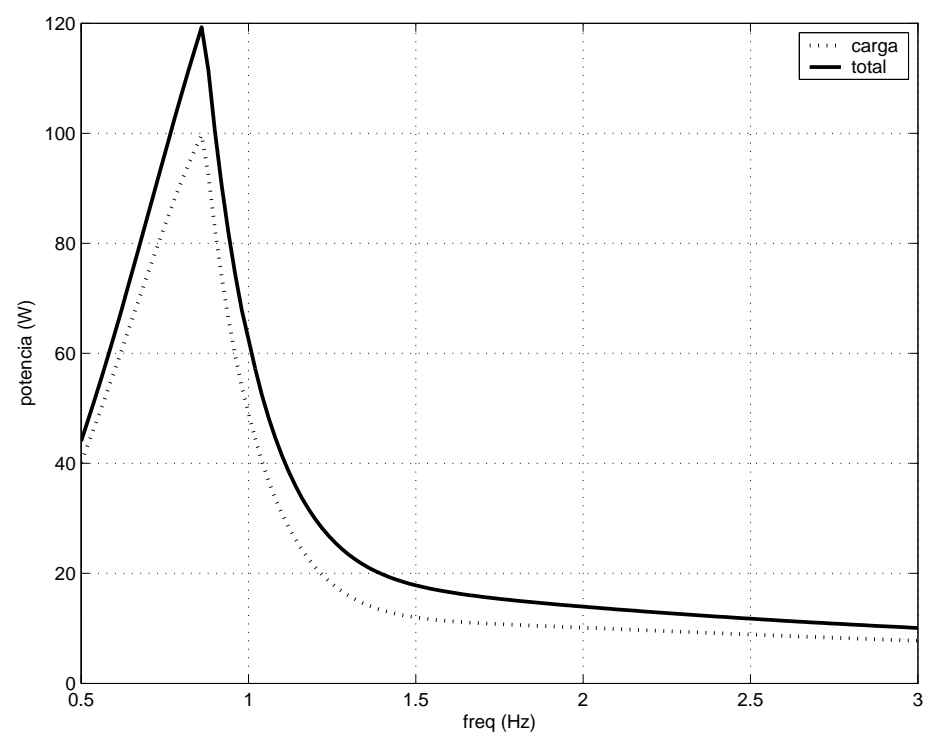

Figura 3.16: Potência de acionamento.

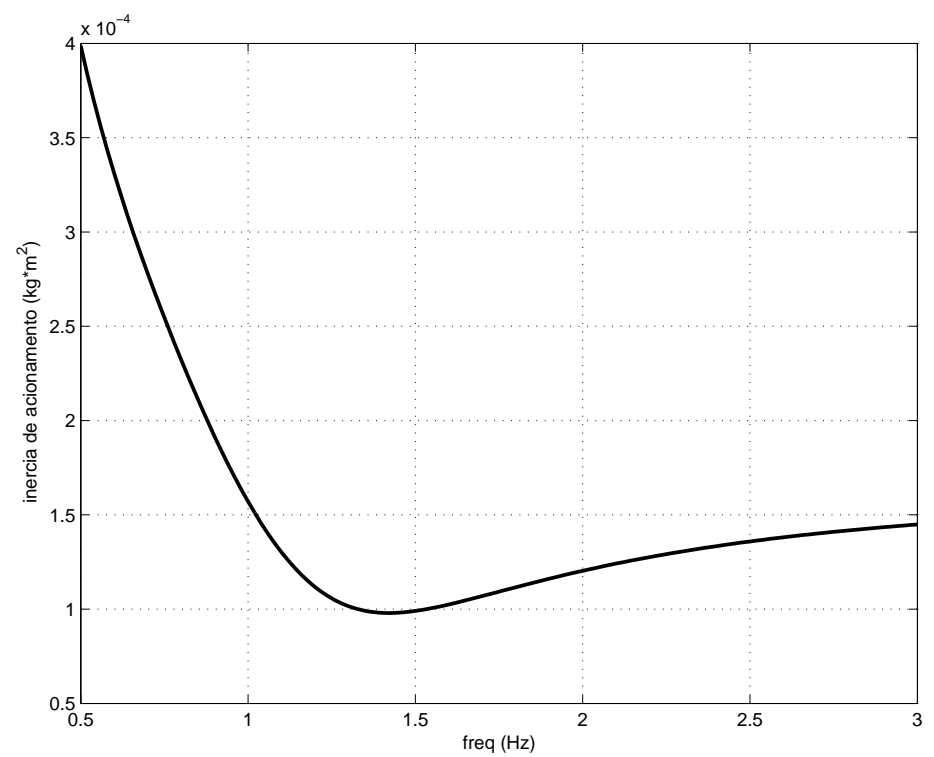

Figura 3.17: Inércia de acionamento.

$$
J_{c}=\frac{T_{c}}{a_{r}}+J_{f}
$$

Um programa foi implementado no Matlab para automatizar os cálculos de dimensionamento de geradores de ondas, as listagens desse programa podem ser encontradas em Carneiro e Mello (2007a). A tabela 3.3 apresenta os dados mais relevantes obtidos no dimensionamento do protótipo.

Através de consulta a catálogos de fornecedores foram selecionados os seguintes componentes (tabela 3.4): 
Tabela 3.3: Dados obtidos no dimensionamento do gerador de ondas.

\begin{tabular}{ll}
\hline Grandeza & Valor \\
\hline Velocidade linear na castanha do fuso & $0,811 \mathrm{~m} / \mathrm{s}$ \\
Aceleração linear na castanha do fuso & $4,38 \mathrm{~m} / \mathrm{s}^{2}$ \\
Rotação do motor & $3039 \mathrm{rpm}$ \\
Aceleração do motor & $1720 \mathrm{rad} / \mathrm{s}^{2}$ \\
Força de acionamento no carro do fuso & $123 \mathrm{~N}$ \\
Torque do motor & $0,375 \mathrm{Nm}$ \\
Potência do motor & $119 \mathrm{~W}$ \\
Inércia da carga & $3,99 \cdot 10^{-4} \mathrm{~kg} \cdot \mathrm{m}^{2}$ \\
\hline
\end{tabular}

Tabela 3.4: Principais componentes do sistema de acionamento.

\begin{tabular}{lll}
\hline Item & Modelo & Fabricante \\
\hline Servomotor & SGMAH02AAF21 & Yaskawa \\
Servo driver & SGDH-02AE & Yaskawa \\
Guia linear & SHS15V1 & THK \\
Fuso & BLK 1616-7.2 & THK \\
\hline
\end{tabular}

As tabelas 3.5 e 3.6 apresentam respectivamente as principais características do motor e do fuso selecionados.

Tabela 3.5: Principais características do servomotor selecionado.

\begin{tabular}{lc}
\hline Característica & Valor \\
\hline Potência & $200 \mathrm{~W}$ \\
Rotação nominal & $3000 \mathrm{rpm}$ \\
Rotação de pico & $5000 \mathrm{rpm}$ \\
Torque nominal & $0,637 \mathrm{Nm}$ \\
Torque de pico & $1,910 \mathrm{Nm}$ \\
Aceleração angular & $60100 \mathrm{rad} / \mathrm{s}^{2}$ \\
Momento de inércia do rotor & $0,106 \cdot 10^{-4} \mathrm{~kg} \cdot \mathrm{m}^{2}$ \\
Inércia permitida da carga & $3.690 \cdot 10^{-4} \mathrm{~kg} \cdot \mathrm{m}^{2}$ \\
Encoder & incremental de $13 \mathrm{bits}$ \\
\hline
\end{tabular}

Tabela 3.6: Principais características do fuso selecionado.

\begin{tabular}{lc}
\hline Característica & Valor \\
\hline Diâmetro & $16 \mathrm{~mm}$ \\
Passo & $16 \mathrm{~mm}$ \\
Comprimento entre mancais & $420 \mathrm{~mm}$ \\
Comprimento total & $480 \mathrm{~mm}$ \\
Momento de inércia por comprimento & $5,05 \cdot 10^{-4} \mathrm{~kg} \cdot \mathrm{cm}^{2} / \mathrm{mm}$ \\
Rotação crítica & $4200 \mathrm{rpm}$ \\
\hline
\end{tabular}




\subsection{Mecanismo do gerador de ondas}

O sistema de acionamento do gerador de ondas foi montado sobre um perfil de alúminio, de forma a flexibilizar e facilitar sua montagem no conjunto de gerador de ondas. O motor é conectado ao fuso através de um acoplamento elástico do tipo fole de alta rigidez torcional, um suporte fixado na castanha do fuso o conecta à guia linear. O sistema de acionamento é conectado ao flap através de um braço mecânico, o qual foi fabricado a partir de um tubo de alumínio e possui suportes com mancais de rolamentos em ambas as extremidades (figura 3.18).

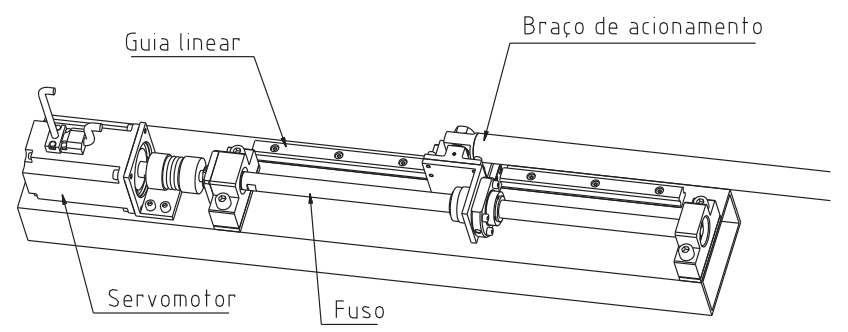

Figura 3.18: Detalhe do sistema de acionamento.

O flap é conectado ao sistema de acionamento através do braço mecânico citado anteriormente, posicionado em sua parte superior. Na parte inferior encontram-se dois mancais de deslizamento fabricados em nylon.

Um suporte foi confeccionado a partir de tubos de aço inox soldados para apoiar os quatro flaps nas paredes do tanque. Alinhamentos nos 3 eixos podem ser feitos através de oito pontos de fixação (figura 3.19).

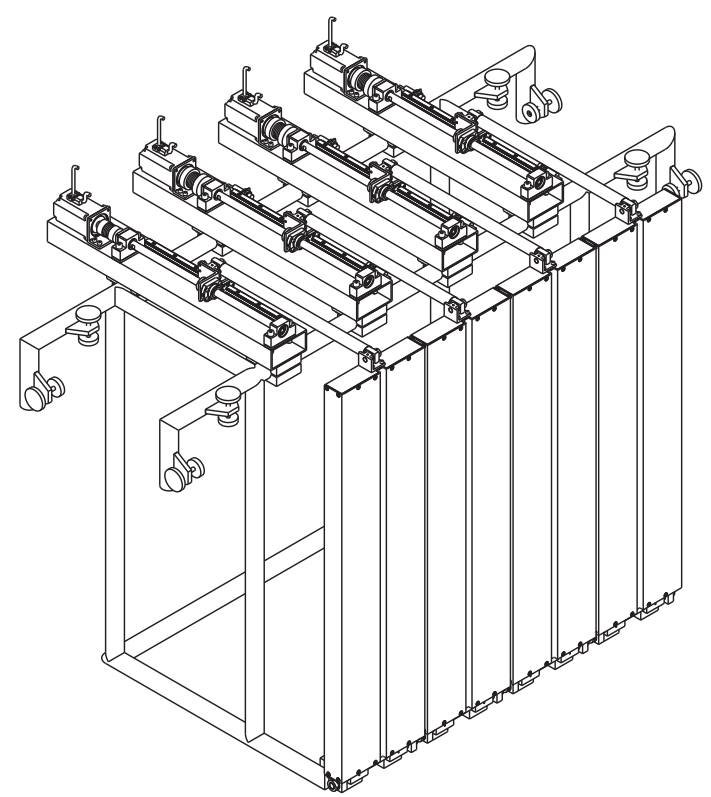

Figura 3.19: Desenho do gerador de ondas. 
Na figura 3.20 pode-se observar o sistema montado no canal de ensaios do LENO.

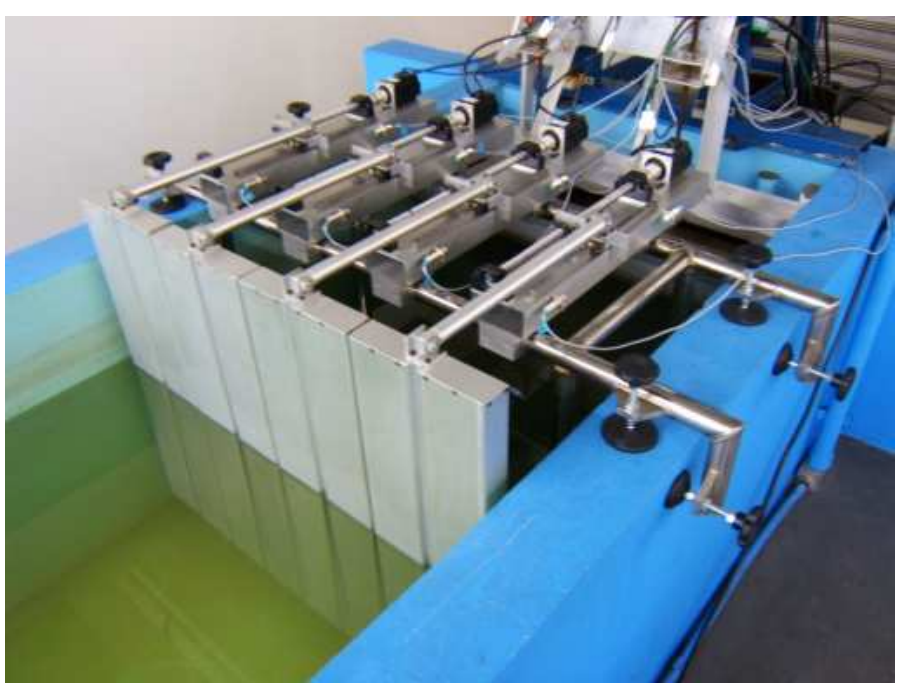

Figura 3.20: Foto do gerador de ondas. 


\section{Sensor de altura de ondas}

$\mathrm{Na}$ absorção de ondas existe a necessidade de um sensor para efetuar a realimentação hidrodinâmica da malha de controle. Os sensores mais utilizados são os de altura de onda, montados diretamente na frente do gerador de ondas, movendo-se junto com o sistema. (SCHäFFER; KLOPMAN, 2000).

Segundo pesquisa do ITTC (1999) entre seus membros, o sensor de altura de onda mais utilizado é o do tipo resistivo, como pode-se observar na tabela 4.1

Tabela 4.1: Sensores de altura de onda mais utilizados entre os membros do ITTC (1999).

\begin{tabular}{cc}
\hline Tipo do sensor & Respostas \\
\hline Resistivo & 19 \\
Servo & 15 \\
Capacitivo & 11 \\
Acústico & 6 \\
\hline
\end{tabular}

O LENO possui sensores resistivos que foram desenvolvidos pelo Instituto de Pesquisas Tecnológicas do Estado de São Paulo (IPT). No presente trabalho, foram desenvolvidos sensores de onda por ultra-som e foram montados sensores capacitivos.

\subsection{Sensor resistivo}

Os sensores resistivos consistem em um par de eletrodos verticais parcialmente imersos na água e têm uma saída em tensão proporcional ao comprimento imerso.

Os sensores do laboratório foram feitos com dois eletrodos de aço inox de 1,0 mm de diâmetro e 0,50 m de comprimento. Os eletrodos são suportados por um perfil de alúminio com formato de asa, para diminuir a força de arraste e interferência na superfície da água. Um suporte de alumínio fixado ao sensor, perfurado a cada 10,0 $\mathrm{mm}$, permite realizar sua calibração estática (figura 4.1).

A eletrônica do sensor é analógica e está dividida em duas partes. A primeira parte é composta por uma fonte de alimentação, um conversor, um amplificador e um 


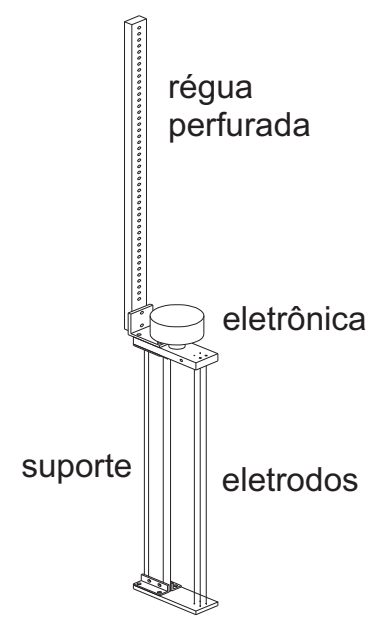

Figura 4.1: Ilustração do sensor de altura de onda resistivo.

modulador, situados em uma caixa estanque fixada no suporte do sensor. A segunda parte é composta por um condicionador de sinais que possui um demodulador, um filtro e um amplificador com ajuste de ganho e de zero.

A leitura deste tipo de sensor sofre influência da condutividade da água. Esta por sua vez, depende de diversos fatores, como a temperatura e presença de contaminantes na água. De forma que existe a necessidade de calibração antes da realização de um ensaio, aumentando bastante o tempo dispendido em cada ensaio.

Uma vez que os eletrodos não possuem isolação elétrica com a água, existem interferências mútuas entre sensores. Para diminuir este efeito, cada um dos sensores do LENO possui sua própria freqüência de trabalho.

Outro característica que tem influência na leitura do sensor é a mudança da tensão superficial da água, que ocorre na presença de algum contaminante. Isto aumenta o tempo de resposta do sensor, uma vez que a água fica mais tempo aderida ao seu eletrodo, causando um efeito de histerese.

\subsection{Sensor capacitivo}

Os sensores capacitivos são bastante semelhantes aos sensores resistivos, porém usam eletrodos isolados. Com isso as interferências mútuas são reduzidas, possibilitando a utilização de mais de um sensor com a mesma freqüência de operação.

Foram montados três protótipos de sensores capacitivos baseados em um sensor comercial de nível de líquidos utilizados em instalações industriais. Dois sensores com eletrodos de 0,40 m comprimento e um com 0,60 m. O diâmetro externo dos eletrodos é de $0,5 \mathrm{~mm}$. O suporte com perfil do tipo asa e a haste de suporte perfurada são 
semelhantes aos do sensor resistivo.

Sua eletrônica também é dividida em duas partes. Fixado no sensor tem-se um conversor de capacitância em corrente elétrica, o qual possui um pré ajuste de zero e ganho. O condicionador de sinais externo possui um conversor de corrente em tensão, um filtro e um amplificador com ajuste de ganho e de zero.

\subsection{Sensor por ultra-som}

Na tentativa de diminuir a influência das variações físico-químicas da água e do ambiente do tanque na medição da altura de onda e desta forma diminuir o tempo despendido na calibração dos sensores, este trabalho apresenta o desenvolvimento de um sensor baseado em ultra-som.

A medição de nível utilizando sensores de ultra-som é amplamente utilizada na indústria (HAUPTMANN; HOPPE; PüTTMER, 2002), porém os sensores normalmente encontrados realizam apenas a medição de nível estático.

\subsubsection{Revisão teórica}

\subsubsection{Equação da onda acústica}

O ultra-som é definido como ondas acústicas imperceptíveis ao ouvido humano, cujas freqüências são superiores a 20 kHz e são caracterizadas por vibrações mecânicas que se propagam em um determinado meio.

Em meios sólidos podem existir dois tipos de ondas acústicas, as ondas longitudinais e as de cisalhamento, enquanto que em um fluido invíscido somente pode existir a onda longitudinal. Numa onda longitudinal as partículas se deslocam na mesma direção da propagação da onda, enquanto que na onda de cisalhamento o deslocamento ocorre perpendicularmente à direção de propagação (figura 4.2).

Neste trabalho estuda-se apenas a onda longitudinal propagando-se em meio líquido. Para uma onda plana que se propaga na direção do eixo $x$, a equação de onda é dada por:

$$
\frac{\partial^{2} p}{\partial x^{2}}=\frac{1}{c^{2}} \frac{\partial^{2} p}{\partial t^{2}}
$$

onde $p$ é a pressão acústica e $c$ é a velocidade de fase da onda. 


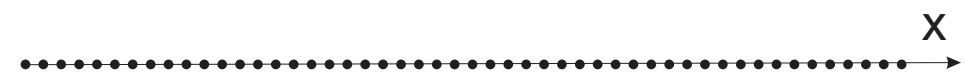

(a)

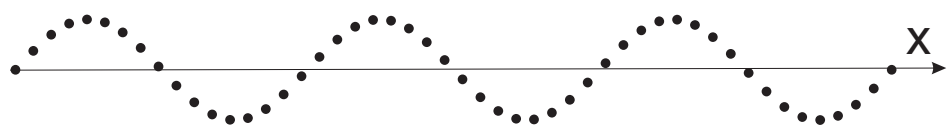

(b)

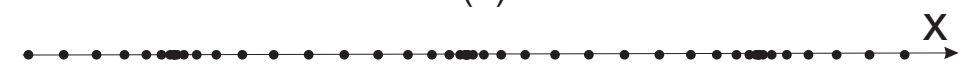

(c)

Figura 4.2: Deslocamento das partículas em uma onda acústica: (a) posição de equilíbrio; (b) onda de cisalhamento; (c) onda longitudinal.

A solução na forma complexa da pressão acústica para uma onda plana se propagando na direção positiva de $x$ é:

$$
\boldsymbol{p}=\boldsymbol{A} e^{j(\omega t-k x)}
$$

onde $k$ é o número de onda, definido por:

$$
k=\frac{\omega}{c}=\frac{2 \pi}{\lambda}
$$

A velocidade da onda longitudinal na água varia de acordo com a temperatura e a pressão. Grosso e Mader (1972) propõem uma expressão que relaciona a velocidade da onda em $\mathrm{m} / \mathrm{s}$ com a temperatura da água em graus Celsius, obtida a partir de medições em laboratório:

$$
c(\Theta)=\sum_{i=0}^{5} q_{i} \Theta^{i}
$$

onde $q_{i}$ é dado pela tabela 4.2 e $\Theta$ é a temperatura em graus Celsius.

Tabela 4.2: Coeficientes da equação 4.4.

\begin{tabular}{cr}
\hline$i$ & $q_{i}$ \\
\hline 0 & $0,140238754 \cdot 10^{4}$ \\
1 & $0,503711129 \cdot 10^{1}$ \\
3 & $-0,580852166 \cdot 10^{-1}$ \\
3 & $0,334198834 \cdot 10^{-3}$ \\
4 & $-0,147800417 \cdot 10^{-5}$ \\
5 & $0,314643091 \cdot 10^{-8}$ \\
\hline
\end{tabular}




\subsubsection{Fenômenos de transmissão}

Quando uma onda acústica se propaga em um fluido e encontra uma interface com um segundo fluido, ondas refletidas e transmitidas são geradas, como mostra a figura 4.3 .

A onda acústica incidente será representada por $p_{i}$, a onda transmitida por $p_{t} \mathrm{e}$ a refletida por $p_{r}$. Considerando que a onda incidente viaja na direção de $x$ positivo, temos:

$$
\begin{aligned}
& p_{i}=P_{i} e^{j\left(\omega t-k_{1} x\right)} \\
& p_{r}=P_{r} e^{j\left(\omega t+k_{1} x\right)} \\
& p_{t}=P_{t} e^{j\left(\omega t-k_{2} x\right)}
\end{aligned}
$$

onde $P_{i}, P_{r}$ e $P_{t}$ são as amplitudes de pressão das ondas.

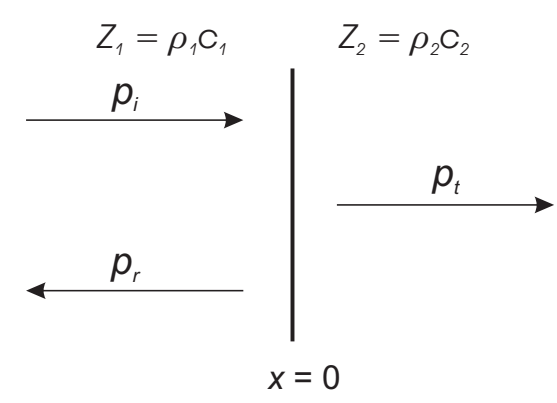

Figura 4.3: Reflexão e transmissão de uma onda acústica.

A onda transmitida tem a mesma freqüência da onda incidente, mas como os fluidos possuem velocidade de propagação diferentes, os números de onda são diferentes:

$$
\begin{aligned}
& k_{1}=\frac{\omega}{c_{1}} \\
& k_{2}=\frac{\omega}{c_{2}}
\end{aligned}
$$

A velocidade das partículas da onda incidente $v_{i}$, refletida $v_{r}$ e transmitida $v_{t}$ são dadas por: 


$$
\begin{aligned}
v_{i} & =\frac{P_{i}}{\rho_{1} c_{1}} e^{j\left(\omega t-k_{1} x\right)} \\
v_{r} & =\frac{P_{r}}{\rho_{1} c_{1}} e^{j\left(\omega t+k_{1} x\right)} \\
v_{t} & =\frac{P_{t}}{\rho_{2} c_{2}} e^{j\left(\omega t-k_{2} x\right)}
\end{aligned}
$$

Os coeficientes de transmissão $\boldsymbol{T}$ e de reflexão $\boldsymbol{R}$ são definidos como:

$$
\begin{aligned}
& \boldsymbol{T}=\frac{P_{t}}{P_{i}}=\frac{2 Z_{2}}{Z_{1}+Z_{2}} \\
& \boldsymbol{R}=\frac{P_{r}}{P_{i}}=\frac{Z_{2}-Z_{1}}{Z_{1}+Z_{2}}
\end{aligned}
$$

onde $Z_{1}$ e $Z_{2}$ são as impedâncias acústicas dos dois meios, dadas por:

$$
\begin{aligned}
& Z_{1}=\rho_{1} c_{1} \\
& Z_{2}=\rho_{2} c_{2}
\end{aligned}
$$

As equações 4.13 e 4.14 mostram que, quanto maior a diferença das impedâncias acústicas dos dois meios, maior será a porcentagem da onda refletida. Já quando as impedâncias acústicas dos meios forem iguais não ocorre reflexão, ou seja, a onda é toda transmitida.

No caso de incidência oblíqüa (figura 4.4) o ângulo de reflexão $\theta_{r}$ é igual ao ângulo de incidência $\theta_{i}$ e o ângulo de transmissão $\theta_{t}$ é dado pela Lei de Snell:

$$
\frac{\operatorname{sen}\left(\theta_{i}\right)}{c_{1}}=\frac{\operatorname{sen}\left(\theta_{t}\right)}{c_{2}}
$$

$\mathrm{Na}$ incidência oblíqua as equações 4.13 e 4.14 tomam a forma:

$$
\begin{aligned}
\boldsymbol{T} & =\frac{2 Z_{2} \cos \left(\theta_{i}\right)}{Z_{1} \cos \left(\theta_{t}\right)+Z_{2} \cos \left(\theta_{i}\right)} \\
\boldsymbol{R} & =\frac{Z_{2} \cos \left(\theta_{i}\right)-Z_{1} \cos \left(\theta_{t}\right)}{Z_{2} \cos \left(\theta_{i}\right)+Z_{1} \cos \left(\theta_{t}\right)}
\end{aligned}
$$




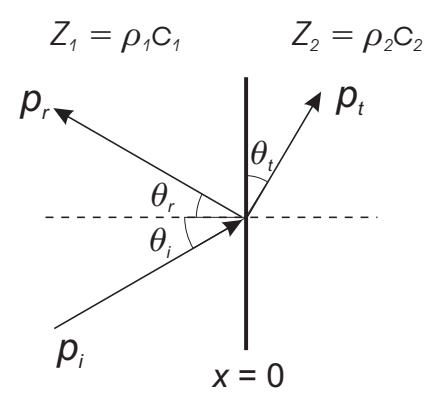

Figura 4.4: Reflexão e transmissão de uma onda acústica com incidência oblíqua.

\subsubsection{Transdutor de ultra-som}

Um transdutor de ultra-som é um dispositivo que converte um sinal elétrico em uma onda ultra-sônica e vice-versa. A maioria dos transdutores encontrados comercialmente utilizam cerâmicas piezelétricas para transformar a energia elétrica em energia mecânica.

Transdutores de ultra-som de banda larga são utilizados para aplicações envolvendo pulsos curtos, onde alta resolução axial é desejada para se medir velocidade e atenuação sobre uma faixa contínua de freqüências (GALLEGO-JUAREZ, 1989). A largura da banda de um transdutor está relacionada com a largura do pulso emitida pelo transdutor ao ser excitado por um sinal elétrico, de forma que quanto maior a banda do transdutor, mais estreito é o pulso gerado. A construção de um transdutor de banda larga é mostrada na figura 4.5 .

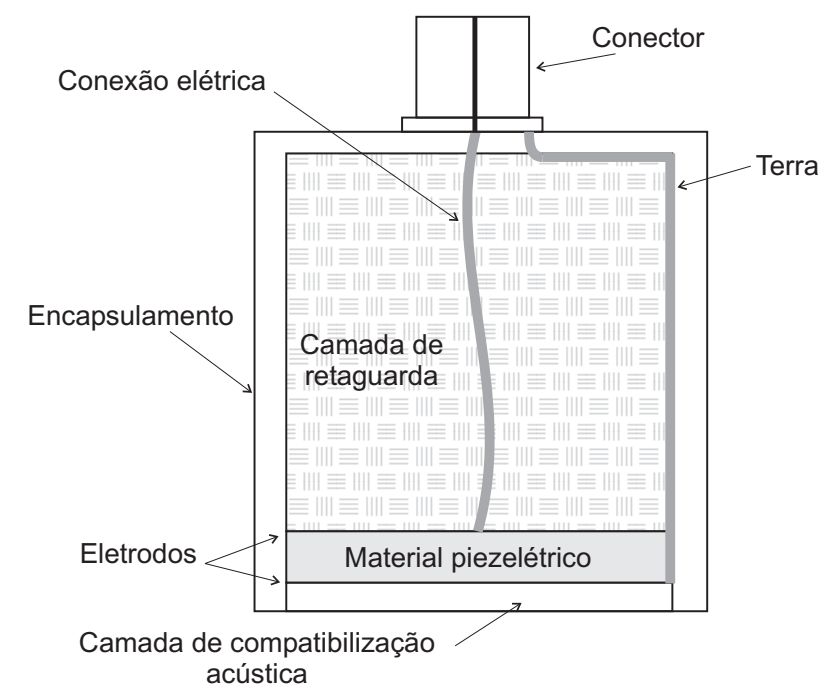

Figura 4.5: Típica construção de um transdutor de ultra-som de banda larga. Adaptado de Andrade (2006). 
Os principais componentes desse tipo de transdutor são uma cerâmica piezelétrica, uma camada de retaguarda e uma camada de compatibilização acústica. O material piezelétrico tem por objetivo converter a energia elétrica em mecânica e vice-versa. A camada de retaguarda é um material com alta atenuação e deve possuir impedância acústica próxima à do material piezelétrico, esta camada é utilizada para absorver as ondas acústicas emitidas para trás do transdutor, desta forma reduzindo a largura do pulso. A camada de compatibilização acústica tem por objetivo realizar o casamento de impedância acústica entre a cerâmica e o meio, de forma a possibilitar a máxima transmissão de energia do material piezelétrico para o meio (ANDRADE, 2006).

O campo acústico gerado por um transdutor de ultra-som de raio $\boldsymbol{a}$, emitindo uma onda contínua, pode ser dividido em duas regiões ao longo do eixo de propagação da onda (figura 4.6). A região de campo próximo, também conhecida como região de difração de Fresnel, que fica nas vizinhanças do transdutor e é caracterizada pela superposição das ondas de borda e ondas diretas. As interferências construtiva e destrutiva dessas ondas, provocam máximos e mínimos na intensidade da onda acústica. A outra é a região de campo distante ou região de Fraunhofer, na qual é formada uma frente de onda quase plana, que é atenuada à medida que se distancia do transdutor. Nesta região o campo tende a ser divergente (COSTA et al., 2004).

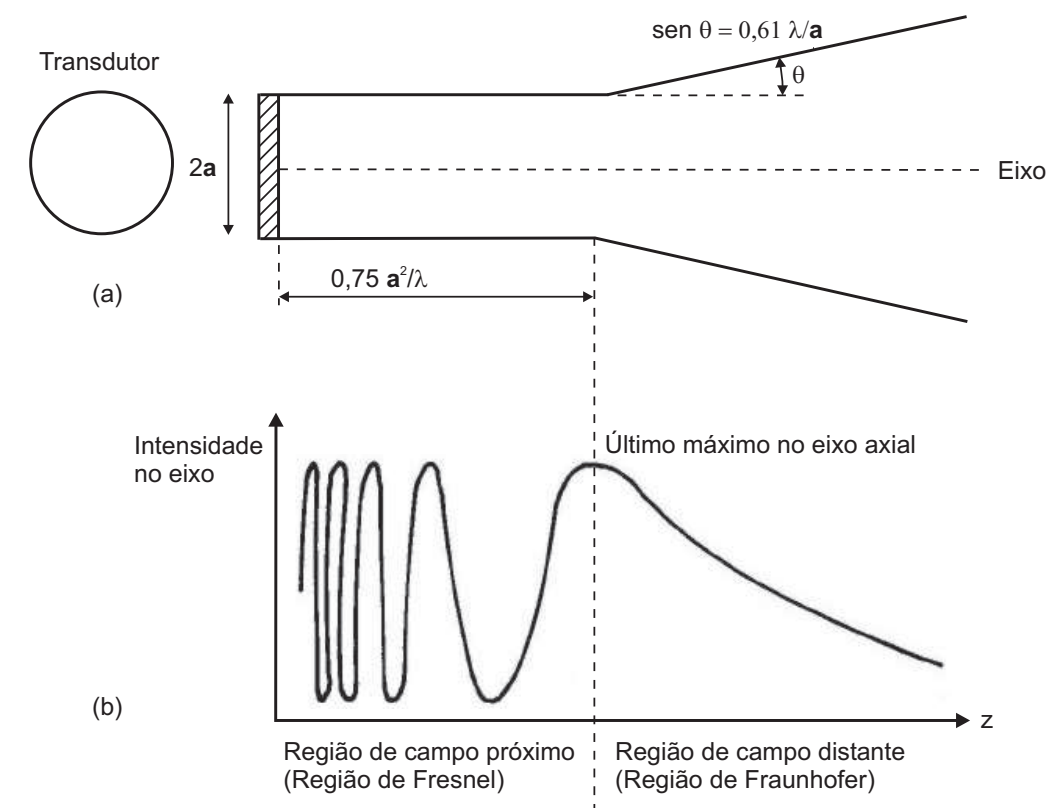

Figura 4.6: Campo acústico de um transdutor de ultra-som (a)Seção longitudinal; (b)Variação de intensidade de pressão ao longo do eixo do transdutor. Reproduzido de Costa et al. (2004).

No caso de transdutores de banda larga, desaparecem os pontos de máximo e mínimo de intensidade acústica no eixo acústico na região de Fresnel.

O campo acústico também possui lóbulos de pressão em função do ângulo com 
seu eixo. A maior parte da energia é projetada no lóbulo principal, que está centrado no eixo do transdutor (figura 4.7). Quanto maior é o raio do transdutor comparado com o comprimento de onda, mais lóbulos laterais possuirá a forma de radiação.

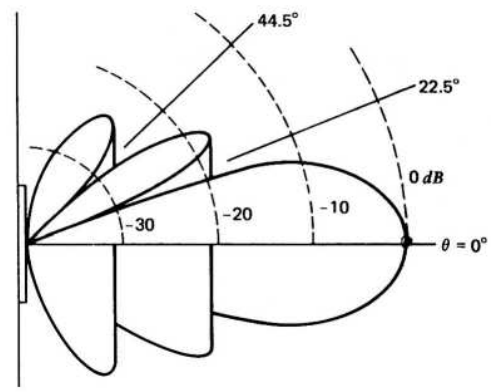

Figura 4.7: Formato dos lóbulos de pressão para um transdutor circular com $k \boldsymbol{a}=10$. Reproduzido de Kinsler et al. (1982).

\subsubsection{A técnica de pulso-eco}

Na técnica de pulso-eco a distância é obtida a partir do tempo de vôo do pulso ultra-sônico e da sua velocidade de propagação (equação 4.20). A velocidade da onda de ultra-som na água depende da sua temperatura e como foi visto anteriormente esta é uma relação bem definida (equação 4.4). A figura 4.8 apresenta um esquema da técnica de pulso-eco com o transdutor de ultra-som localizado dentro da água.

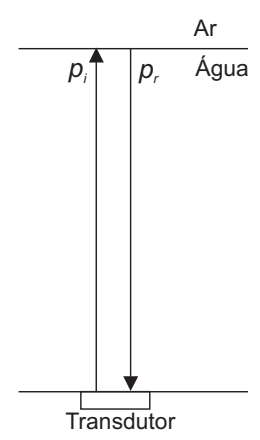

Figura 4.8: Técnica de pulso-eco para medição de nível.

$$
d=\frac{\Delta t c(\Theta)}{2}
$$

onde $d$ é a distância medida, $\Delta t$ é o tempo de vôo do pulso ultra-sônico, $c$ é a velocidade de propagação do som na água, dada pela equação 4.4 e $\Theta$ é a temperatura da água.

O principal desafio encontrado durante o desenvolvimento deste tipo de sensor é 
a perda de sinal quando o pulso de ultra-som reflete na superfície inclinada da onda (figura 4.9).

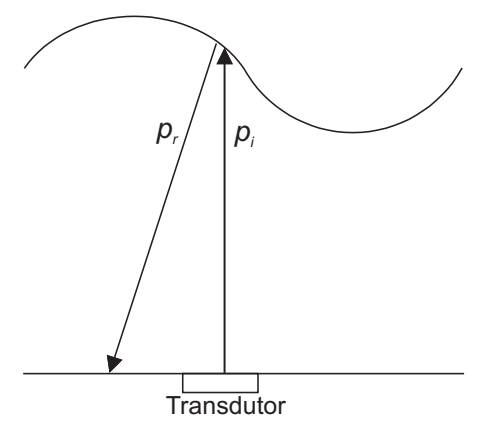

Figura 4.9: Ilustração da perda de sinal do sensor por ultra-som para uma superfície inclinada.

Para solucionar este problema foram feitos estudos da utilização de ondas de ultra-som guiadas. A guia de ondas utilizada em um sensor de nível deve direcionar a onda de ultra-som de forma a promover a menor perda de energia do pulso e ao mesmo tempo não pode interferir na altura de onda medida. Desta forma a guia de ondas será confeccionada com uma de suas paredes perfurada fazendo com que a água entre na guia de onda com uma menor perda de carga. A figura 4.10 apresenta uma ilustração do sensor de altura de ondas por ultra-som com uma guia de ondas.

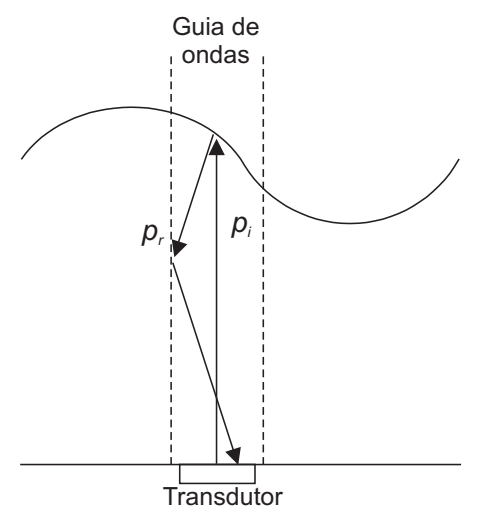

Figura 4.10: Ilustração do sensor por ultra-som com guia de ondas.

\subsubsection{Guia de ondas}

Ondas de ultra-som podem ser confinadas dentro de um duto, ou seja, uma guia de ondas. As guias de onda são utilizados para diminuir perda de energia, por exemplo, devido ao espalhamento da onda pelos lóbulos laterais de um transdutor.

As ondas de ultra-som podem se propagar em diferentes modos dentro de uma guia de ondas. Cada modo pode ser interpretado como uma onda plana se propagando 
num caminho de ziguezague ao longo da guia de ondas por sucessivas reflexões nos contornos, como pode ser observado na figura 4.11 (REDWOOD, 1963).

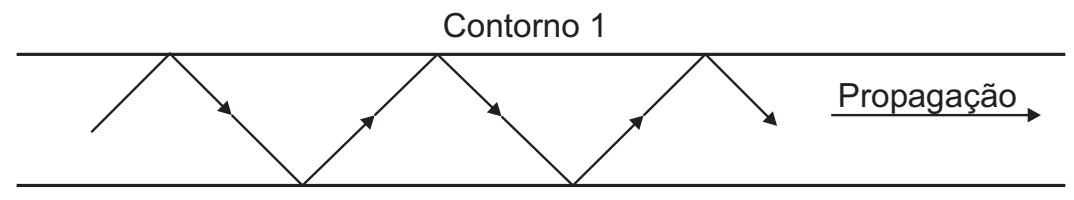

Contorno 2

Figura 4.11: Propagação de uma onda de ultra-som por um caminho de ziguezague.

Diferentemente de uma onda em um meio sem contornos, em uma guia de onda a velocidade de fase e de grupo variam com a freqüência. A velocidade de fase $C$ é a taxa com que o ponto de intersecção da frente de onda com a parede da guia viaja em paralelo com a parede, a velocidade de fase é sempre maior que a velocidade da onda em um meio sem contornos $c$. Já a velocidade de grupo $C_{g}$ é a velocidade com que a energia se propaga e portanto a velocidade com que a frente de onda se desloca. Esta velocidade é sempre menor que a velocidade da onda em um meio infinito $c$. A figura 4.12 ilustra esse fenômeno.

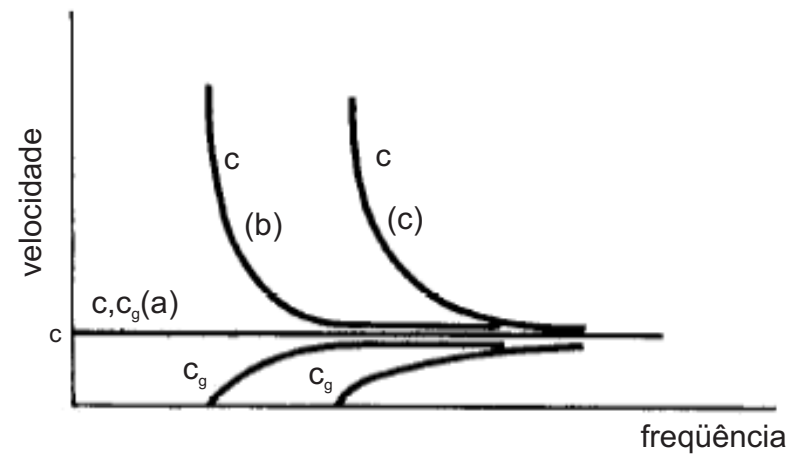

(a) Modo de onda longitudinal

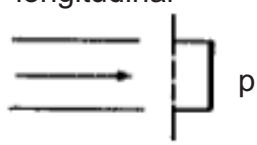

(b) Segundo modo

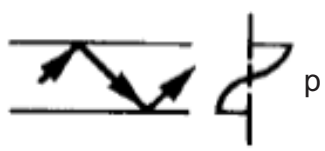

(c) Terceiro modo

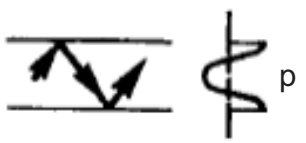

Figura 4.12: Velocidades de fase e de grupo em uma guia de ondas, onde $p$ é a distribuição de pressão, $C$ é a velocidade de fase, $C_{g}$ é a velocidade de grupo e $c$ é a velocidade em um meio infinito.

As velocidades de fase e de grupo podem ser obtidas através das equações $4.21 \mathrm{e}$ 4.22 para uma guia de ondas de lâmina, ou seja, uma camada fina de fluido cercada por duas superfícies planas em forma de sanduíche (figura 4.13). 


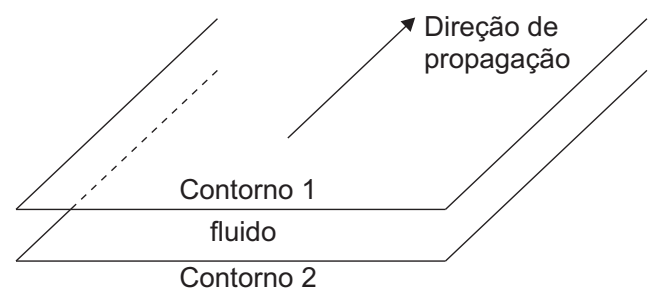

Figura 4.13: Guia de ondas tipo lâmina.

$$
\begin{aligned}
C & =c / \cos (\theta) \\
C_{g} & =c \sin (\theta)
\end{aligned}
$$

A pressão da onda acústica dentro da guia de ondas de lâmina para cada modo é dada por:

$$
p_{m}=A_{m} \cos \left(k_{x m}\right) e^{j\left(\omega t-k_{m z} t\right)}
$$

Os possíveis valores para o número de onda $k_{x}$, são obtidos através da condição de contorno e são:

$$
k_{x m}=\frac{l \pi}{D} \quad l=0,1,2, \ldots
$$

onde, $D$ é a distância entre as placas e o número de onda $k_{m z}$ é dado por:

$$
k_{m z}=\sqrt{(w / c)^{2}-k_{x m}^{2}}
$$

Para a propagação ocorrer $k_{m z}$ deve ser um valor real, de forma que para freqüências maiores a direção de propagação tem ângulo de $90^{\circ}$ com o eixo de transmissão e $k_{z}$ se torna imaginário, o que representa uma onda estacionária que decai exponencialmente com a distância, estas são as chamadas ondas evanescentes. A freqüência de corte é definida como:

$$
f_{c}=\frac{k_{m x} c}{2 \pi}
$$

Então cada modo de propagação possui sua freqüência de corte abaixo da qual esse modo não se propaga. A única exceção é o modo zero (modo longitudinal) que pode se propagar em todas as freqüências. 
O estudo da interferência entre modos de propagação de uma onda contínua é importante, pois esta pode levar a erros na medição de absorção da onda ultra-sônica, uma vez que a perda de sinal devido à interferência de fase pode ser confundida com a perda devido a sua atenuação intrínseca.

No caso de um pulso ultra-sônico, a atenuação devido a interferência entre os modos não é mais um efeito importante, porém este sofre distorção através da dispersão do sinal, pois as diferentes componentes em freqüência do pulso viajam a diferentes velocidades de grupo e de fase.

Neste trabalho as guias de onda serão utilizadas para direcionar pulsos ultrasônicos, o efeito de dispersão do sinal não será importante, pois o objeto de interesse é o tempo de vôo do pulso ultra-sônico e não a medição de sua dispersão.

Mais informações sobre guias de onda podem ser encontradas em Redwood (1963), Kinsler et al. (1982) e Harris, Hill e Tuner (1995). Nas referências citadas acima, são desenvolvidas as soluções para guias de onda circular e retangulares e também são apresentados aspectos de guias de onda em meios sólidos, nos quais encontramos não somente as ondas longitudinais, mas também as ondas de cisalhamento.

\subsubsection{Descrição da eletrônica}

A eletrônica do sensor de ultra-som foi projetada pelo grupo de pesquisas de ultrasom do Departamento de Engenharia Mecatrônica e Sistemas Mecânicos da USP. A figura 4.14 mostra o diagrama de blocos de todos os circuitos do sistema que foi adaptado ao presente projeto.

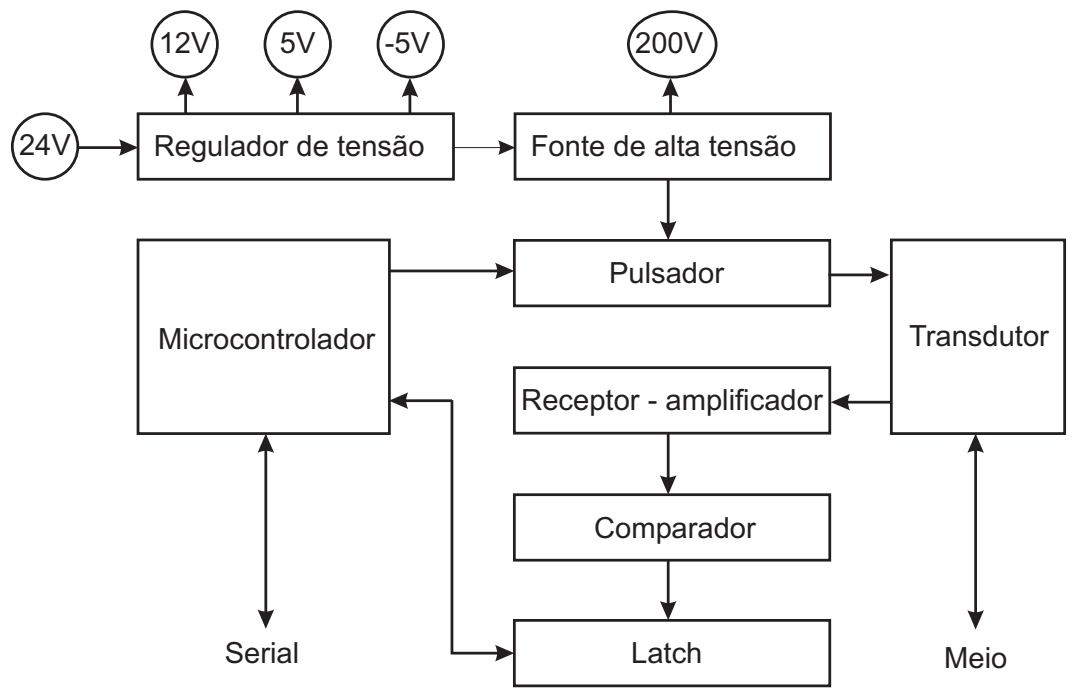

Figura 4.14: Eletrônica do sensor de ultra-som. 
Todo o sistema é alimentado por um fonte externa de $24 \mathrm{Vcc}$, que pode ser não regulada, a partir da qual são geradas tensões de +12 Vcc, +5 Vcc e $-5 V_{c c}$ através de reguladores de tensão chaveados. O bloco de fonte de alta-tensão é alimentado pela fonte de $12 \mathrm{Vcc}$ e a partir de um regulador chaveado tipo Boost atinge-se a alta-tensão de aproximadamente $260 \mathrm{Vcc}$.

O bloco pulsador é composto por um circuito que gera um pulso estreito necessário à excitação de um transdutor de ultra-som de banda larga. O circuito gera um pulso de $-220 \mathrm{~V}$ de tensão com tempo de subida de poucos nanosegundos.

O sinal de eco recebido pelo transdutor é amplificado pelo bloco receptor amplificador. Este circuito permite que o ganho do amplificador seja ajustável através de um potenciômetro, até um ganho de cerca de $50 \mathrm{~dB}$.

Posteriormente, o sinal analógico proveniente do amplificador, é convertido para sinal padrão TTL através do bloco comparador. Este bloco é formado por um circuito comparador de alta-velocidade, suportando comparar um sinal de referência com o sinal do transdutor. A tensão de referência pode ser ajustada através de um potenciômetro.

O sinal de eco no padrão TTL é responsável por gerar o clock do bloco Latch. Este circuito gera na saída um sinal lógico nível "1" toda vez que um sinal de eco é recebido. Após a leitura do sinal de eco-válido deve-se reiniciar o Latch de forma a permitir que um novo sinal de eco seja validado.

Um microcontrolador é responsável por controlar o sinal de disparo do pulsador, ler o sinal de eco através do Latch, medir o tempo do pulso-eco e realizar a interface com o mundo exterior através de uma rede padrão RS232.

\subsubsection{Descrição do software}

O software de controle do sensor de altura de ondas por ultra-som foi implementado em linguagem $\mathrm{C}$ para microcontroladores (CCS) e funciona da seguinte forma:

O microcontrolador recebe um sinal para iniciar a leitura de altura de onda através do pino RTS da porta serial RS232, a seguir o microcontrolador dispara o circuito pulsador. Após um intervalo de tempo $t_{1}$ pré-determinado por calibração, o microcontrolador envia ao Latch o sinal de Habilita Eco ao mesmo tempo que inicia o contador de tempo. Esta janela de tempo $t_{1}$ tem por objetivo filtrar o eco inicial devido a reflexões internas no transdutor. Quando o Latch detectar o eco, o microcontrolador pára o contador de tempo, desliga o sinal de Habilita Eco e aguarda um sinal através da porta RTS para enviar o valor do contador de tempo pela serial. Após enviar a 
mensagem, o microcontrolador zera o contador de tempo e o processo se reinicia. A figura 4.15 ilustra este procedimento. Caso um eco válido não seja detectado, o microcontrolador envia pela serial o valor de fundo de escala.

A resolução do contador de tempo é de $0,2 \mu \mathrm{s}$. Para uma velocidade média do pulso ultra-sônico de $1482 \mathrm{~m} / \mathrm{s}\left(20^{\circ} \mathrm{C}\right)$ a resolução de medição é de 0,15 mm.

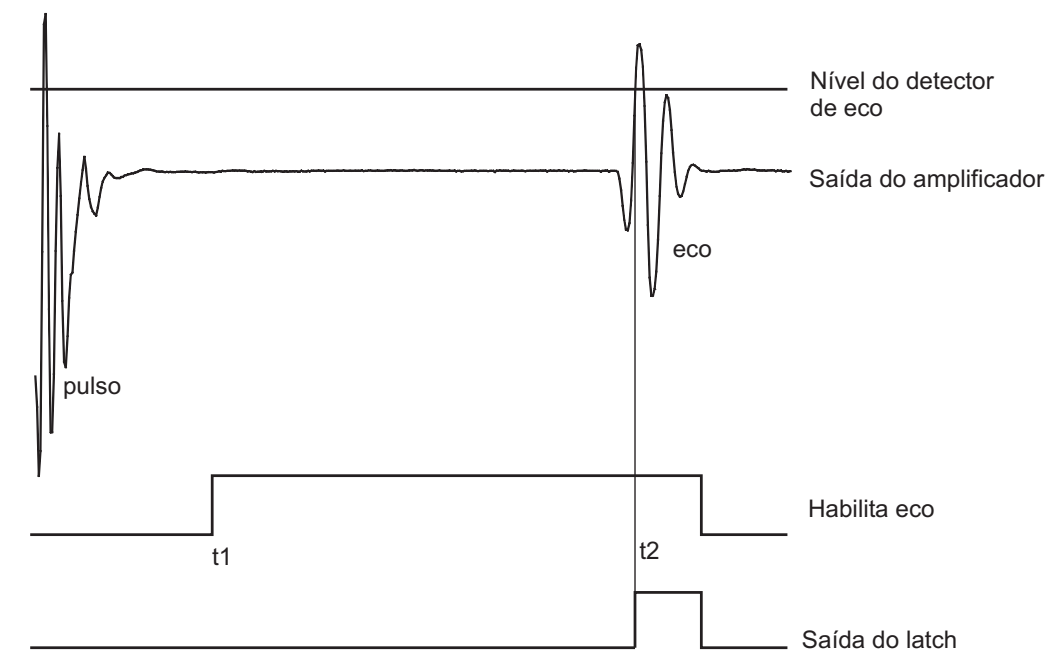

Figura 4.15: Janela de tempo de detecção de eco.

A listagem do programa do microcontrolador e o esquema elétrico da placa do sensor de altura de ondas podem ser encontrados em Carneiro e Mello (2007b).

\subsubsection{Ensaios preliminares}

Foram realizados ensaios preliminares utilizando a guia de onda representada na figura $4.16 \mathrm{com}$ um transdutor de ultra-som de $5 \mathrm{MHz}$ com diâmetro de $6,35 \mathrm{~mm}$. No ensaio foram utilizados um sensor de ultra-som sem a guia de onda e um sensor resistivo como testemunha (figura 4.17), os transdutores de ultra-som foram fixados em uma placa dentro do canal do LENO e ondas foram geradas com o gerador de ondas tipo cunha já existente instalado no canal.

A guia de ondas utilizada foi confeccionada de alumínio a partir de chapas dobradas, sua secção é de $10 \mathrm{~mm}$ por $15 \mathrm{~mm}$. A face frontal da guia de ondas foi perfurada com furos de diâmetro de $3 \mathrm{~mm}$ com espaçamento de $10 \mathrm{~mm}$. As dimensões da superfície perfurada foram definidas de forma a apresentar uma velocidade adequada de escoamento da água acumulada dentro da guia de ondas, para minimizar o atraso entre as alturas fora e dentro da guia de ondas.

A figura 4.18(a) mostra a comparação entre o sinal do sensor de ultra-som com e sem a guia de onda, as faixas em vermelho representam a perda do sinal de ultra-som. 


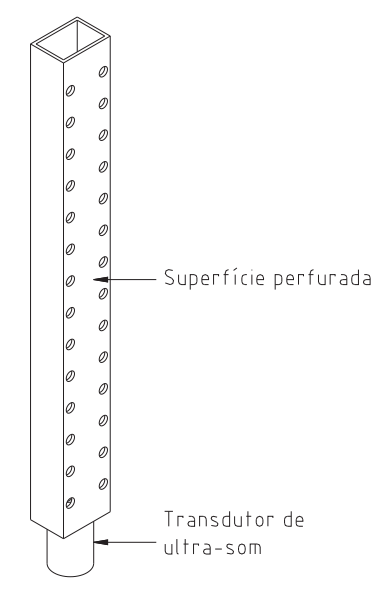

Figura 4.16: Guia de ondas do sensor de ultra-som.

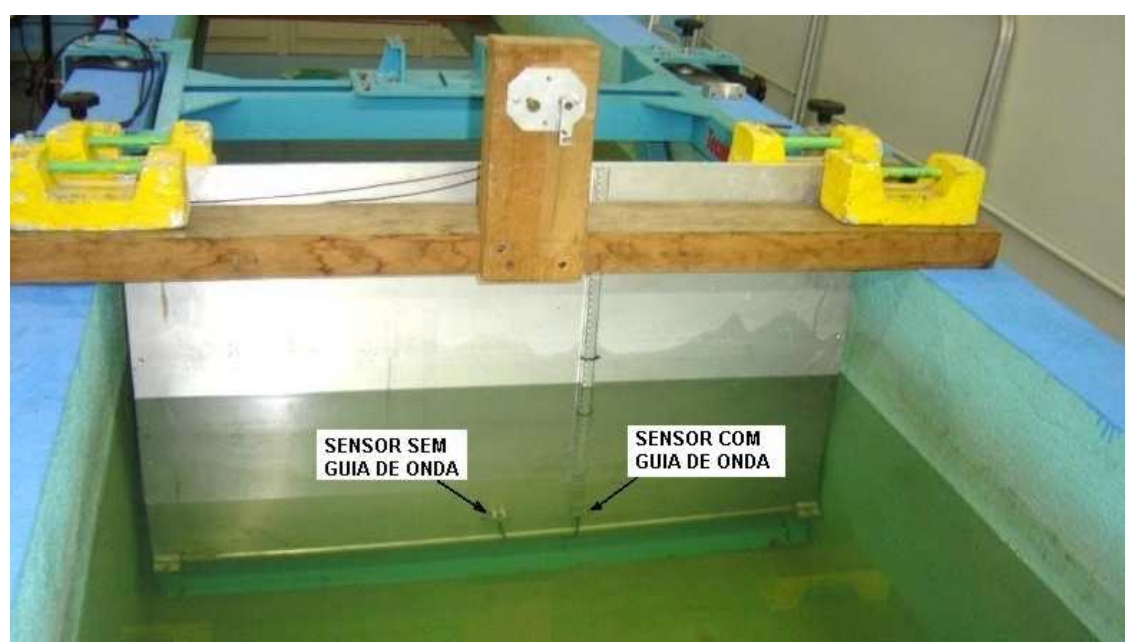

Figura 4.17: Foto do ensaio do sensor de altura de ondas por ultra-som.

Enquanto que na figura 4.18(b), pode-se observar a comparação entre os sinais do sensor de ultra-som e o sensor resistivo.

Comparando os sinais dos três sensores, pode-se observar que eles não apresentaram diferenças elevadas de amplitude e de fase do sinal de altura de onda.

Observou-se também a existência de turbulência na superfície da água dentro da guia de ondas, o que acarretava na perda do eco do sinal de ultra-som para alturas de onda mais altas. Desta forma foi estudado outro perfil para a superfície perfurada da guia de onda. Os furos tomaram forma oblonga para diminuir a descontinuidade da vazão de água entre a guia de ondas e o exterior (figura 4.19).

Outra providência para diminuir a dispersão do eco do ultra-som na superfície irregular da água foi a utilização de um transdutor com freqüência mais baixa, de $2 \mathrm{MHz}$. Como o comprimento da onda de ultra-som é maior, a reflexão do pulso ultra-sônico fica menos sensível às irregularidades da superfície livre da água. 


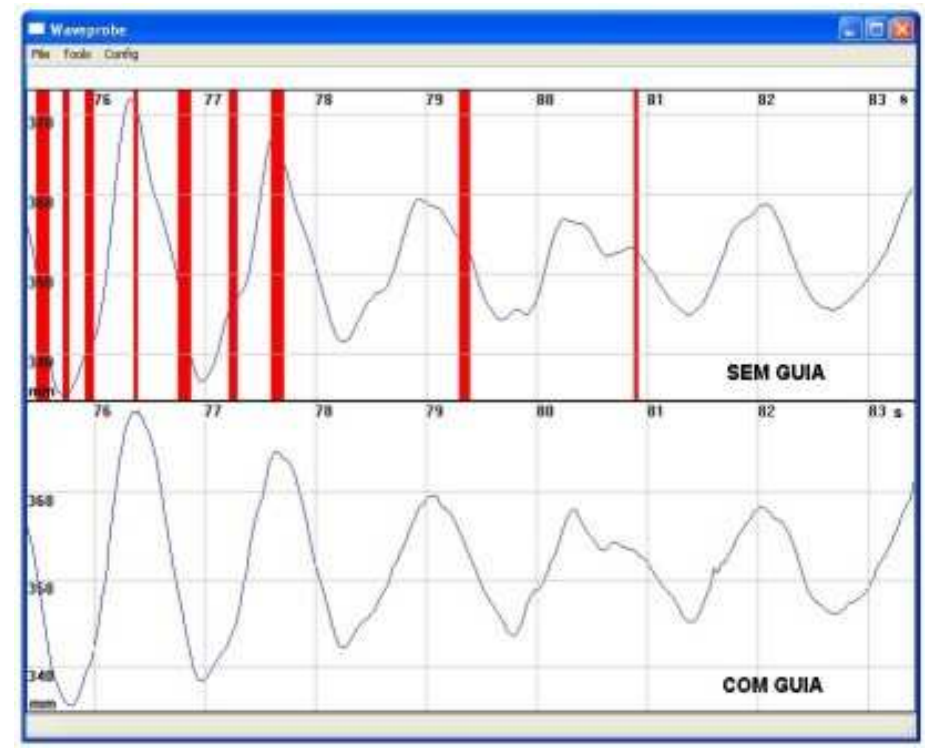

(a) Sensores por ultra-som com e sem guia de ondas.

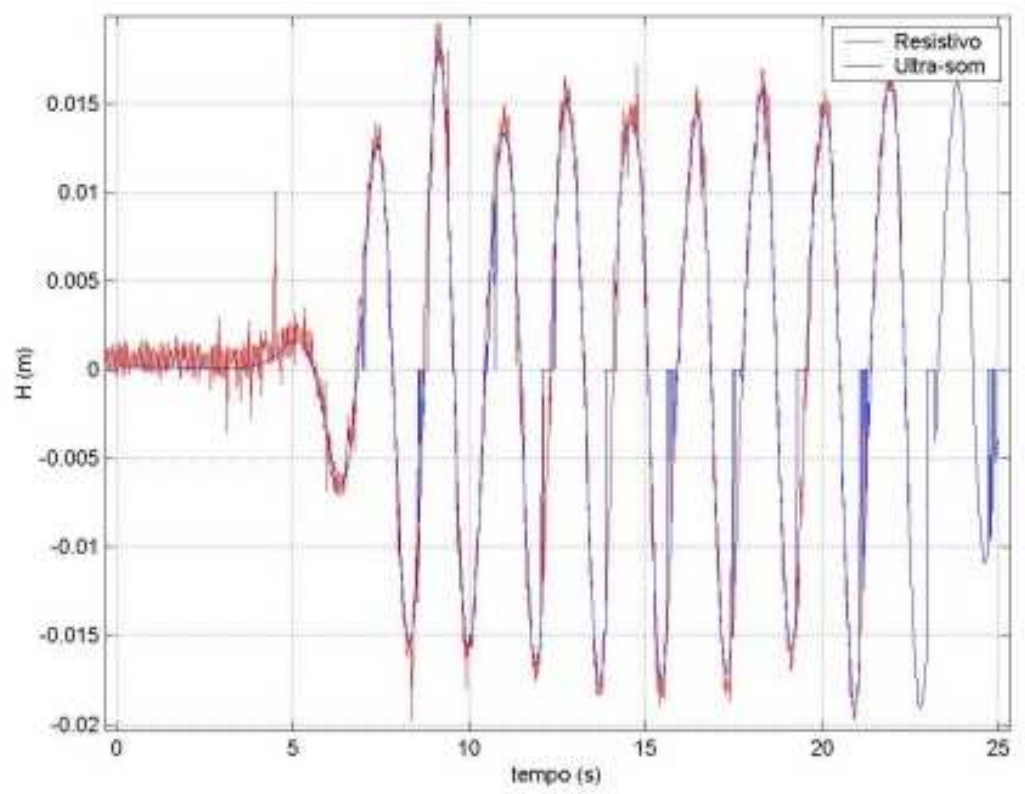

(b) Sensor por ultra-som e sensor resistivo.

Figura 4.18: Exemplos de sinais obtidos no ensaio do sensor de altura de ondas.

\subsection{Caracterização dos sensores de altura de onda capacitivo e por ultra-som}

\subsubsection{Calibração estática}

Em um primeiro momento foi realizada a calibração estática dos sensores. Para o sensor capacitivo, foi utilizada a sua haste perfurada de suporte como referência, deslocando o sensor verticalmente em passos de $20 \mathrm{~mm}$, enquanto a superfície da água foi mantida constante. Enquanto que para o sensor por ultra-som, foi utilizado 


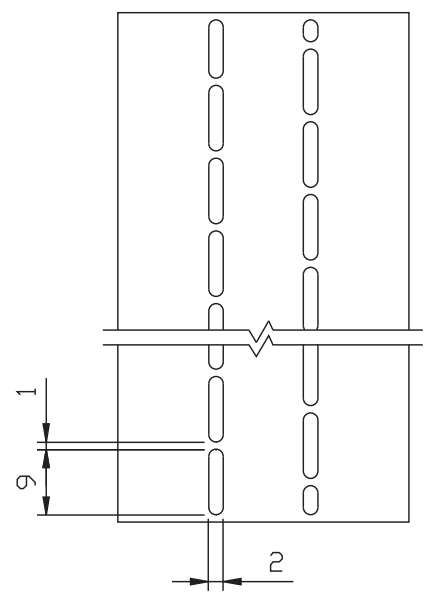

Figura 4.19: Superfície perfurada modificada da guia de onda.

um sistema servo-acionado para o posicionamento e a leitura da altura foi feita através do encoder do motor. As figuras 4.20 e 4.21 mostram os resultados da calibração estática dos sensores, que apresentaram os seguintes comportamentos:

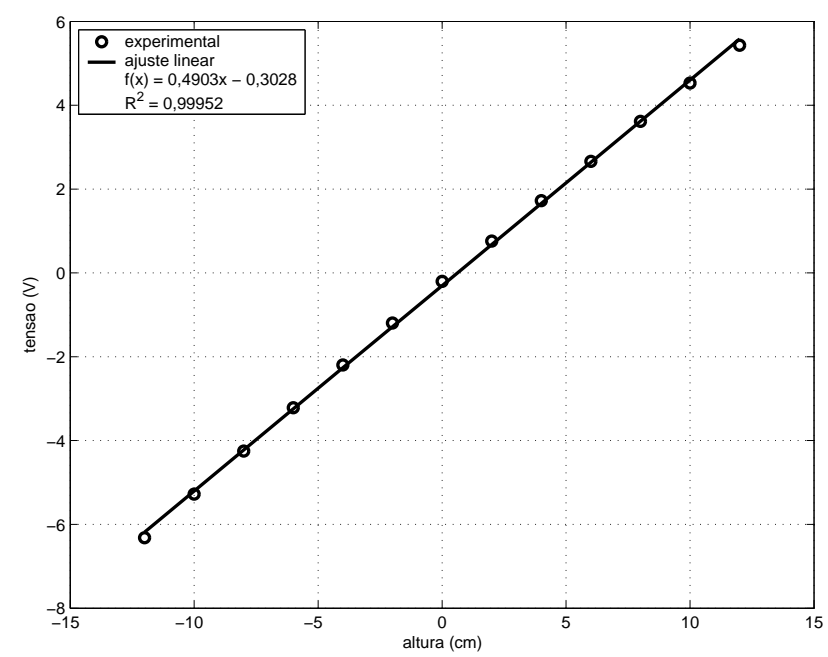

Figura 4.20: Calibração estática do sensor de altura de onda capacitivo.

O sensor por ultra-som apresentou uma maior linearidade do que o capacitivo. Uma forma de comparar a linearidade dos dois sensores é através da análise dos coeficientes $A$ e $B$ de uma curva de ajuste de segunda ordem $f(x)=A x^{2}+B x+C$ (tabela 4.3).

Neste ponto é importante salientar que a calibração estática do sensor capacitivo deve ser realizada antes de cada ensaio, uma vez que suas constantes de calibração mudam conforme as condições ambientais e da água, conforme foi apontando anteriormente. Enquanto que para o sensor por ultra-som, deve-se fazer a medição da temperatura da água para se determinar a velocidade de propagação da onda ultra-sônica. 


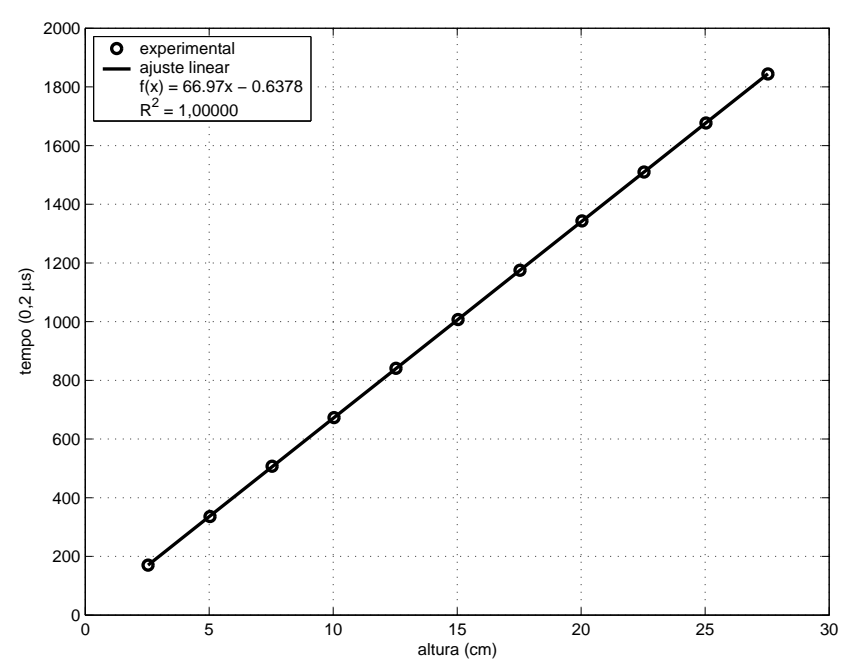

Figura 4.21: Calibração estática do sensor de altura por ultra-som.

Tabela 4.3: Coeficientes de calibração estática dos sensores de altura de onda para uma curva de segunda ordem $\left(f(x)=A x^{2}+B x+C\right)$.

\begin{tabular}{ccccc}
\hline Tipo do sensor & A & B & C & $\begin{array}{c}\text { Não linearidade } \\
|A / B| \cdot 100\end{array}$ \\
\hline Capacitivo & $-0,0016$ & 0,4903 & $-0,2122$ & $0,33 \%$ \\
Ultra-som & $-0,0073$ & 67,19 & $-0,5516$ & $0,01 \%$ \\
\hline
\end{tabular}

\subsubsection{Calibração dinâmica}

A seguir, foi realizado um ensaio para se avaliar o comportamento dinâmico do sensor de altura de ondas capacitivo.

Neste ensaio, o sistema de acionamento do gerador de ondas foi posicionado verticalmente e o sensor de altura de ondas foi fixado de forma a se mover junto com a castanha do fuso. Foram realizadas as aquisições do sinal do sensor de altura de ondas e do encoder do motor.

Um sensor capacitivo foi posicionado próximo ao sensor avaliado como "testemunha", tendo por finalidade verificar a perturbação da superfície livre da água, devido ao movimento do sensor ensaiado, na figura 4.22 pode-se observar este efeito que deve ser considerado durante a análise dos dados.

Os ensaios foram realizados simulando ondas regulares para toda a faixa de freqüência de interesse, ou seja, de 0,5 a $3,0 \mathrm{~Hz}$, com intervalo de $0,25 \mathrm{~Hz}$ e com declividade de onda equivalentes a $1 \%, 2 \%, 4 \%$ e $8 \%$.

Após o ensaio com o sensor capacitivo, este foi substituído pelo sensor por ultrasom para se avaliar a resposta em freqüência da guia de ondas, ou seja, se existem diferenças significativas da altura da água dentro e fora da guia de ondas durante a 


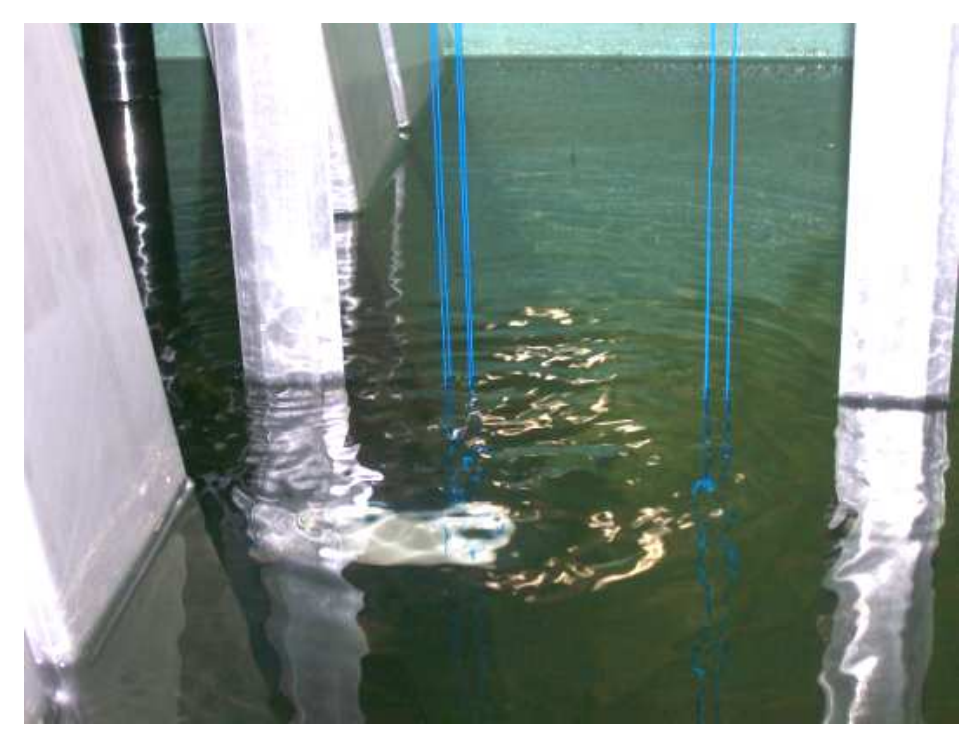

Figura 4.22: Perturbação da superfície da água durante o ensaio de caracterização dos sensores de altura de onda.

leitura de ondas geradas.

A figura 4.23 apresenta a configuração do ensaio, onde:

1. sensor ensaiado;

2. sensor capacitivo de testemunha;

3. sistema de acionamento do gerador de ondas posicionado verticalmente;

4. condicionador de sinais dos sensores capacitivos;

5. sistema de aquisição de sinais analógicos do LENO;

6. sistema de controle do gerador de ondas e aquisição do sensor por ultra-som e encoder;

7. computador de controle do gerador de ondas;

8. osciloscópio utilizado para calibração do sensor por ultra-som.

A figura 4.24 apresenta um exemplo da série temporal obtida neste ensaio, mostrando os sinais de referência, leitura do encoder, do sensor capacitivo e do sensor testemunha para a freqüência de $1,0 \mathrm{~Hz}$ e $14 \%$ de declividade.

Durante o ensaio ocorreu um problema na sincronização entre o sistema de aquisição digital do gerador de ondas (encoder e sensor de altura de ondas por ultrasom) e o sistema de aquisição analógico (sensores de altura de onda capacitivos), o que acarretou em uma incerteza na medição da fase do comportamento dinâmico do 

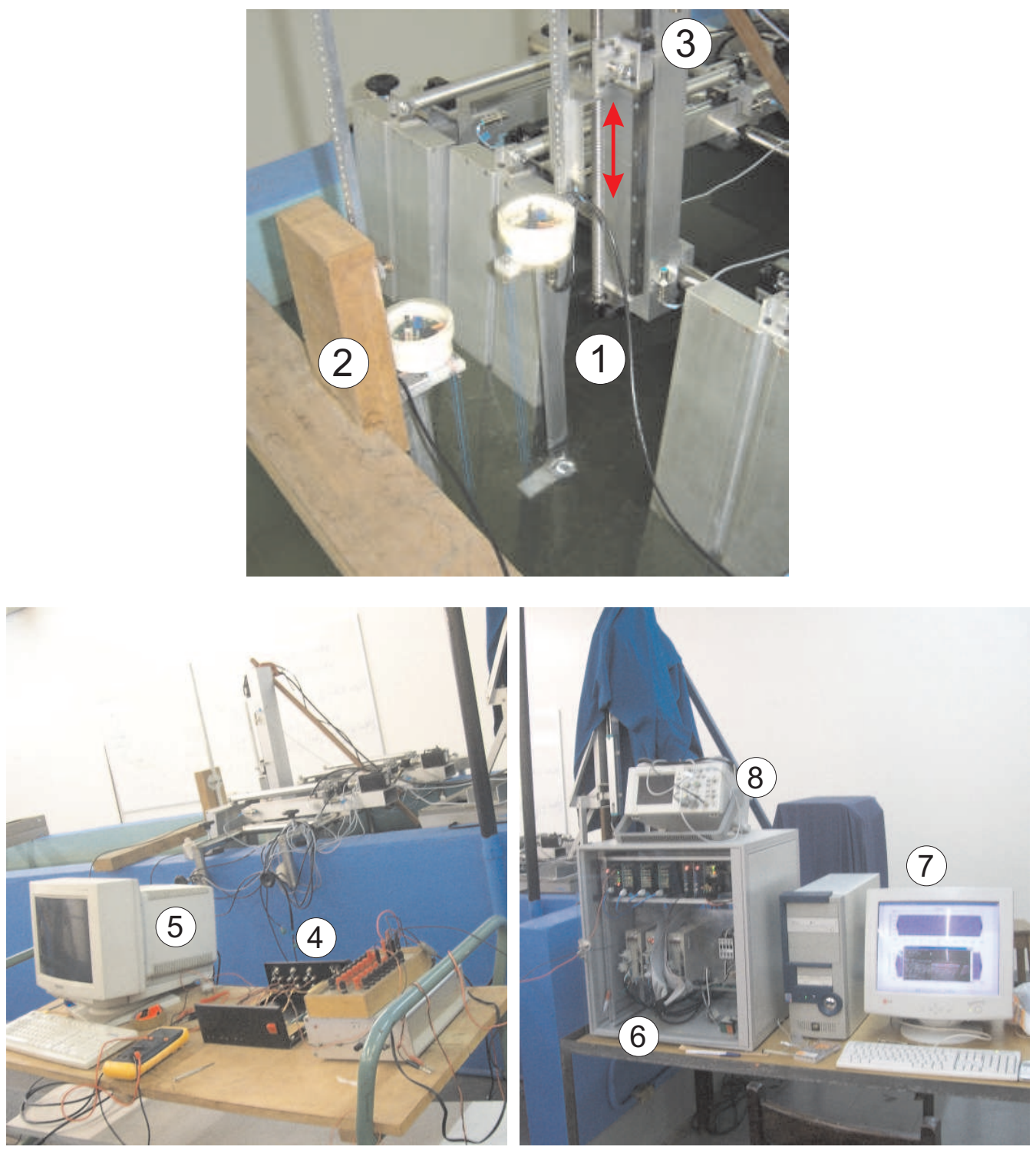

Figura 4.23: Configuração do ensaio de caracterização dos sensores de altura de onda.

sensor capacitivo. Desta forma, fase do sensor capacitivo, será realizada apenas a análise da tendência de sua curva média.

A análise dos dados foi realizada através da densidade espectral de potência cruzada entre as séries temporais. Para tanto, foi implementado no Matlab uma rotina para realizar os cálculos de forma automática. As figuras 4.25 e 4.26 apresentam respectivamente a resposta dinâmica dos sensores por ultra-som e capacitivo.

Foi utilizada uma equação de ajuste para os dados experimentais baseada no modelo de um sistema dinâmico de segunda ordem com um grau de liberdade (OGATA, 1998): 

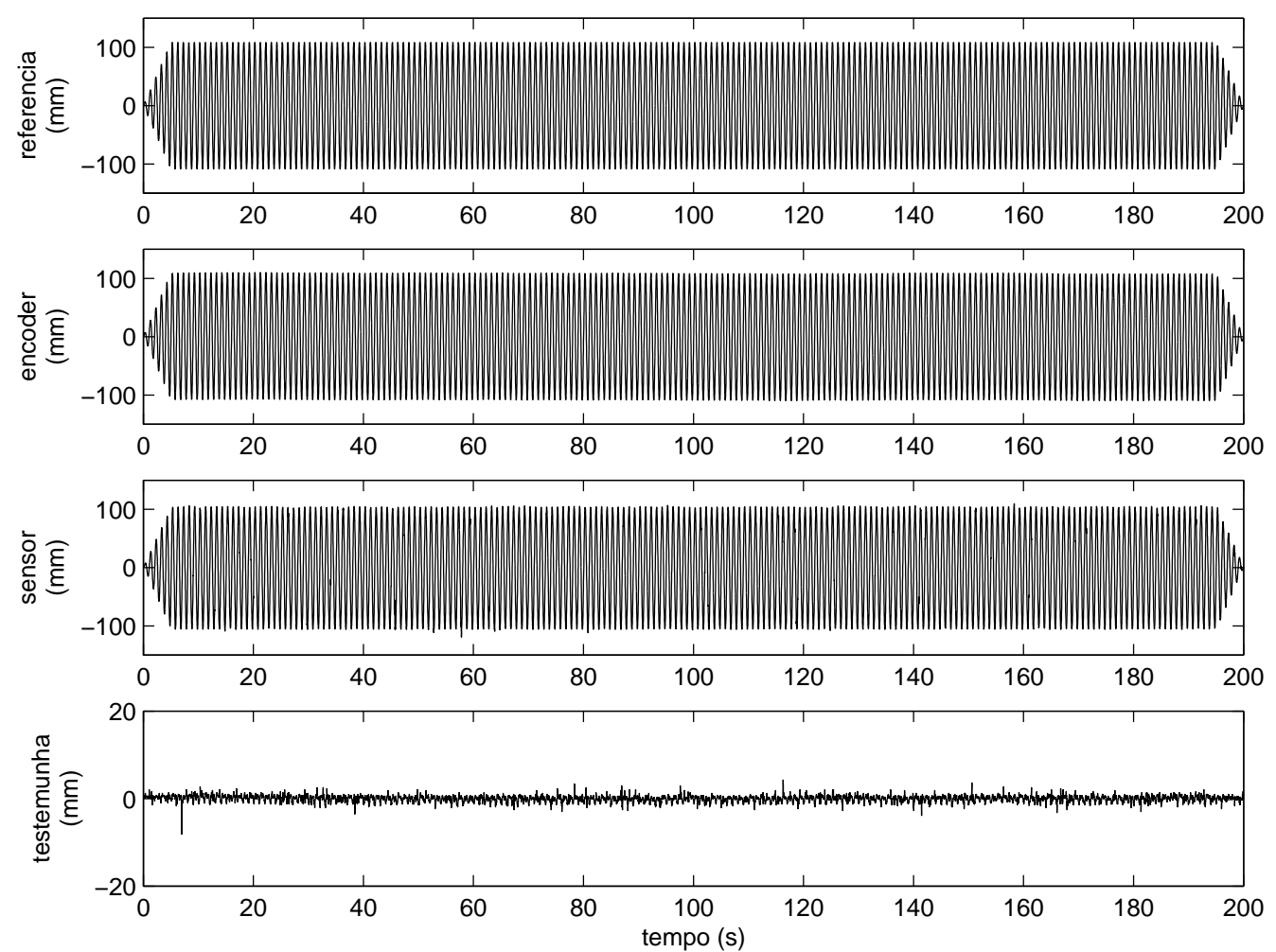

Figura 4.24: Exemplo de série temporal do ensaio dinâmico do sensor capacitivo. Freqüência de $1,0 \mathrm{~Hz}$ e $14 \%$ de declividade
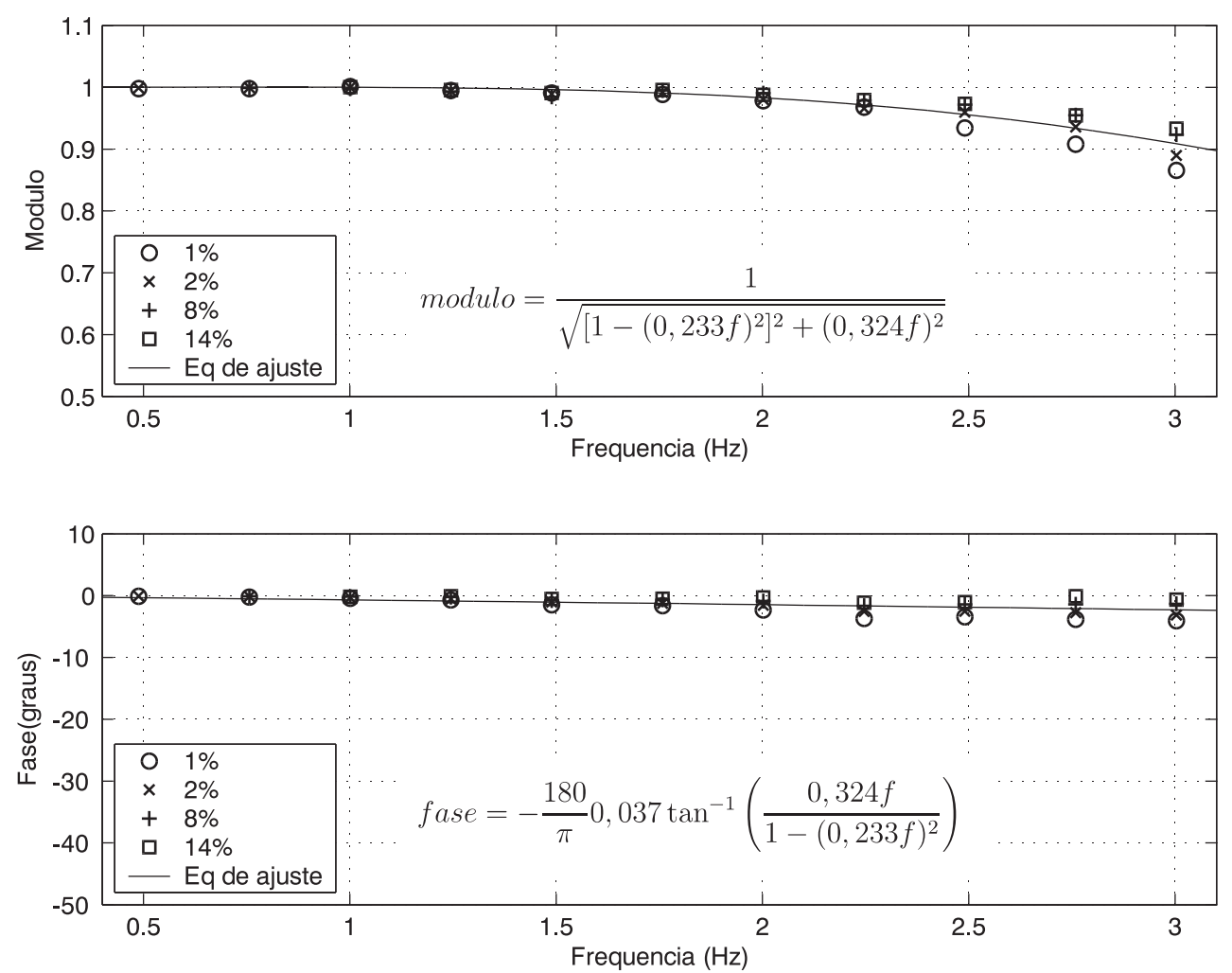

Figura 4.25: Resposta dinâmica do sensor de altura de ondas por ultra-som. 

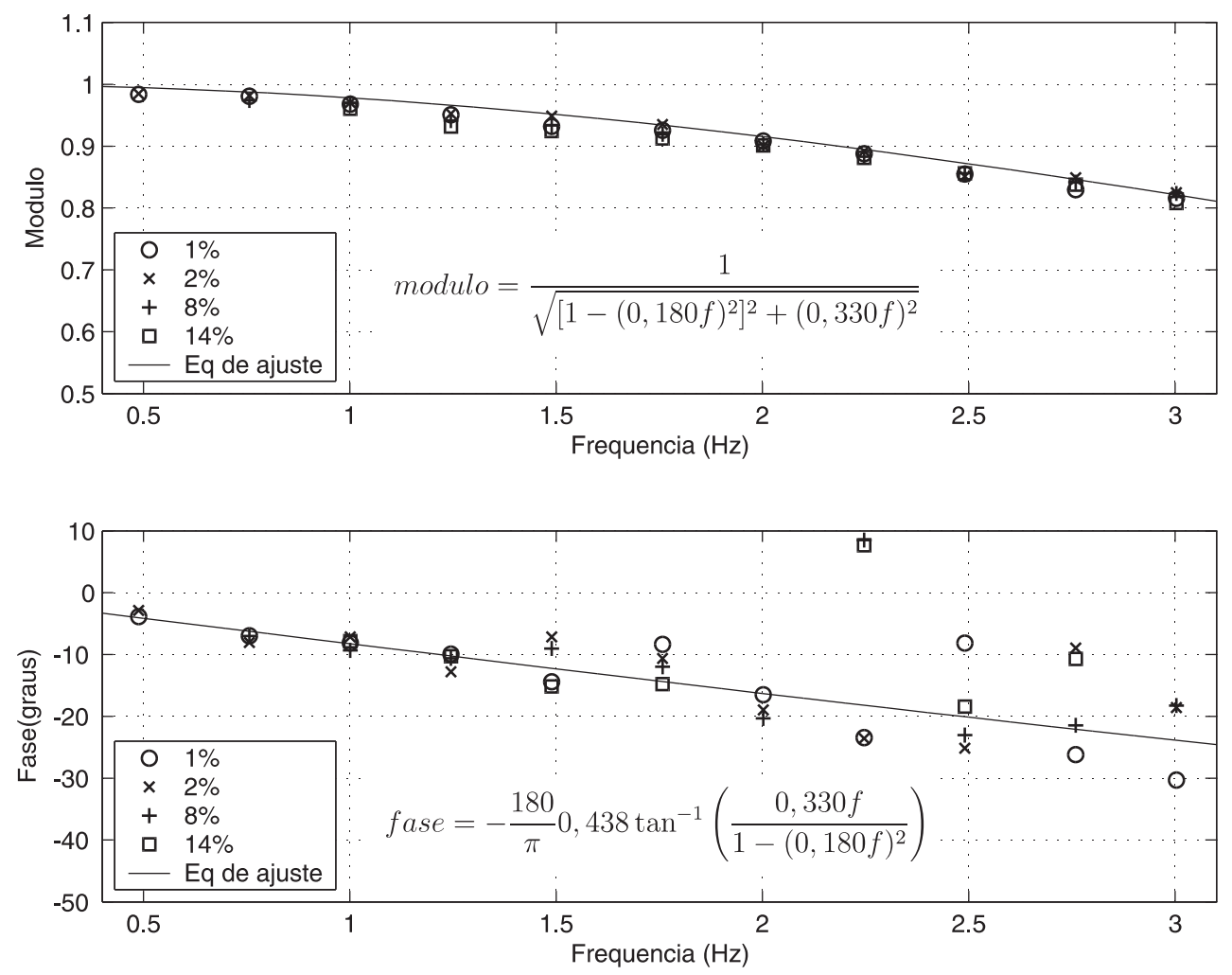

Figura 4.26: Resposta dinâmica do sensor de altura de ondas capacitivo.

$$
\begin{aligned}
& |G(j \omega)|=\frac{1}{\sqrt{\left(1-\frac{\omega^{2}}{\omega_{n}^{2}}\right)^{2}+\left(2 \zeta \frac{\omega}{\omega_{n}}\right)^{2}}} \\
& \angle G(j \omega)=-\tan ^{-1}\left(\frac{2 \zeta \frac{\omega}{\omega_{n}}}{1-\frac{\omega^{2}}{\omega_{n}^{2}}}\right)
\end{aligned}
$$

onde $G(j \omega)$ é a função de transferência, $\omega_{n}$ é a freqüência angular natural e $\zeta$ o coeficiente de amortecimento.

O movimento da superfície da água, detectado pelo sensor testemunha, foi pequeno comparado ao movimento do sensor ensaiado. A relação entre as alturas adquiridas dos dois sensores chegou a um máximo de $2 \%$ no ensaio do sensor capacitivo e de $1,6 \%$ para o sensor por ultra-som.

Aplicando um critério de freqüência de corte nas equações de ajuste, de 5\% para o módulo e de $5^{\circ}$ para a fase, resulta na tabela 4.4 , na qual se pode comparar a resposta dinâmica dos dois tipos de sensores.

Na tabela 4.4, pode-se observar que o sensor de altura de ondas por ultra-som apresentou uma melhor resposta comparado com o sensor capacitivo, tanto em fase, 
Tabela 4.4: Freqüência de corte dos sensores de altura de onda

\begin{tabular}{ccc}
\hline Tipo do sensor & \multicolumn{2}{c}{ Freqüências de corte $(\mathrm{Hz})$} \\
& Amplitude $(5 \%)$ & Fase $\left(5^{\circ}\right)$ \\
\hline Ultra-som & 2,57 & $>3,00$ \\
Capacitivo & 1,52 & 0,60 \\
\hline
\end{tabular}

quanto em módulo.

A resposta dinâmica do sensor capacitivo mostra que, ocorre uma perda de precisão quando se usa apenas a calibração estática, principalmente para ondas acima de $1,5 \mathrm{~Hz}$, para a amplitude, ou para qualquer freqüência quando se compara a fase do sensor de altura de onda com algum outro sensor. Enquanto que, o sensor por ultrasom pode ser utilizado em uma faixa de freqüências bem maior sem a necessidade de se fazer uma correção da dinâmica de sua leitura. 


\section{Arquitetura de controle}

O sistema de controle do gerador de ondas possui duas camadas, a malha de controle interna que é responsável pelo controle de posição do servomotor e a malha externa que é responsável pelo controle da geração e absorção das ondas.

A malha de controle de posição do servomotor é realizada pelo driver do servomotor, enquanto que a malha de absorção de ondas é realizada por um microcomputador PC. Um microcontrolador é responsável pelo interfaceamento entre o computador e o driver do motor, a comunicação com o sensor de altura de onda e a leitura dos sensores de fim de curso do fuso. O diagrama de blocos do sistema de controle pode ser visualizado na figura 5.1 .

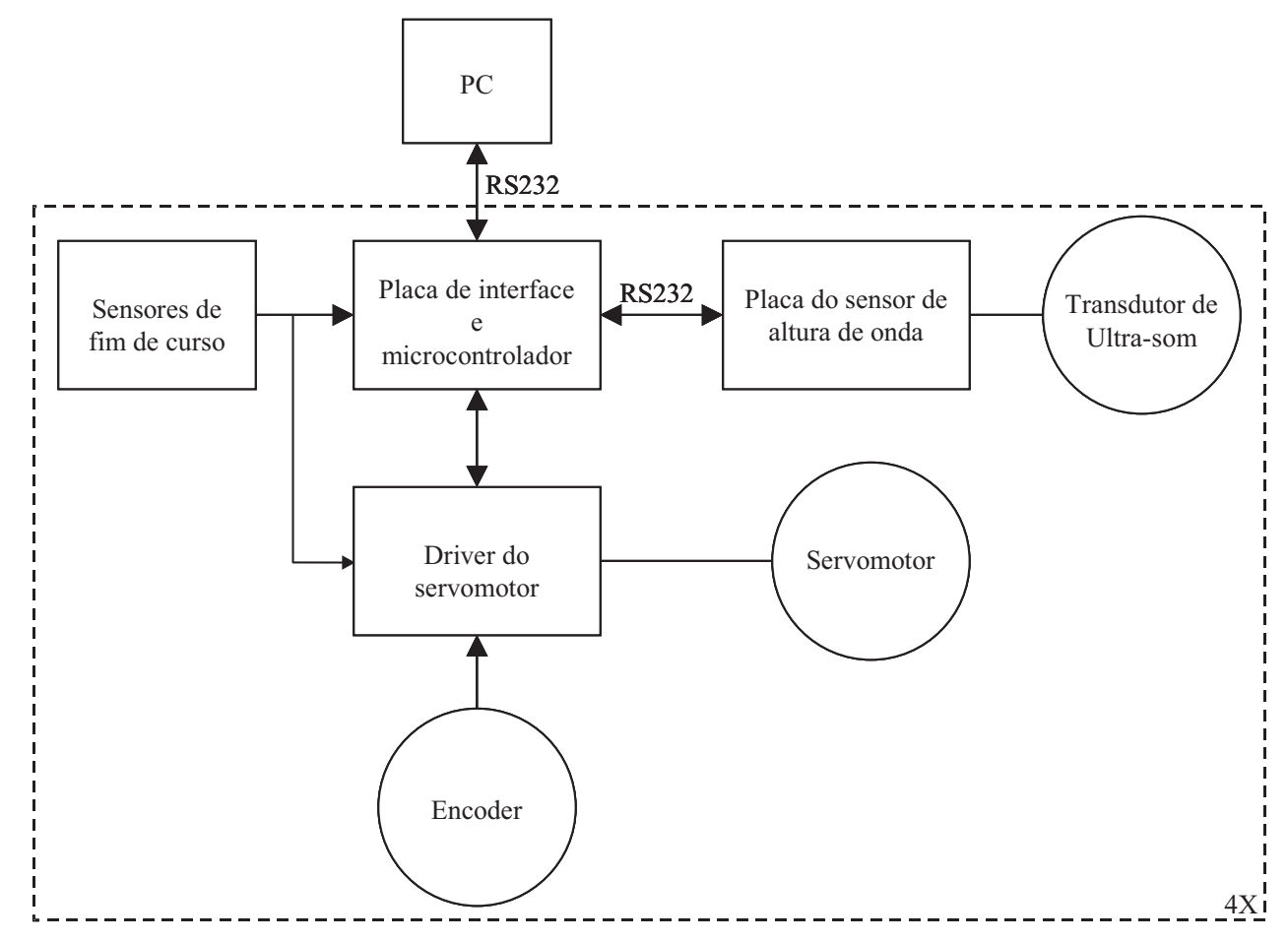

Figura 5.1: Arquitetura do sistema de controle.

Neste capítulo, descreve-se primeiramente o sistema eletrônico do gerador de ondas e a seguir o seu software de controle. 


\subsection{Sistema eletrônico}

As placas do sistema de controle do gerador de ondas foram projetadas e confeccionadas procurando um padrão industrial, a fim de facilitar a obtenção de componentes e a manutenção do equipamento. O padrão escolhido foi o Eurocard, comumente encontrado em painéis de equipamentos industriais.

Desta forma, o conjunto da eletrônica do protótipo foi montado em um sub-rack de 19 polegadas e altura padrão 3U. Foram feitos os layouts das placas com dimensões de $100 \mathrm{~mm}$ por $160 \mathrm{~mm}$, os esquemas elétricos podem ser encontrados em Carneiro e Mello (2007a) e Carneiro e Mello (2007b). O sub-rack contém os seguintes cartões:

- 4 unidades da placa de interface e microcontrolador (figura 5.2(c));

- 2 unidades da placa do sensor de altura de ondas, com dois sensores por placa (figura 5.2(b));

- 1 unidade de fonte de alimentação com tensão de entrada de $24 \mathrm{~V} c c$ e saídas de $-12 \mathrm{~V},-5 \mathrm{~V}, 5 \mathrm{~V}, 12 \mathrm{~V}$ e $260 \mathrm{~V}$ em corrente contínua (figura 5.2(a)).

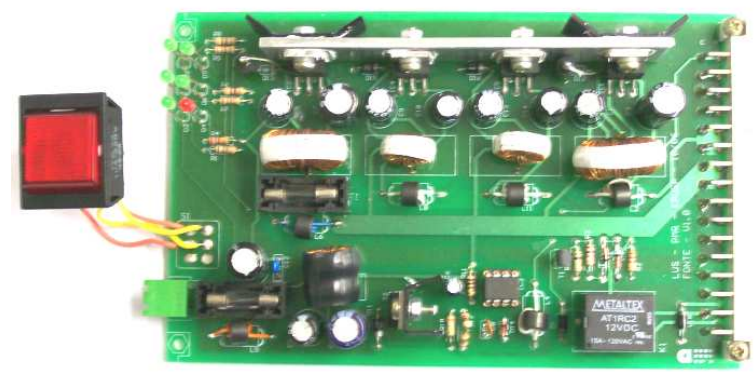

(a) Regulares de tensão da fonte de alimentação.

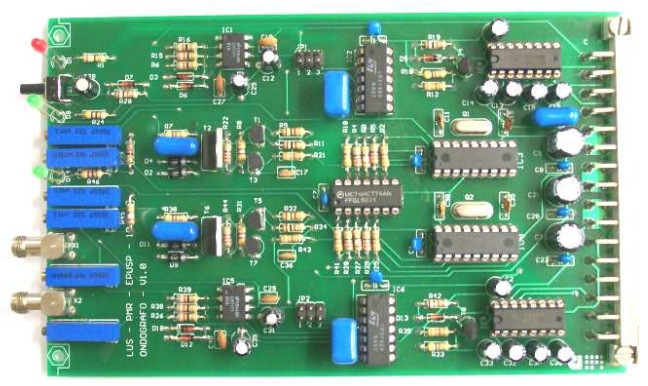

(b) Sensor por ultra-som.

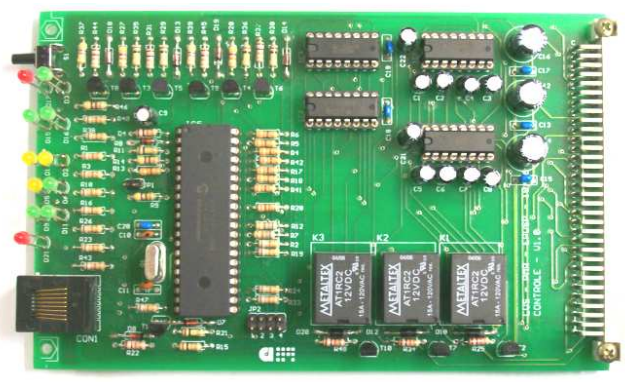

(c) Interface e microcontrolador.

Figura 5.2: Placas desenvolvidas para o sistema de controle.

O sub-rack por sua vez, foi montado em um gabinete, junto com os drivers dos servomotores, a fonte de alimentação de $24 \bigvee_{c c}$ e o sistema de proteção elétrica. A figura 5.3 mostra o sistema montado. 


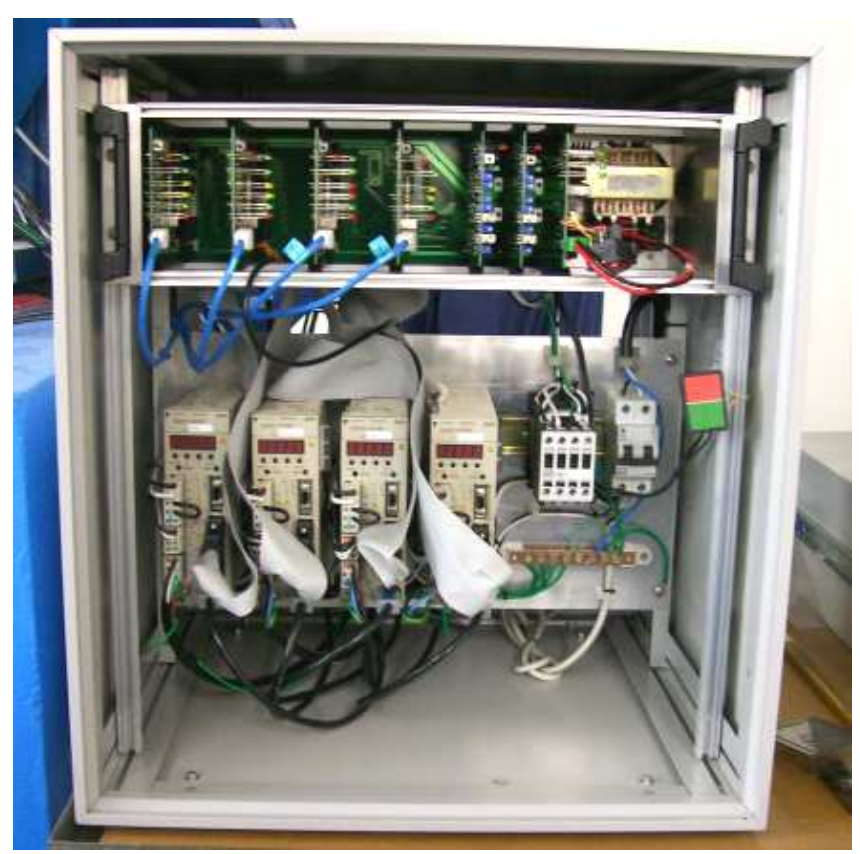

Figura 5.3: Foto do rack.

\subsubsection{Malha de controle de posição}

Conforme foi apontado anteriormente, a malha de posição do atuador é realizada pelo driver do servomotor. Ele pode trabalhar em modo de controle de posição com entradas digitais, ou em modo de controle de velocidade ou de torque com entradas analógicas. O modo de controle de posição possui um controlador proporcional e um controlador proporcional integral de velocidade, cascateados com a malha de corrente.

O modo de controle de posição possui também um redutor eletrônico que possibilita que o servomotor percorra uma distância pré-programada para cada pulso recebido, essa distância foi ajustada de forma a obter uma resolução de 0,1 mm por pulso no movimento do braço mecânico de acionamento. Desta forma, o motor pode ser controlado como se fosse um motor de passo, em malha aberta, facilitando assim seu acionamento.

O driver possui ainda uma malha de controle feedforward para melhorar o tempo de resposta para sistemas com alta rigidez. Outra ferramenta é o filtro de smoothing, que suaviza a curva de aceleração do acionamento. A figura 5.4 apresenta o diagrama da malha de controle de posição do driver do servomotor.

Os parâmetros do controlador foram ajustados automaticamente através da função de auto-tunning do driver (YASKAWA, 2005). Essa ferramenta ajusta os ganhos das malhas de posição e velocidade, a constante de tempo de integração da malha de velocidade e a constante de tempo do filtro do torque de referência, continuamente 


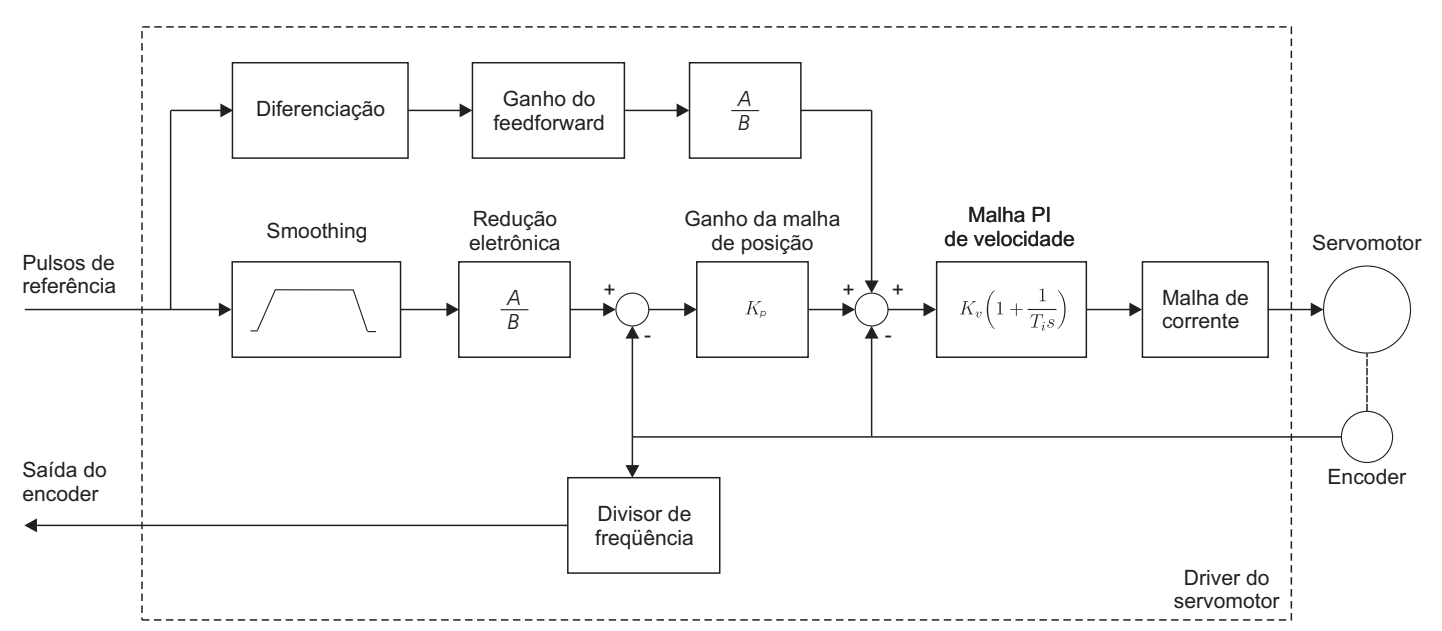

Figura 5.4: Diagrama do controle de posição do driver do servomotor.

durante a execução de um ensaio.

A placa de interface e microcontrolador realiza o controle e supervisão do motor através de entradas e saídas digitais. A tabela 5.1 lista os sinais interfaceados e suas funções.

Tabela 5.1: Sinais digitais de controle do motor

\begin{tabular}{cl}
\hline Símbolo & Descrição \\
\hline S-ON & SERVO-ON: Liga o servomotor \\
P-CON & Seleciona o modo de controle da malha de velocidade entre PI e P \\
P-OT & Sensor de fim de curso. Sentido positivo \\
N-OT & Sensor de fim de curso. Sentido negativo \\
ALM-RST & Limpa condição de alarme \\
PULS & Pulso para movimentação \\
SIGN & Sentido da movimentação \\
CLR & Limpa contador de posição \\
ALM & Alarme \\
TGON & Detecta se o motor está mais rápido do que uma determinada \\
& velocidade programada em parâmetro \\
S-RDY & Indica que o motor está pronto para operação \\
PAO & Fase A do encoder \\
PAB & Fase B do encoder \\
PBC & Pulso de origem do encoder \\
ALO1 & Código do alarme, bit 1 \\
ALO2 & Código do alarme, bit 2 \\
ALO3 & Código do alarme, bit 3 \\
COIN & Coincidência de posição, com erro programado em parâmetro
\end{tabular}




\subsubsection{Sistema de proteção elétrica}

O sistema eletrônico foi implementado de forma a previnir a integridade do equipamento no caso de alguma falha. Na figura 5.5 podemos observar o esquema do sistema de proteção.

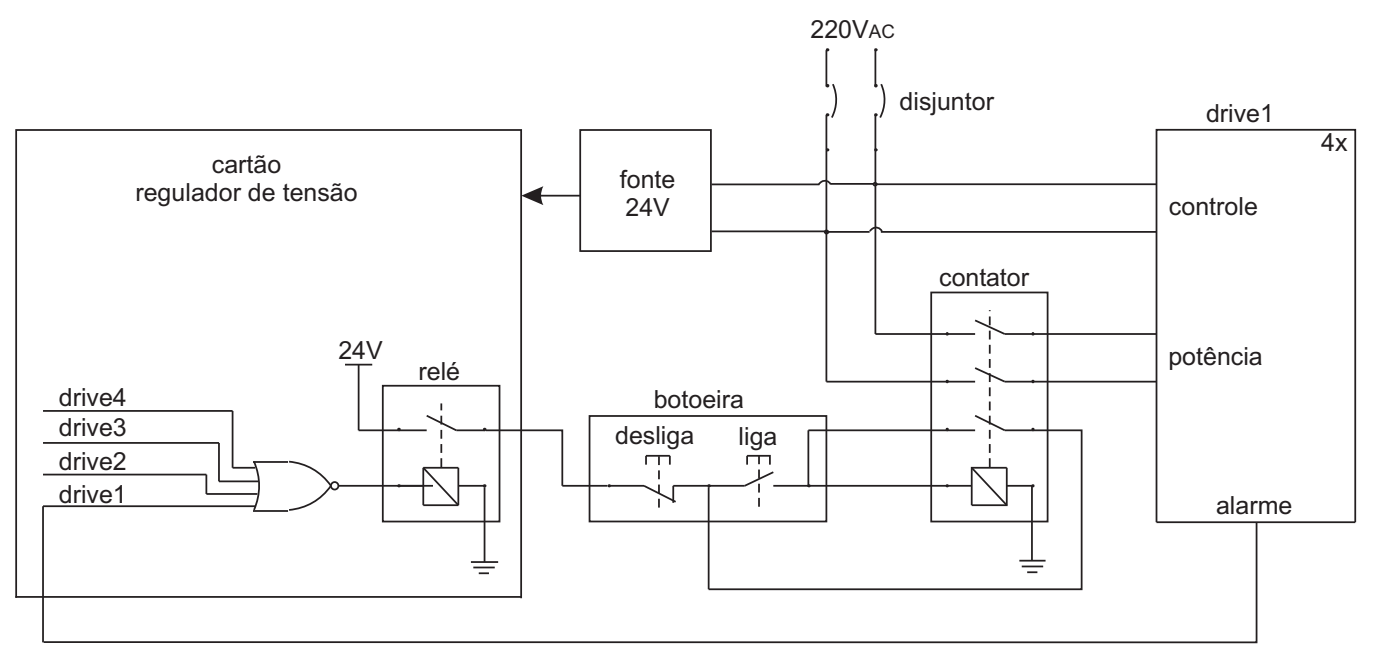

Figura 5.5: Esquema do sistema de proteção.

Em caso de acidente, o sistema de segurança está equipado com um botão de emergência na botoeira do painel. Este ao ser pressionado desliga a alimentação da potência de todos os drivers através de um contator, desligando assim os motores.

Uma falha na fonte de $24 \mathrm{~V}$ ou nos reguladores de tensão também desarma o contator. Uma terceira situação que também desliga os motores é o acionamento de um sinal de alarme do driver. Este alarme pode ter várias causas, dentre elas:

- parametrização do driver incoerente;

- sobrecorrente;

- supereaquecimento;

- falha do circuito regenerativo;

- erro de comunicação com o encoder;

- falta de fase de alimentação;

- falha de conexão entre o o motor e o driver;

- etc.

Mais detalhes sobre os alarmes, suas possíveis causas e correções, podem ser encontrados no manual do servomotor (YASKAWA, 2005). 


\subsection{Software de controle}

O software para o controle do sistema foi desenvolvido na liguagem Python no ambiente Microsoft Windows. Essa linguagem foi escolhida pois, por ser uma liguagem de alto nível, provém um tempo de implementação reduzido e também permite uma fácil migração para outros sistemas operacionais, como por exemplo o Linux. Em contrapartida, é uma linguagem interpretada e desta forma, mais lenta que uma linguagem compilada. Assim, foram necessários cuidados extras com a temporização do sistema.

O software de controle é responsável pela interface homem-máquina (IHM), enviando os comandos necessários para as placas de interface, que por sua vez devem comandar os geradores de onda. A comunicação entre o PC e as placas de interface são realizadas através de quatro portas seriais com padrão de comunicação RS232.

Durante a geração de ondas, o software recebe pela serial a cada $20 \mathrm{~ms}$ as leituras dos sensores de altura de onda por ultra-som e dos encoders dos motores e deve enviar a próxima posição para os geradores de onda, proveniente de um arquivo de ondas préprocessado. A figura 5.6 apresenta a sequência de operações do software de controle durante a geração de ondas e o intertravamento com o software do microcontrolador da placa de interface. Na figura também é mostrado onde o algoritmo de absorção de ondas deverá ser implementado.

O software do microcontrolador da placa de interface foi desenvolvido em C para microcontroladores (CCS). Sua rotina principal é um interpretador dos comandos recebidos pela serial. Esta rotina direciona a operação para as sub-rotinas de geração de ondas e de referenciamento e para as sub-rotinas de diagnóstico, nas quais se pode realizar a leitura diretamente de todos os sinais digitais do driver do servomotor e o sensor de altura de ondas.

Durante a execução da sub-rotina de geração de ondas (figura 5.6), a placa de interface é responsável por controlar a temporização do sistema, sincronizando os quatro geradores de ondas e o microcomputador de controle em ciclos de $20 \mathrm{~ms}$, assim como, controlar o driver do servomotor e comandar os sensores de altura de onda.

Os pulsos de comando de movimentação enviados ao driver são distribuídos uniformemente no tempo, durante o ciclo de 20 ms, através do algoritmo de Bresenham (FOLEY; DAM, 1981). Esse algoritmo, utilizado em computação gráfica, define quais pontos devem ser preenchidos em uma matriz de pontos a fim de formar uma aproximação discreta de uma linha reta entre dois pontos dados. O algoritmo utiliza 


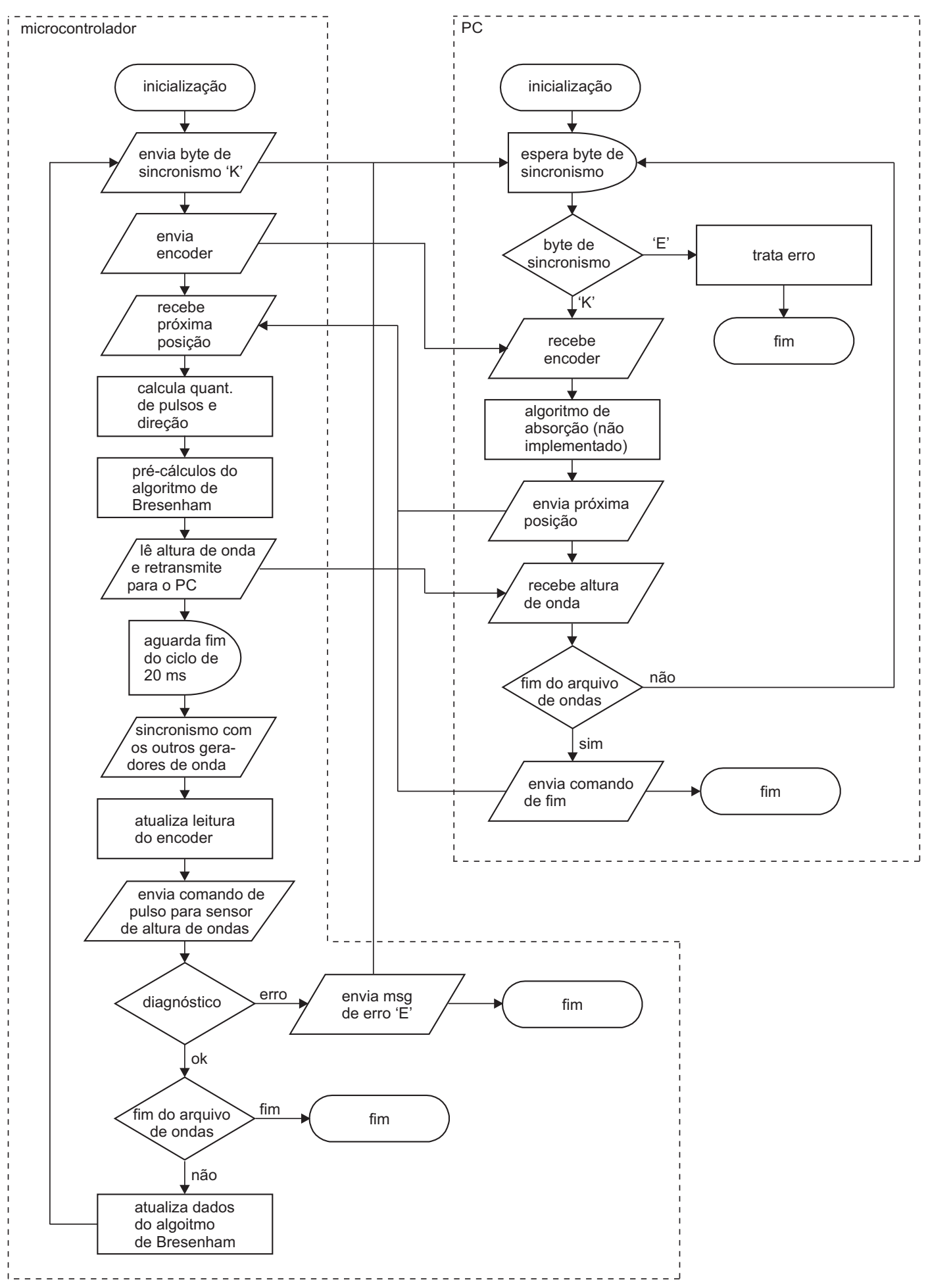

Figura 5.6: Fluxograma da rotina de geração de ondas.

apenas operações de soma e subtração de números inteiros e operação de rotação de bits, o que o torna ideal para a implementação em microcontroladores.

O algoritmo de Bresenham foi modificado de forma que o eixo $x$ de um gráfico de duas dimensões representasse o tempo e uma mudaça da linha no eixo $y$ significaria um comando de pulso. A figura 5.7 ilustra o funcionamento do algoritmo, mostrando a linha desenhada pelo algoritmo original e os pulsos resultantes do algoritmo 
modificado, com 13 pulsos distribuídos em um ciclo com 30 divisões.
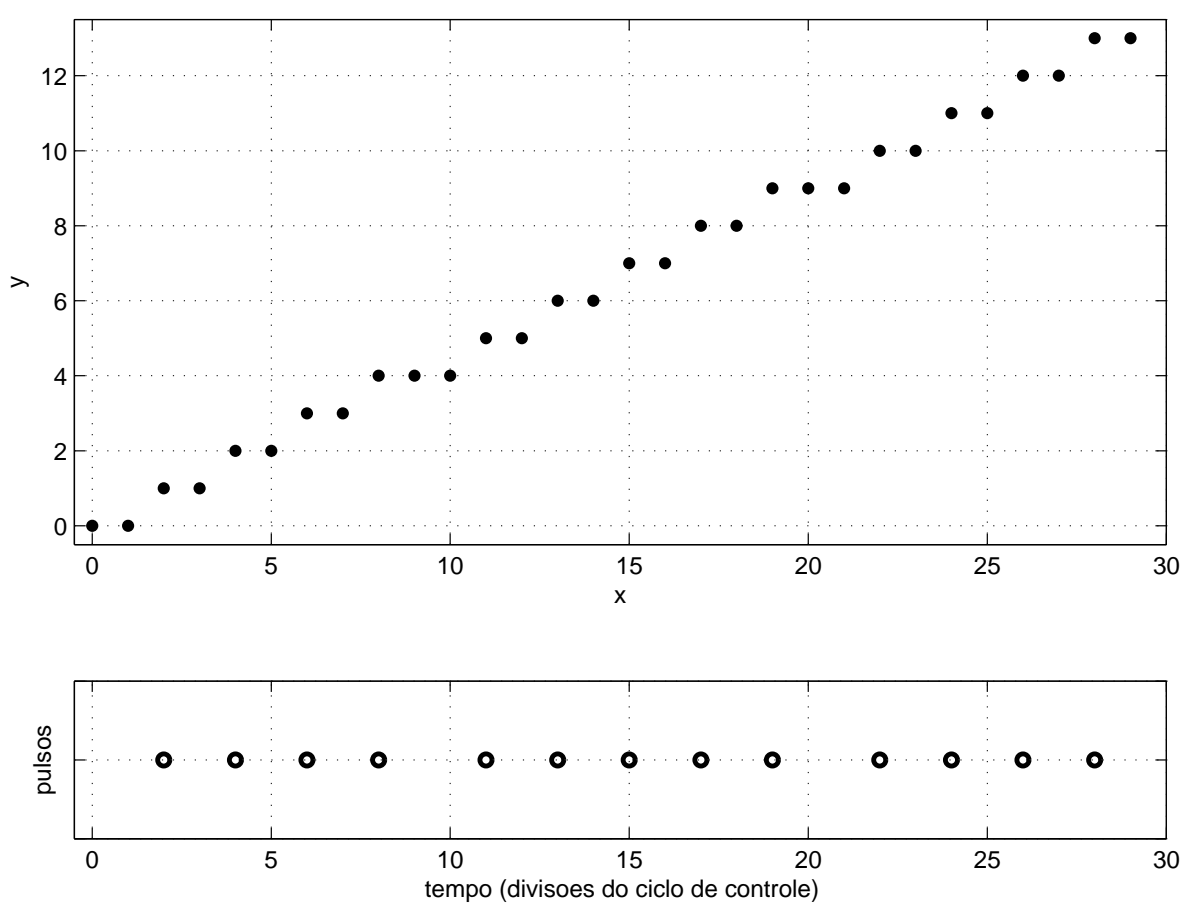

Figura 5.7: Ilustração do funcionamento do algoritmo de Bresenham.

O ciclo de 20 ms foi dividido em 200 partes através da interrupção de um dos contadores do microcontrolador, de maneira que a distribuição dos pulsos no tempo é executada em paralelo com a rotina de geração de ondas, permitindo que as outras operações ocorram de forma independente. A última subdivisão do ciclo é reservada para a operação de sincronismo entre os módulos de geradores de onda.

Uma operação de diagnóstico é realizada no início de cada ciclo, na qual é verificado se ocorreu algum alarme, se o atuador chegou no fim de curso ou se houve atraso na comunicação com o microcomputador. Caso algum desses eventos ocorra, o microcontrolador pára a geração de ondas e envia um sinal de erro pela serial.

As listagens dos programas do microcontrolador e do PC podem ser encontradas em Carneiro e Mello (2007a) e Carneiro e Mello (2007b). 


\section{Análise de desempenho do gerador de ondas}

Para verificar o desempenho do gerador de ondas foram realizadas uma série de medidas experimentais. A partir destes resultados foi feita uma comparação da função de transferência calculada teoricamente com a obtida experimentalmente. Também foi avaliada a resposta dinâmica da movimentação do atuador.

Além dessas análises quantitativas também foi feita uma análise qualitativa do gerador de ondas, quanto ao seu desempenho mecânico e quanto sua interação hidrodinâmica com o tanque.

Neste capítulo também é avaliada uma técnica para se realizar a estimação do coeficiente de reflexão de ondas, método que poderá ser utilizado no desenvolvimento e análise de desempenho do algoritmo de absorção de ondas.

\subsection{Procedimento experimental}

As variáveis que interessam para a análise do gerador de ondas são o deslocamento do atuador e a altura da onda gerada para uma certa freqüência e uma certa altura da lâmina de água. Na literatura é encontrado comumente a avaliação da altura de onda a uma distância do gerador, na qual se pode desconsiderar a influência das ondas evanescentes. Neste trabalho, adicionalmente foram medidas as alturas de onda diretamente na frente do gerador.

Para uniformizar os experimentos, adotaram-se os seguintes procedimentos:

- A lâmina de água foi mantida sempre em 0,80 m;

- O primeiro sensor de altura de onda capacitivo foi fixado a uma distância de 3,5 m a partir do gerador de ondas na posição central. Esta distância foi adotada considerando que a partir de uma distância de três vezes a lâmina de água se pode desprezar a influência das ondas evanescentes; 
- Ao início de cada dia de ensaio foi realizada a calibração estática dos sensores capacitivos e foi medida a temperatura da água;

- A distância relativa entre os outros dois sensores capacitivos e o primeiro sensor foi definida de forma a atender os pré-requisitos da convergência do algoritmo de estimação das ondas refletidas (Anexo $A$ );

- Todas as ondas foram geradas com direção de propagação paralela ao comprimento do tanque;

- Entre os ensaios aguardou-se o repouso da água.

Os experimentos foram realizados no canal de ensaios do LENO. O gerador de ondas do tipo cunha, pré-existente no canal, foi retirado e no lugar foi instalado o gerador de ondas desenvolvido neste trabalho. A figura 6.1 apresenta um esquema geral do arranjo experimental:

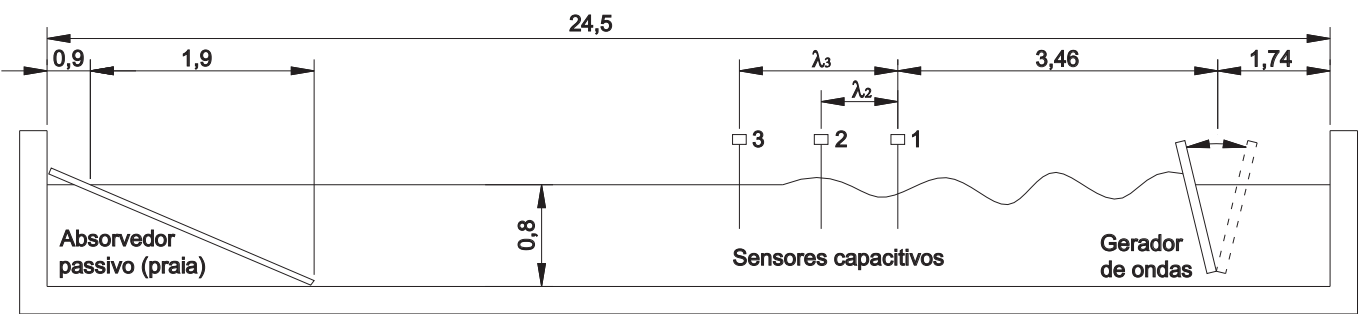

Figura 6.1: Configuração do ensaio para levantamento da função de transferência do protótipo (medidas em metros).

O sistema de aquisição utilizado foi o mesmo apresentado no ensaio dos sensores (capítulo 4.4.2), ou seja, a aquisição digital dos encoders dos motores e dos sensores de altura de onda por ultra-som e a aquisição analógica dos sensores capacitivos.

O ensaio foi realizado com ondas regulares em toda a faixa de freqüência de interesse, de 0,5 a 3,0 Hz, com intervalos de 0,25 Hz. Para verificar a influência da declividade da onda na função de transferência $H / S$ foram geradas ondas com três declividades $(H / L): 1 \%, 4 \%$ e $8 \%$.

Os arquivos com os sinais de referência foram pré-processados com uma rotina implementada no Matlab. A altura da onda foi definida através da declividade e de seu comprimento teórico (equação 2.16). Enquanto que o curso do atuador foi calculado através da função de transferência teórica (equação 3.12).

A tabela 6.1 apresenta os valores calculados de altura $H$, o comprimento de onda $L$, a declividade $H / L$, o stroke na linha de água $S$ e no ponto de conexão com o braço de acionamento $S_{c}$ e as distâncias medidas dos sensores capacitivos 
em relação o primeiro sensor $\lambda_{2}$ e $\lambda_{3}$. Para a freqüência de $0,5 \mathrm{~Hz}$, as ondas com declividade de $4 \%$ e $8 \%$ necessitariam de um stroke maior do que o disponível, então, elas foram substituídas por declividades menores que atendessem o máximo stroke e a metade do mesmo (ensaios 2 e 3 ). Algumas ondas foram repetidas para se verificar a repetibilidade do ensaio, conforme mostrados nos ensaios 34, 35 e 35 da tabela 6.1

Tabela 6.1: Dados do ensaio para determinação do desempenho do gerador de ondas.

\begin{tabular}{cccccrrrr}
\hline $\begin{array}{c}\text { Número } \\
\text { do ensaio }\end{array}$ & $\begin{array}{c}\mathrm{f} \\
(\mathrm{Hz})\end{array}$ & $\begin{array}{c}H \\
(\mathrm{~m})\end{array}$ & $\begin{array}{c}L \\
(\mathrm{~m})\end{array}$ & $\begin{array}{c}H / L \\
(\%)\end{array}$ & $\begin{array}{c}S \\
(\mathrm{~mm})\end{array}$ & $\begin{array}{c}S_{c} \\
(\mathrm{~mm})\end{array}$ & $\begin{array}{c}\lambda_{2} \\
(\mathrm{~m})\end{array}$ & $\begin{array}{c}\lambda_{3} \\
(\mathrm{~m})\end{array}$ \\
\hline 1 & 0,50 & 0,048 & 4,846 & 1,0 & 88,3 & 104,8 & 0,503 & 1,005 \\
2 & & 0,069 & & 1,4 & 126,3 & 150,0 & & \\
3 & & 0,139 & & 2,9 & 252,7 & 300,0 & & \\
\hline 4 & 0,75 & 0,026 & 2,650 & 1,0 & 26,6 & 31,6 & 0,503 & 1,005 \\
5 & & 0,106 & & 4,0 & 106,4 & 126,3 & & \\
6 & & 0,211 & & 8,0 & 212,8 & 252,7 & & \\
\hline 7 & 1,00 & 0,016 & 1,555 & 1,0 & 11,1 & 13,2 & 0,503 & 1,005 \\
8 & & 0,062 & & 4,0 & 44,6 & 52,9 & & \\
9 & & 0,125 & & 8,0 & 89,1 & 105,8 & & \\
\hline 10 & 1,25 & 0,010 & 0,998 & 1,0 & 6,2 & 7,4 & 0,047 & 0,157 \\
11 & & 0,040 & & 4,0 & 24,9 & 29,5 & & \\
12 & & 0,080 & & 8,0 & 49,7 & 59,0 & & \\
\hline 13 & 1,50 & 0,007 & 0,693 & 1,0 & 4,2 & 4,8 & 0,047 & 0,157 \\
14 & & 0,028 & & 4,0 & 16,1 & 19,1 & & \\
15 & & 0,056 & & 8,0 & 32,2 & 39,2 & & \\
\hline 16 & 1,75 & 0,005 & 0,509 & 1,0 & 2,8 & 3,4 & 0,047 & 0,157 \\
17 & & 0,020 & & 4,0 & 11,3 & 13,5 & & \\
18 & & 0,041 & & 8,0 & 22,7 & 26,9 & & \\
\hline 19 & 2,00 & 0,004 & 0,390 & 1,0 & 2,1 & 2,5 & 0,047 & 0,157 \\
20 & & 0,016 & & 4,0 & 8,5 & 10,0 & & \\
21 & & 0,031 & & 8,0 & 16,9 & 20,1 & & \\
\hline 22 & 2,25 & 0,003 & 0,308 & 1,0 & 1,6 & 1,9 & 0,098 & 0,203 \\
23 & & 0,012 & & 4,0 & 6,6 & 7,8 & & \\
24 & & 0,024 & & 8,0 & 13,1 & 15,6 & & \\
\hline 25 & 2,50 & 0,002 & 0,250 & 1,0 & 1,3 & 1,6 & 0,047 & 0,157 \\
26 & & 0,010 & & 4,0 & 5,3 & 6,2 & & \\
27 & & 0,020 & & 8,0 & 10,5 & 12,5 & & \\
\hline 28 & 2,75 & 0,002 & 0,206 & 1,0 & 1,1 & 1,3 & 0,047 & 0,157 \\
29 & & 0,008 & & 4,0 & 4,3 & 5,1 & & \\
30 & & 0,016 & & 8,0 & 8,6 & 10,2 & & \\
\hline 31 & 3,00 & 0,002 & 0,173 & 1,0 & 0,9 & 1,1 & 0,047 & 0,157 \\
32 & & 0,007 & & 4,0 & 3,6 & 4,3 & & \\
33 & & 0,014 & & 8,0 & 7,2 & 8,5 & & \\
\hline 34 & 1,25 & 0,010 & 0,998 & 1,0 & 6,2 & 7,4 & 0,049 & 0,152 \\
35 & 2,00 & 0,031 & 0,390 & 8,0 & 16,9 & 20,1 & 0,049 & 0,152 \\
36 & 2,25 & 0,012 & 0,308 & 4,0 & 6,6 & 7,8 & 0,098 & 0,202 \\
\hline & & & & & & & & \\
\hline
\end{tabular}




\subsection{Resultados preliminares}

Durante o experimento para a determinação do desempenho do gerador de ondas, foram observados alguns fatores que atrapalhavam na sua realização e análise, pois afetavam a qualidade das ondas geradas. A seguir são listados esses fatores e as providências tomadas.

Foi observado que existia um grande fluxo de água no espaço entre a parede do tanque e a lateral do flap. Além de perturbar o movimento da superfície livre adjacente ao gerador de ondas, este fluxo de água também estava induzindo a formação de ondas transversais no canal, como mostra a figura 6.2.

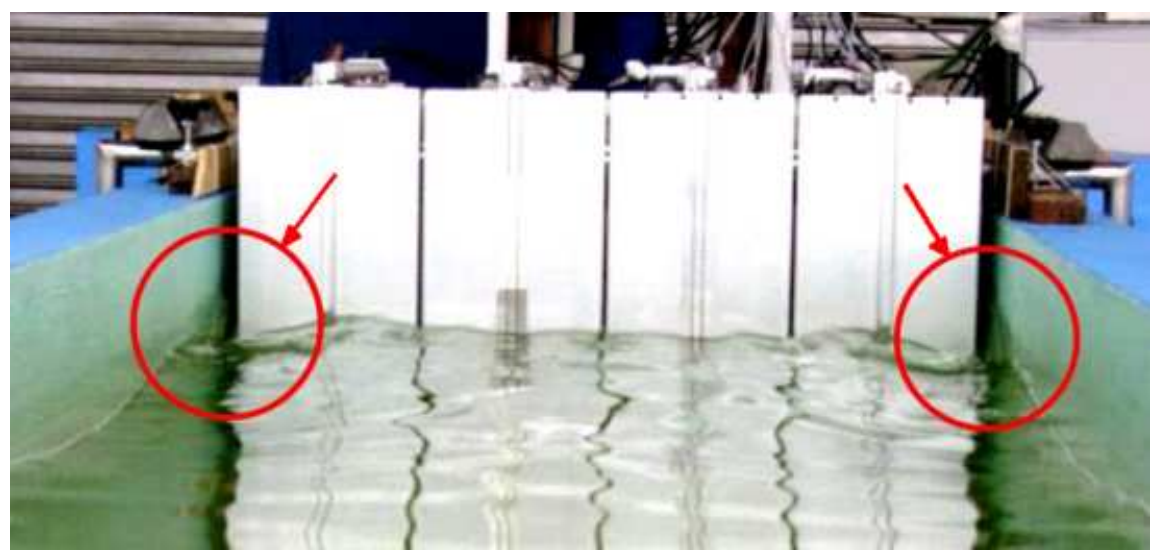

Figura 6.2: Fluxo de água entre a parede do tanque e o flap.

Para minimizar este problema, foram instaladas vedações nas laterais dos flaps e entre eles. Essas vedações devem ser flexíveis para se adaptar as variações da parede e a movimentação do gerador de ondas. A figura 6.3 apresenta as modificações realizadas, enquanto que a figura 6.4 mostra a onda gerada após as modificações.

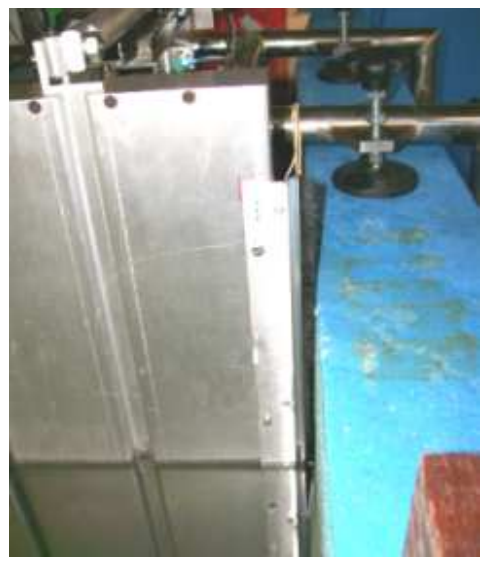

(a) Vedação lateral.

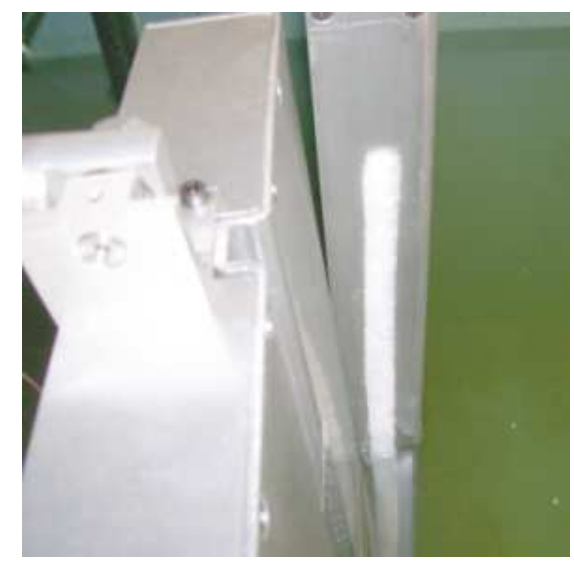

(b) Vedação entre flaps.

Figura 6.3: Vedações instaladas no gerador de ondas. 


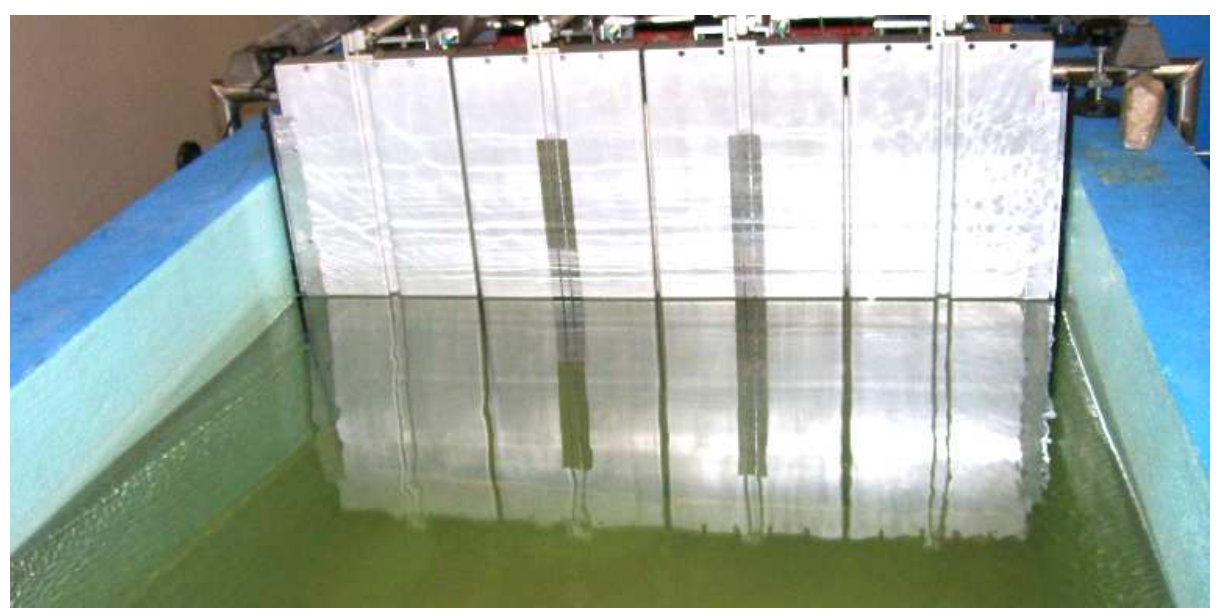

Figura 6.4: Onda gerada após a instalação das vedações.

Outro efeito observado foi que na parte traseira do gerador de ondas, formava-se uma onda estacionária, devido à reflexão na parede do tanque. Na freqüência de $0,75 \mathrm{~Hz}$ esta onda estacionária apresentou ressonância, acarretando no transbordamento do tanque durante a geração da onda com declividade de $8 \%$.

Com o intuito de absorver as ondas geradas atrás do gerador, um absorvedor do tipo poroso foi instalado. Esse tipo de absorvedor é constituído por uma ou mais malhas posicionadas verticalmente ao longo do canal. A onda ao passar pelas malhas perde energia, uma vez que são criadas vorticidades.

O absorvedor montado foi feito utilizando o material disponível no LENO. Quatro telas metálicas com furos de $20 \mathrm{~mm}$ foram dispostas atrás do gerador, com distâncias do flap de $75 \mathrm{~cm}, 100 \mathrm{~cm}, 125 \mathrm{~cm}$ e $160 \mathrm{~cm}$. Nas três telas mais afastadas do gerador, foi fixada uma malha plástica de fios trançados. Entre a terceira e a quarta tela foi posicionado um aglomerado da malha plástica com limitação do movimento vertical à linha de água estática. Desta forma, a porosidade do absorvedor diminui gradativamente a medida que se distancia do gerador (figura 6.5).

Após as modificações, foi observado que os problemas foram minimizados, possibilitando dar continuidade aos ensaios. Desta forma, foram geradas todas as ondas da tabela 6.1 .

O tanque apresentou ressonância lateral para a onda de $3 \mathrm{~Hz}$. Então, esta freqüência foi substituída por $2,9 \mathrm{~Hz}$. A figura 6.6 apresenta uma comparação entre essas duas ondas. 


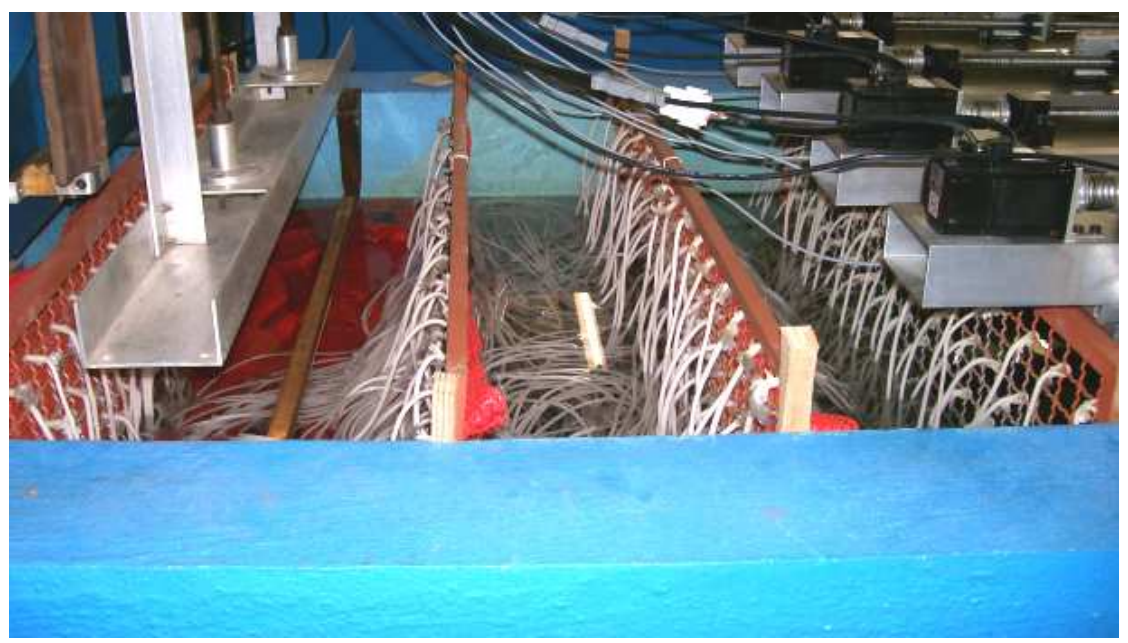

Figura 6.5: Absorvedor poroso instalado atrás do gerador de ondas.

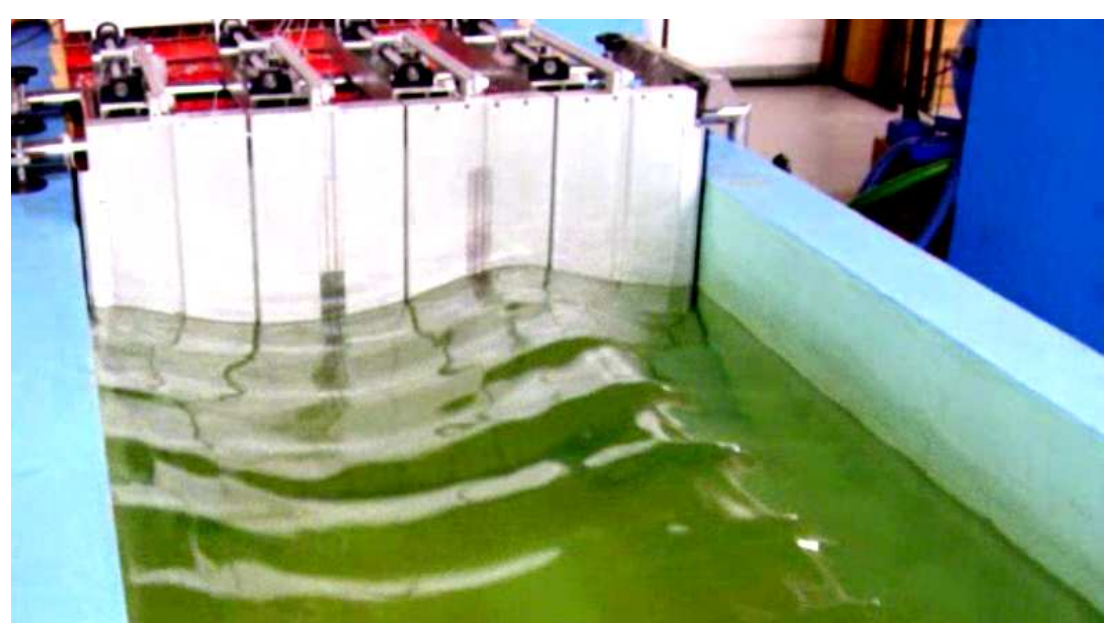

(a) Ressonância: onda de $3,0 \mathrm{~Hz}$.

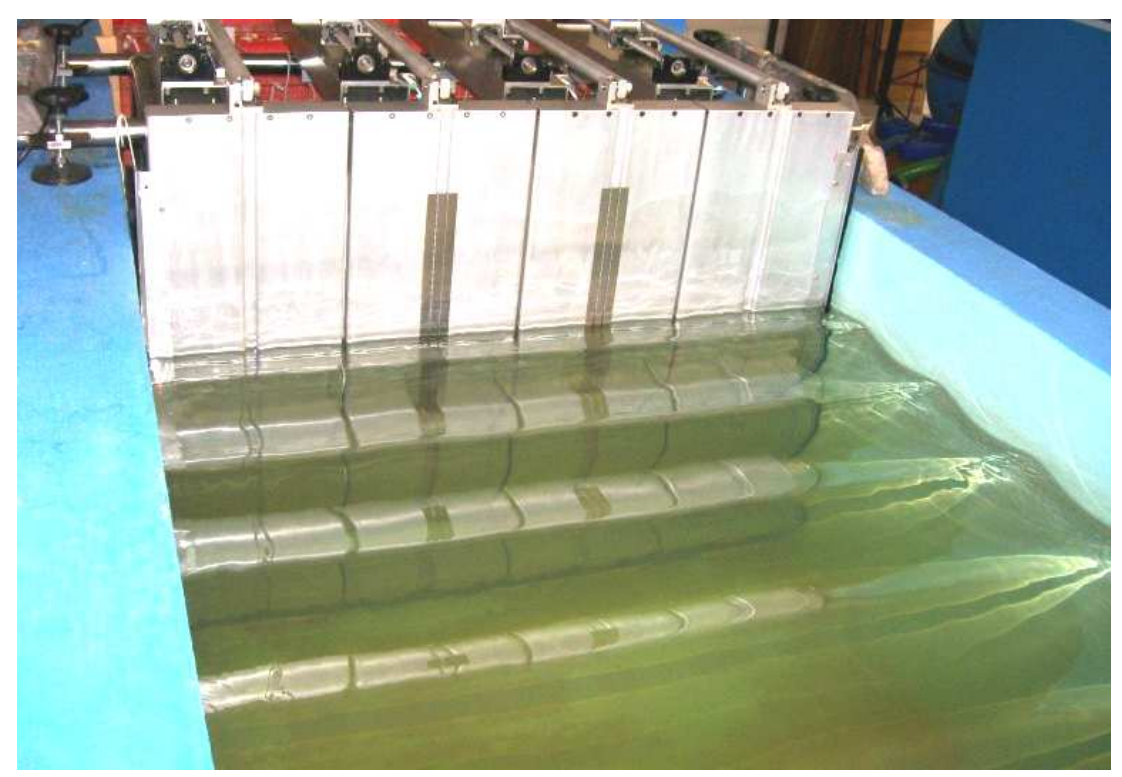

(b) Sem ressonância: onda $2,9 \mathrm{~Hz}$.

Figura 6.6: Efeito de ressonância lateral do tanque. 


\subsection{Análise dos dados}

Através de análise visual se constatou que o sistema analógico de aquisição de dados disponível no LENO apresentou um grande nível de ruído, o que impossibilitou o tratamento dos dados na sua forma bruta, sendo necessário aplicar um filtro à série temporal após a aquisição.

Os sinais correspondentes à elevação da água possuem um transitório no início e a partir de um determinado instante, sofrem a influência da onda refletida na praia, características que dependem da freqüência da onda gerada. A figura 6.7 apresenta um exemplo dos sinais adquiridos após a filtragem, mostrando o sinal de referência e os registros do encoder, do sensor de altura de ondas por ultra-som e dos sensores capacitivos, para a freqüência de $1,25 \mathrm{~Hz}$ e com declividade de $1 \%$.

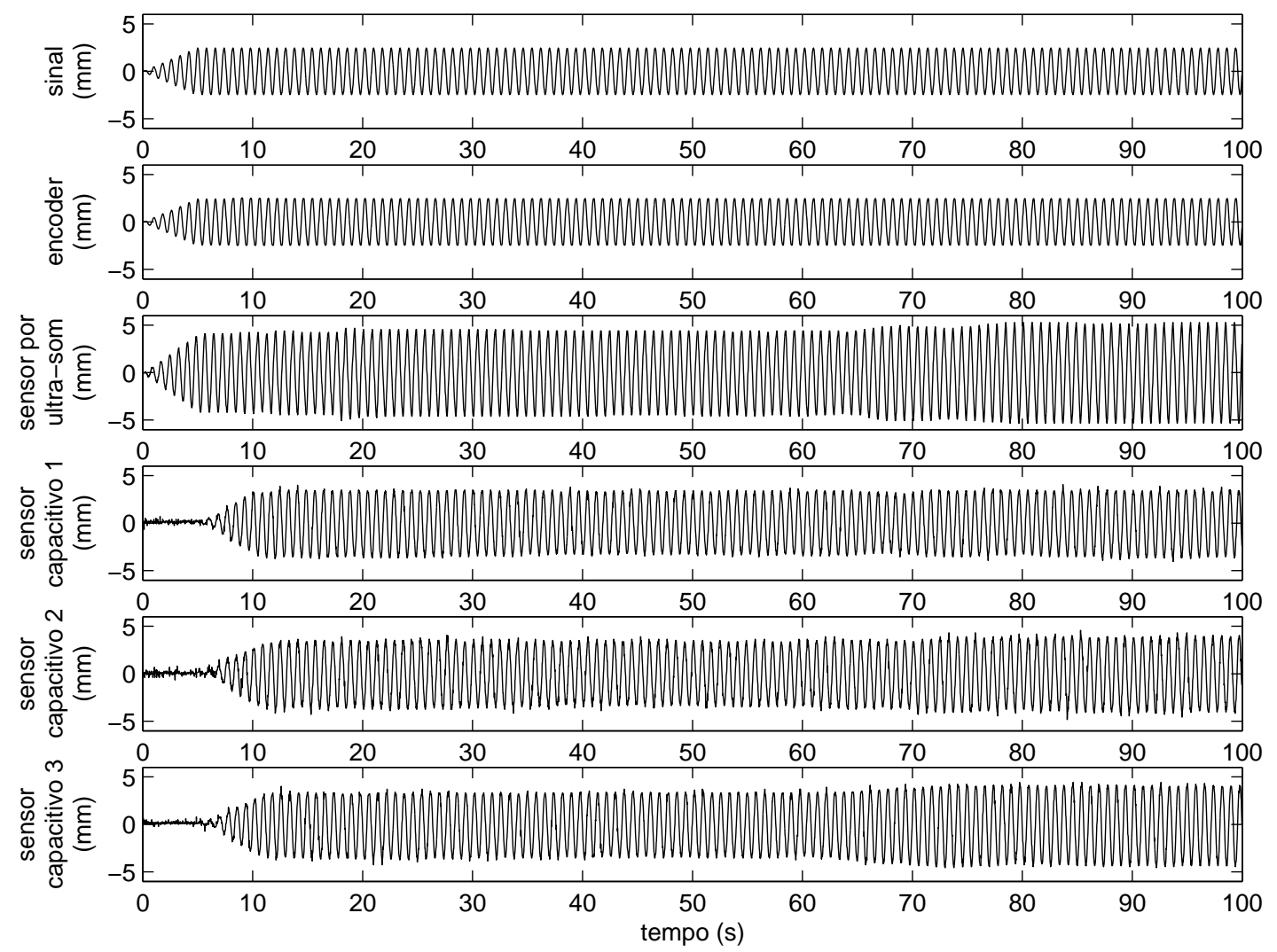

Figura 6.7: Exemplo de série temporal do ensaio para determinação do desempenho do gerador de ondas. Freqüência de $1,25 \mathrm{~Hz}$ e $1 \%$ de declividade.

Desta forma, antes do processamento dos sinais adquiridos, foi realizada uma análise visual para se selecionar a janela temporal que corresponde ao fenômeno físico de interesse. No registro apresentado, pode-se notar que para o sensor de altura de onda por ultra-som o regime transitório termina aos 6 segundos e a onda refletida aparece aos 65 segundos. Enquanto que para o terceiro sensor capacitivo, esses tempo são respectivamente 13 e 62 segundos. A mesma análise foi ser realizada para 
os demais sinais coletados.

Após a determinação da janela temporal, a análise dos dados foi realizada através da densidade espectral de potência cruzada entre as séries temporais, de forma semelhante à utilizada no ensaio para caracterização dos sensores de altura de onda. Todos os valores obtidos podem ser encontrados no Anexo B.

\subsubsection{Função de transferência do motor}

A figura 6.8 apresenta a resposta dinâmica do motor, ou seja, a relação entre a referência e o sinal do encoder. Os dados experimentais foram ajustados por uma equação que representa um sistema dinâmico de segunda ordem com um grau de liberdade.
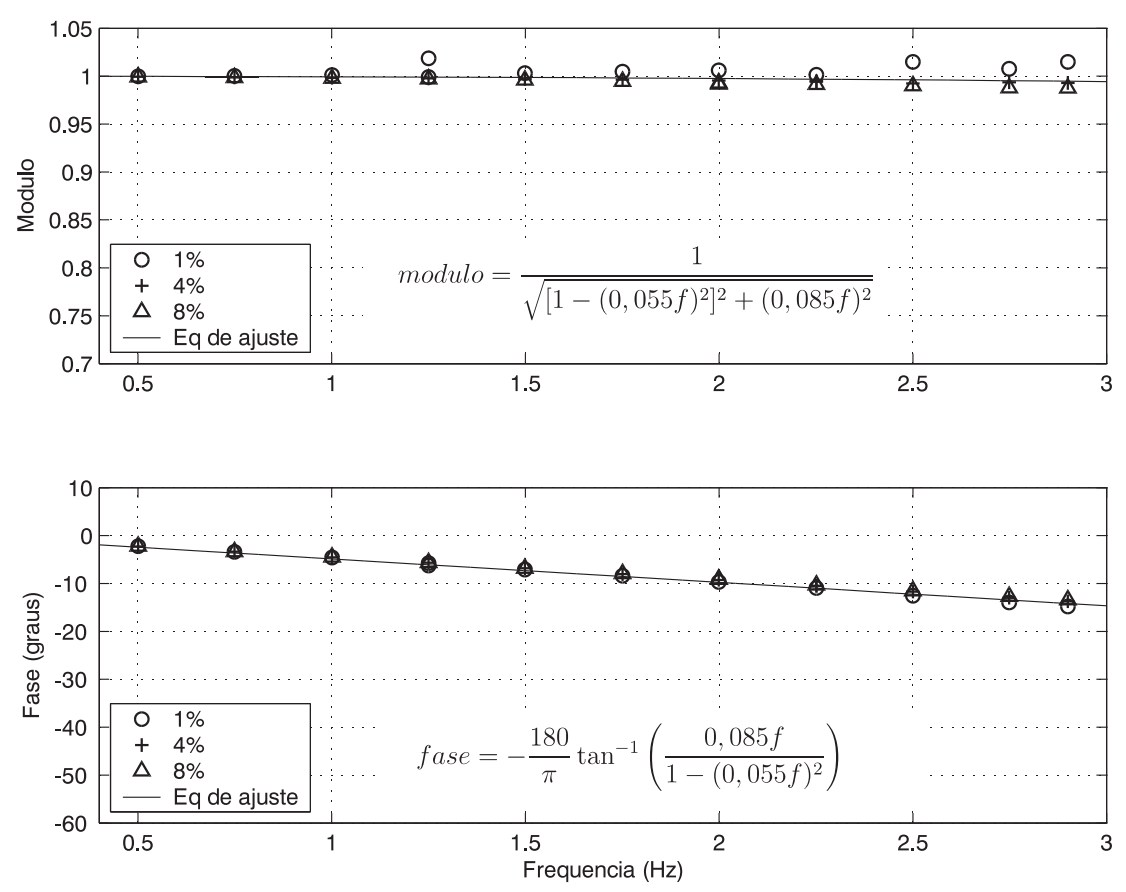

Figura 6.8: Função de transferência experimental do motor.

Através da curva de ajuste, pode-se observar que a resposta dinâmica do motor na região de trabalho possui uma atenuação da amplitude do movimento máxima de $0,6 \%$ e um atraso de fase máximo de $14,7^{\circ}$, ambas ocorrendo na freqüência de $3,0 \mathrm{~Hz}$.

\subsubsection{Função de transferência $H / S$}

A função de transferência $H / S$ foi obtida experimentalmente comparando-se a leitura do encoder dos motores com o sensor capacitivo mais próximo ao gerador de on- 
das. A leitura do sensor capacitivo foi corrigida através da sua equação característica, obtida no ensaio de caracterização dos sensores de altura de onda (figura 4.26).

A função de transferência teórica obtida durante o projeto mecânico do gerador de ondas (figura 3.2) considera que o ponto de pivotamento do flap se encontra no fundo do tanque, o que não ocorre na realidade. Desta forma, foi feita uma correção na função de tranferência teórica obtida anteriormente: a altura de água estática foi igualada à altura alagada do flap $(h=0,627 \mathrm{~m})$.

A figura 6.9 apresenta a função de transferência $H / S$ teórica corrigida e os valores obtidos experimentalmente.

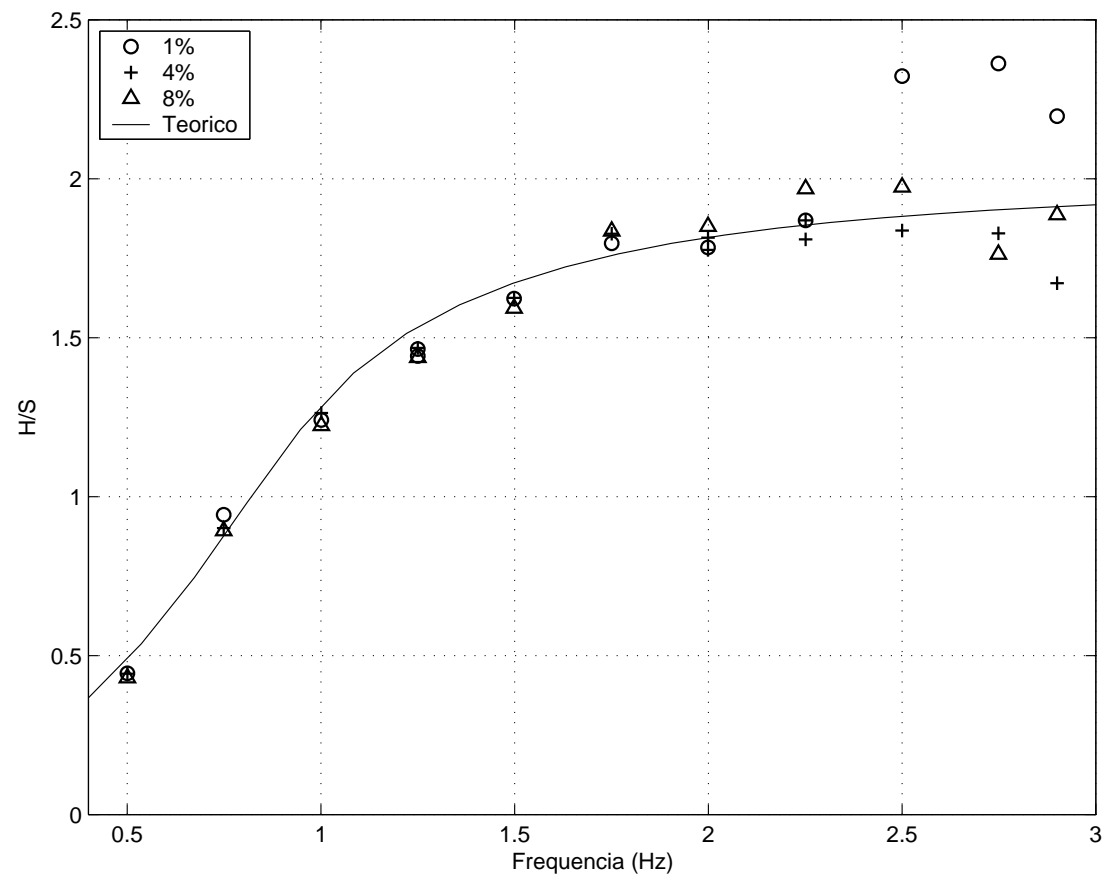

Figura 6.9: Função de transferência $H / S$ experimental.

Pode-se observar que os pontos aderem bem à teoria linear até cerca de 2,25 Hz, a partir dessa freqüência existe um aumento na dispersão das medidas. Esse aumento na dispersão das medidas ocorre para as freqüências de onda mais altas uma vez que a altura da onda diminui com o aumento de sua freqüência, tornando o ruído de fundo mais significativo. Esse efeito também é mais evidente para as ondas com menor declividade, pela mesma razão.

Pode-se notar também que não houve grandes alterações na função de transferência para as três declividades, mesmo sabendo que a teoria linear de ondas não se aplicaria para as ondas com declividade de $8 \%$. A figura 6.10 apresenta as formas das ondas com $1 \%$ e $8 \%$ de declividade para a frequência de $0,75 \mathrm{~Hz}$. As formas de onda concordam com as da figura 2.3 , ou seja, a onda com declividade de $1 \%$ é uma 
onda linear de Airy e a com 8\% é uma onda de Stokes. Aqui é importante apontar que o método utilizado na análise dos dados considera apenas o primeiro harmônico da série temporal.
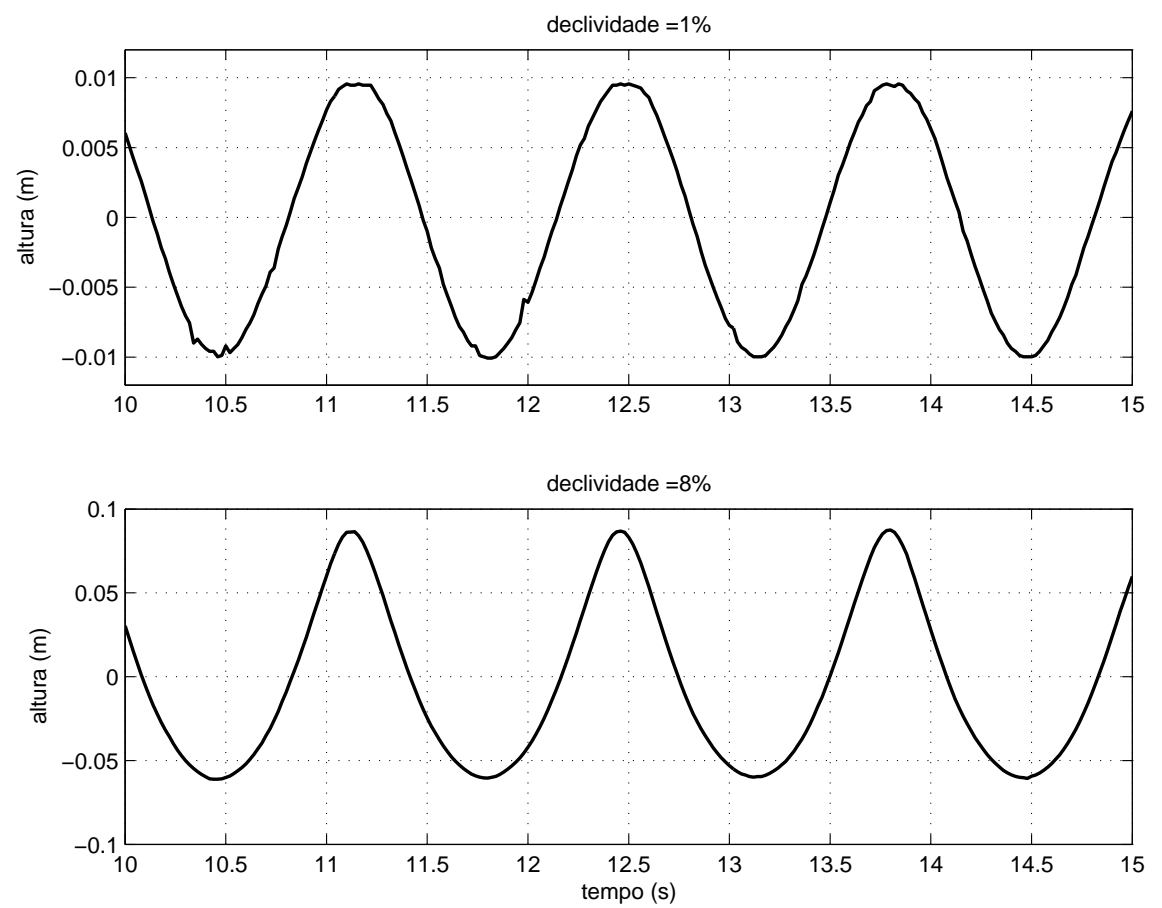

Figura 6.10: Comparação entre as formas de onda para as declividades de $1 \%$ e $8 \%$ (freqüência $0,75 \mathrm{~Hz}$ ).

\subsubsection{Função de transferência $H_{0} / S$}

A função de transferência $H / S$ despreza a parcela da onda evanescente, uma vez que se considera que o ponto de medição está longe o suficiente do gerador de ondas. Porém, no caso do sensor de altura de ondas por ultra-som instalado diretamente na frente do flap, que é responsável pela realimentação hidrodinâmica da malha de controle de absorção de ondas, existe a necessidade de se considerar o efeito das ondas evanescentes.

A função de transferência $H_{0} / S$ relativa à altura de onda diretamente na frente do flap $(x=0)$, é obtida de forma semelhante à função de transferência relativa à onda progressiva $H / S$ (capítulo 3.3), e é descrita a seguir.:

A formulação completa da superfície livre pode ser obtida através do potencial de velocidades (equação 3.2) e da CCDSL (equação 2.8):

$$
\left.\eta=-\frac{A_{p} \omega}{g} \cosh \left(k_{p} h\right) \cos \left(k_{p} x-\omega t\right)-\sum_{m=1}^{\infty} C_{m} \omega e^{-k_{s}(m) x} \cos \left[k_{s}(m) h\right)\right] \operatorname{sen}(\omega t)
$$


onde, a primeira parcela corresponde à onda progressiva e a segunda parcela à onda evanescente.

Simplificando o movimento da superfície livre para a posição do gerador de ondas, $x=0$ :

$$
\left.\eta_{0}=-\frac{A_{p} \omega}{g} \cosh \left(k_{p} h\right) \cos (-\omega t)-\sum_{m=1}^{\infty} \frac{C_{m} \omega}{g} \cos \left[k_{s}(m) h\right)\right] \operatorname{sen}(\omega t)
$$

A equação 6.2 pode ser reescrita na forma:

$$
\eta_{0}=\frac{H}{2} \cos (-\omega t)+\frac{H_{E}}{2} \operatorname{sen}(\omega t)
$$

onde, $H$ é a altura de onda progressiva e $H_{E}$ é a altura de onda evanescente em $x=0$, dadas por:

$$
\begin{aligned}
H & =-\frac{2 A_{p} \omega}{g} \cosh \left(k_{p} h\right) \\
H_{E} & \left.=-\sum_{m=1}^{\infty} \frac{2 C_{m} \omega}{g} \cos \left[k_{s}(m) h\right)\right]
\end{aligned}
$$

Enquanto que o movimento do flap em $z=0$ pode ser obtido através das equações 3.1 e 3.7 :

$$
S=\frac{S_{0}}{2} \operatorname{sen}(\omega t)
$$

Reescrevendo as equações 6.3 e 6.6 na forma complexa, de maneira que a parte real da expressão corresponda ao fenômeno físico estudado, tem-se respectivamente:

$$
\begin{aligned}
\eta_{0} & =\frac{H-i H_{E}}{2} e^{i \omega t} \\
S & =\frac{-i S_{0}}{2} e^{i \omega t}
\end{aligned}
$$

Combinando as equações 6.7 e 6.8 obtem-se a função de transferência $H_{0} / S$ : 


$$
\frac{H_{0}}{S}=\frac{\eta_{0}}{S}=\frac{i H+H_{E}}{S_{0}}
$$

A figura 6.11 apresenta a função de transferência $H_{0} / S$ teórica, com a altura de água estática igualada à altura alagada do flap e os valores experimentais, obtidos através da comparação dos sinais dos sensores de altura de onda por ultra-som e da leitura do encoder dos motores. A leitura do sensor por ultra-som foi corrigida pela sua equação característica obtida experimentalmente (figura 4.25).
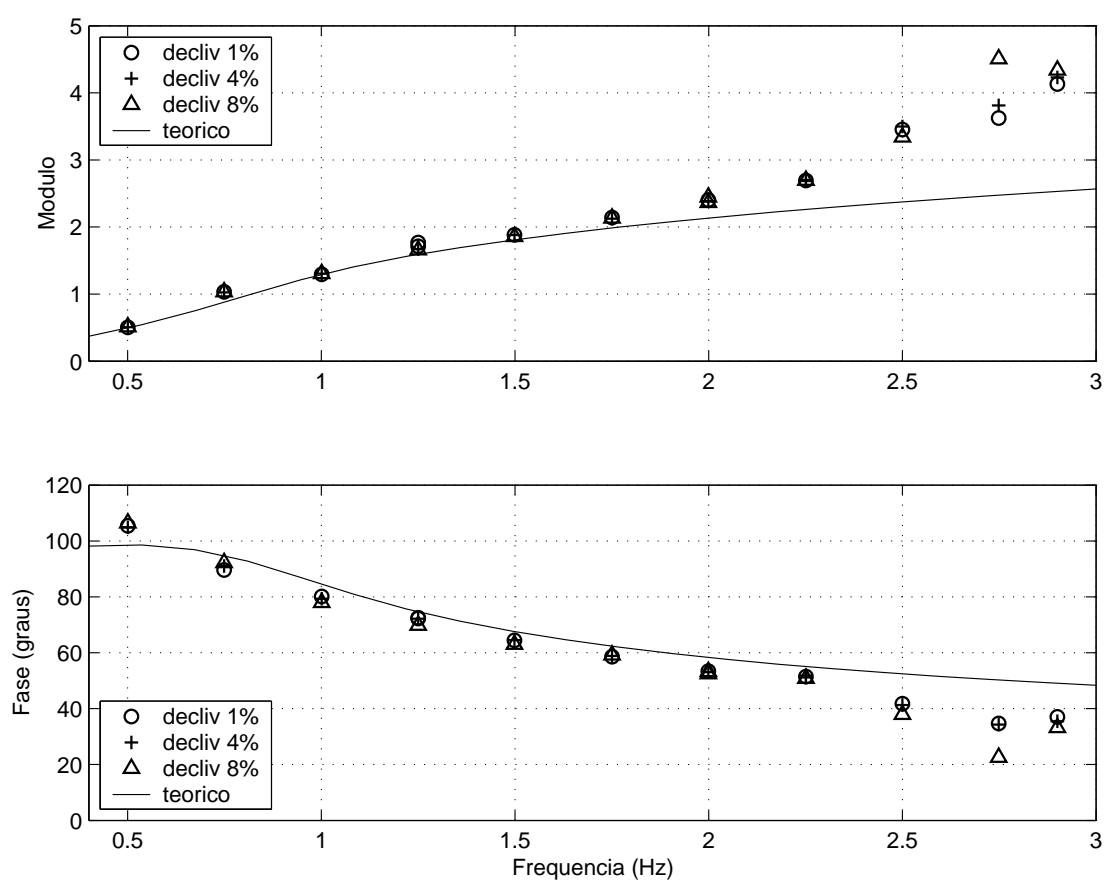

Figura 6.11: Função de transferência $H_{0} / S$ experimental.

Pode-se observar que os pontos aderem bem à teoria linear até cerca de 2,25 Hz. A partir dessa freqüência, os pontos vão se afastando sistematicamente da curva teórica, tanto no módulo quanto em sua fase. Para se determinar o motivo dessa discrepância se faz necessário um estudo mais aprofundado, que não será realizado neste trabalho e propõe-se como trabalho futuro.

Através das três repetições de ondas realizadas, pode-se verificar uma boa repetibilidade dos dados experimentais do comportamento dinâmico do motor, das funções de transferência $H / S$ e $H_{0} / S$.

\subsubsection{Detecção de ondas refletidas}

O método para a detecção de ondas refletidas é uma ferramenta importante para se avaliar o desempenho de um absorvedor passivo do tipo praia ou do tipo poroso e também para o absorvedor ativo implementado em um gerador de ondas. 
Desta forma, durante o ensaio de avaliação do desempenho do gerador de ondas, também foi avaliado o método experimental utilizado para se realizar a medição do coeficiente de reflexão $C r$ de ondas regulares na praia. $\mathrm{O}$ algoritmo utilizado é o método de Mansard \& Funke que foi apresentado por Isaacson (2000) e implementado por Mello (2006).

O método utiliza a leitura de três sensores de altura de onda posicionados em linha, no sentido da propagação da onda. Os sinais dos sensores são comparados com um modelo teórico da superposição de uma onda senoidal incidente e uma onda senoidal refletida. As amplitudes e fases das duas ondas são obtidos minimizandose os erros entre o modelo teórico e os dados experimentais através de mínimos quadrados. A descrição do método encontra-se no Apêndice $A$.

A figura 6.12 apresenta um exemplo da leitura dos três sensores de altura de onda capacitivos, as alturas de onda incidente $H_{i}$ e refletida $H_{r}$ calculadas pelo algoritmo e o coeficiente de reflexão $\mathrm{Cr}=H_{r} / H_{i}$ para a onda de declividade $4 \%$ e freqüência $2,25 \mathrm{~Hz}$.
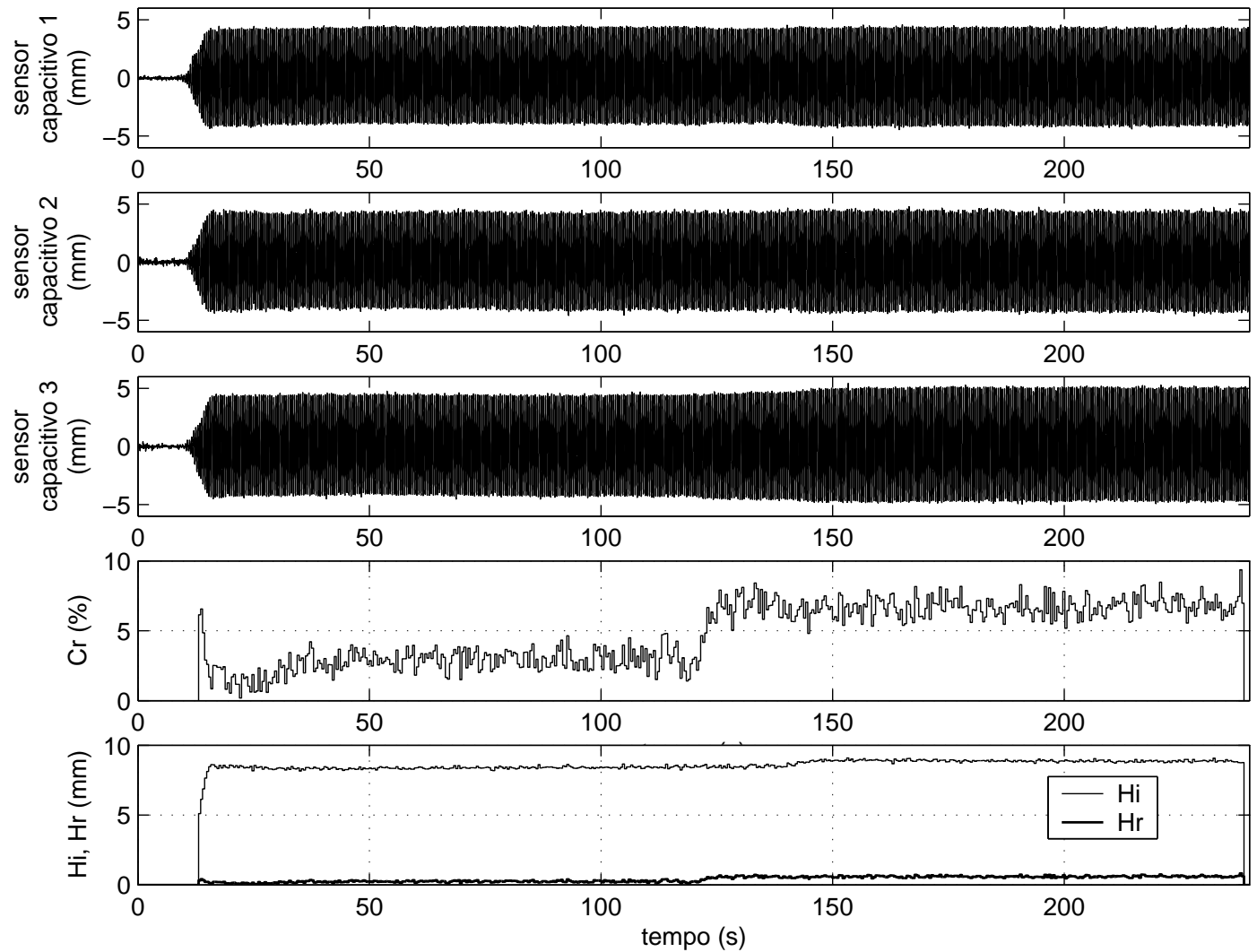

Figura 6.12: Exemplo da detecção de reflexão de ondas. Declividade $4 \%$ e freqüência $2,25 \mathrm{~Hz}$

Pode-se observar a chegada das ondas refletidas nos sensores no tempo de 123 segundos. A altura da onda refletida permanece num patamar constante antes da 
reflexão, sua altura se altera junto com o coeficiente de reflexão e depois permanece constante em outro patamar.

Enquanto que a altura da onda incidente é constante até depois da reflexão, como é esperado. Porém, no tempo de 140 segundos, a altura da onda incidente sofre uma pequena alteração, devido à onda re-refletida no gerador de ondas. Em algumas das ondas ensaiadas, pode-se perceber a alteração do coeficiente de reflexão após a chegada da onda re-refletida, desta forma, o coeficiente de reflexão adotado foi calculado com a altura da onda incidente antes da reflexão e não diretamente no tempo como foi mostrado na figura 6.12 .

A altura das ondas incidentes antes da reflexão concordam com as alturas calculadas através do método da densidade espectral de potência cruzada, conforme pode-se observar na figura 6.13. Até a onda de freqüência $2,5 \mathrm{~Hz}$ a maior diferença entre os dois algoritmos é de 3,7\%. Para as freqüências mais altas, essa diferença aumenta consideravelmente, chegando a $26 \%$, pois o algoritmo de reflexão é bastante sensível a ruídos, uma vez que depende diretamente da leitura das alturas de onda e das fases entre os três sensores.

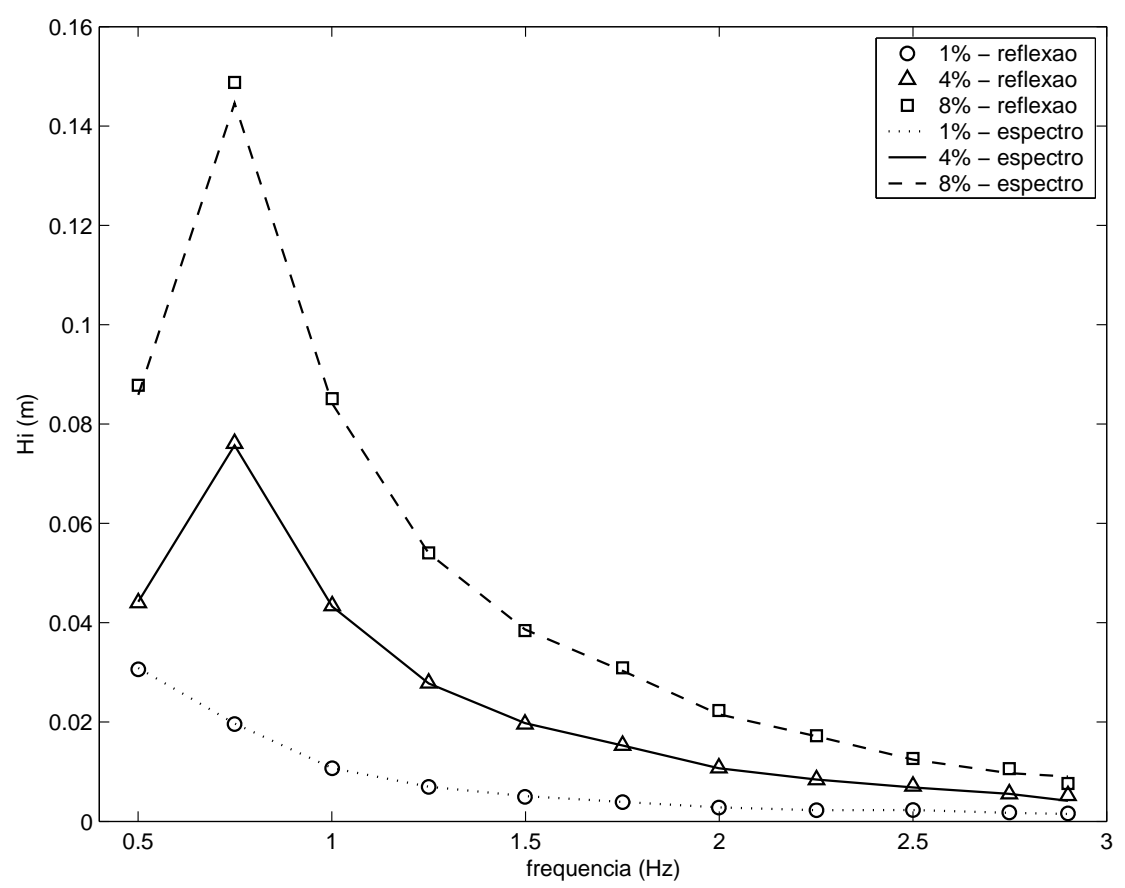

Figura 6.13: Comparação entre as alturas de onda incidente calculadas pelo algoritmo de reflexão e pela densidade espectral de potência.

A figura 6.14 apresenta o coeficiente de reflexão $C r$ da praia obtida pelo método de Mansard \& Funke. O maior coeficiente de reflexão observado foi de 24,5\% para a onda ensaiada de menor freqüência e menor declividade. Pode ser observado na figura a existência de uma tendência do aumento do coeficiente de reflexão conforme 
a declividade da onda diminui.

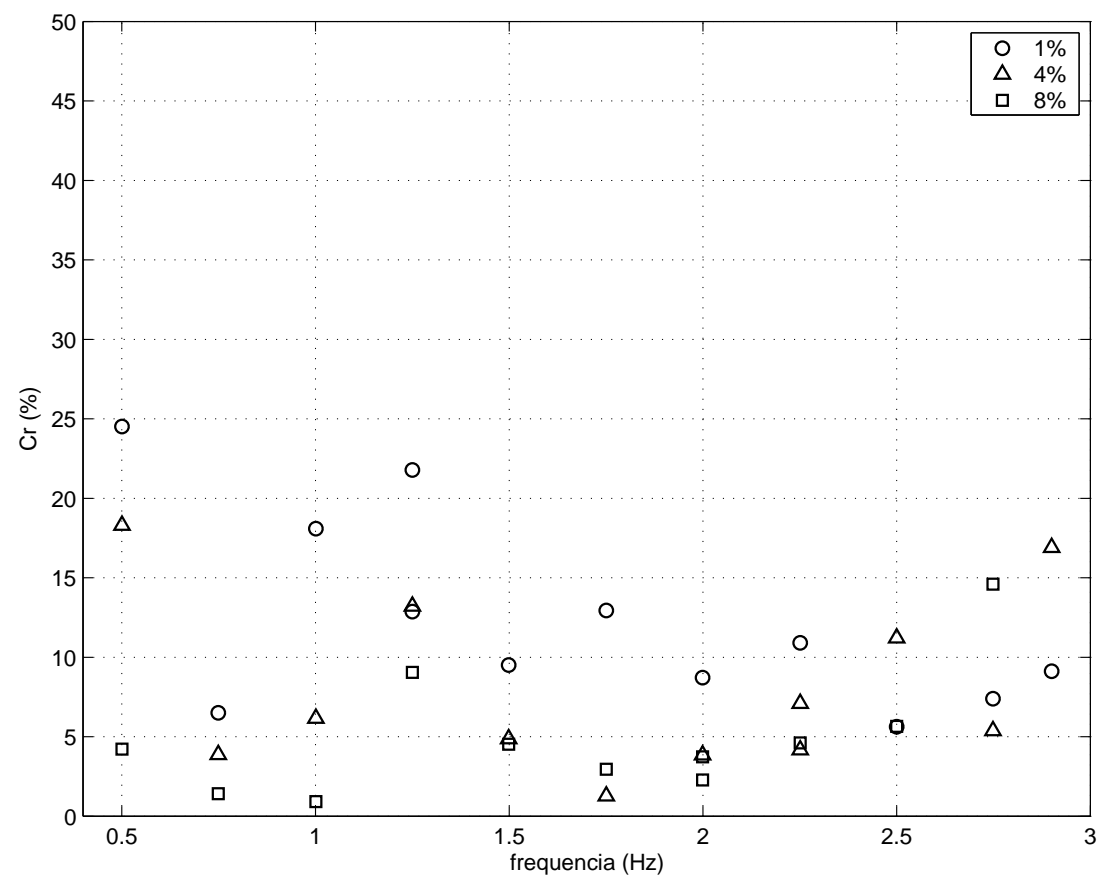

Figura 6.14: Coeficiente de reflexão da praia. 


\section{Conclusões e recomendações}

O desenvolvimento de um sistema capaz de gerar e absorver ondas para um tanque de ensaios de estruturas oceânicas é uma tarefa complexa, uma vez que depende de diversas disciplinas de engenharia, tais como: hidrodinâmica, resistência dos materiais, controle, eletrônica, programação e conhecimento das condições ambientais que devem ser reproduzidas nos ensaios realizados no tanque.

Com o objetivo de simplificar o caminho a ser percorrido, foi proposto um procedimento para o projeto de geradores de onda. Este procedimento foi aplicado com sucesso no desenvolvimento de um protótipo com quatro módulos geradores de onda. O protótipo foi instalado no canal de ensaios do Laboratório de Engenharia Naval e Oceânica da Escola Politécnica da USP.

Para o sistema de sensoriamento do protótipo, foi desenvolvido um sensor de altura de onda por ultra-som, que utiliza a técnica de pulso-eco, com o transdutor imerso na água e reflexão da onda ultra-sônica na interface água-ar da superfície do tanque. O principal desafio encontrado durante seu desenvolvimento foi a perda do sinal de eco, devido à inclinição da superfície da água. Para minimizar este efeito, uma guia para ondas de ultra-som foi adicionada ao sensor.

Foram realizados ensaios para a caracterização deste novo sensor e também para comparar sua resposta com um sensor de altura de ondas capacitivo. Nesses ensaios, o sensor por ultra-som apresentou uma maior linearidade na calibração estática e uma melhor resposta dinâmica, tanto em fase, quanto em módulo, quando comparado com o sensor capacitivo.

Os ensaios também mostraram a importância da calibração dinâmica dos sensores de altura de onda, encontrada em pouquíssimos trabalhos na literatura. Através da calibração dinâmica, determinam-se a faixa de trabalho dos sensores e sua equação característica, que pode ser usada na correção da série temporal adquirida.

Outra característica importante do sensor por ultra-som é que sua calibração depende apenas da medição da temperatura da água. Enquanto que, para o sensor capacitivo, deve ser realizada uma calibração estática ao início de todos os ensaios. 
Desta forma, a utilização de sensores por ultra-som diminuem o tempo gasto na etapa de preparo de um ensaio.

Durante o desenvolvimento do sistema de controle do gerador de ondas, notou-se que o fator crítico na temporização do sistema é proveniente do tempo de comunicação entre o microcontrolador e o PC. A aquitetura adotada é suficientemente rápida para o protótipo, que possui apenas quatro flaps. Porém, uma nova solução deverá ser implementada, de forma a suprir a velocidade de comunicação para os 148 geradores previstos no Calibrador Hidrodinâmco do TPN.

Nos ensaios para determinação do desempenho do gerador de ondas, foram adquiridas uma séries de medidas experimentais. Como resultado desses ensaios, obteve-se a função de transferência tradicional longe do gerador, na qual só são consideradas as ondas progressivas, e também a função de transferência junto ao atuador, que sofre influência das ondas evanescentes.

Durante esses ensaios, foi observado que a água que passava pelas frestas laterais dos flaps gerava uma grande perturbação na onda desejada e também induzia a formação de ondas laterais no tanque. Desta forma, houve a necessidade de se implementar um sistema de vedação nos flaps. Outro problema detectado foi a ocorrência do transbordo do tanque atrás do gerador, para a onda de freqüência de $0,75 \mathrm{~Hz}$. Assim, foi implementado um absorvedor de ondas do tipo poroso atrás do gerador. Após essas modificações, os efeitos que prejudicariam a análise dos resultados do ensaio foram minimizados.

O sistema de aquisição de dados disponível no LENO não possuia filtragem nas entradas analógicas, o que ocasionou um grande nível de ruídos na leitura dos sensores de altura de onda capacitivos. Desta forma, não foi possível realizar a análise dos dados no domínio do tempo, porém foi realizada no domínio da freqüência com a técnica da densidade espectral de potência cruzada.

Os resultados experimentais obtidos, tanto para a função de transferência longe do gerador $H / S$, quanto para a função de transferência próxima ao atuador, apresentaram uma boa aderência com o modelo teórico, até cerca de $2,25 \mathrm{~Hz}$. A partir desta freqüência, os valores experimentais apresentaram uma grande dispersão, uma vez que a relação sinal ruído ficou muito grande.

Analisando a função de transferência obtida próxima ao gerador de ondas, observarse a importância de se considerar o efeito das ondas evanescentes no desenvolvimento do algorítmo para a absorção de ondas, salientado-se que, existe uma grande variação na fase no comportamento dinâmico da geração de ondas. 
Durante o ensaio para caracterização do gerador de ondas, também foi realizada uma avaliação do método de Mansard \& Funke para detecção de ondas refletidas. O método foi implementado com sucesso e se mostrou uma ferramenta importante a ser utilizada durante o desenvolvimento do algorítmo de absorção. Porém, o método se mostrou muito sensível a ruídos, pois depende da leitura temporal da altura de onda e da fase entre os três sensores. Desta forma, estudos mais aprofundados devem ser realizados em trabalhos futuros.

Através das observações realizadas, conclui-se que, o objetivo de prover um ambiente de desenvolvimento para o estudo de métodos de geração e absorção de ondas foi atingido. Através dos estudos realizados neste trabalho, espera-se contribuir com o desenvolvimento do tanque Calibrador Hidrodinâmico do TPN.

\subsection{Recomendações para futuras pesquisas}

O próprio objetivo deste trabalho era gerar uma ferramenta para futuras pesquisas, desta forma, recomendam-se os tópicos a seguir relacionados com o tema desenvolvido:

- Estudo de métodos de absorção de ondas através da correção do movimento dos geradores de onda. Como ponto de partida, sugerem-se os trabalhos de Schäffer e Klopman (2000), Naito (2006) e Maeda et al. (2004);

- Estudo da geração de ondas de segunda ordem;

- Geração de ondas multidirecionais, irregulares e transientes;

- Realizar um estudo mais aprofundado de métodos experimentais para a obtenção do coeficiente de reflexão, incluindo a análise para ondas irregulares.

A seguir são apresentadas sugestões para melhorar o protótipo e também para o projeto do Calibrador Hidrodinâmico:

- Utilização de cabos blindados nos motores e nos sensores, assim como a utilização de um sistema de aquisição de dados com filtragem analógica, para diminuir a contaminação da leitura dos sensores com os ruídos eletromagnéticos provenientes dos servomotores;

- Estudo da utilização de padrões de redes industriais para a interface entre o computador e os drivers dos motores; 
- Estudo da influência da altura do ponto de pivotamento do flap nas funções de transferência e no dimensionamento do gerador de ondas;

- Otimização do absorvedor poroso atrás dos geradores de onda;

- Estudo para a otimização da guia de ondas do sensor de altura de ondas por ultra-som. 


\section{Referências}

ANDRADE, M. A. B. Análise de materiais piezelétricos compósitos para aplicações em transdutores de ultra-som. 171 p. Dissertação (Mestrado) - Escola Politécnica da Universidade de São Paulo, São Paulo, 2006.

CARNEIRO, M. L.; MELLO, P. C. de. Relatório interno: Gerador de ondas. São Paulo: Laboratório de Sensores e Atuadores da Escola Politécnica da USP, 2007.

CARNEIRO, M. L.; MELLO, P. C. de. Relatório interno: Sensor de altura de ondas por ultra-som. São Paulo: Laboratório de Sensores e Atuadores da Escola Politécnica da USP, 2007.

CEM. Coastal Engineering Manual. Engineer Manual 1110-2-1100.

Washington, D.C.: U.S. Army Corps of Engineers, 2002. Disponível em:

<http://chl.erdc.usace.army.mil/>. Acesso em: 8 jan. 2007.

COSTA, E. T.; BUTTON, V. L. da S. N.; DANTAS, R. G.; NICACIO, H.; ALBUQUERQUE, J. A. G.; MAIA, J. M.; HIGUTI, R. T. 1 CD-ROM. Cap. 4 Transdutores de Ultra-som: Modelagem, Construção e Caracterização. In: Sensores: Tecnologias e Aplicações. São Paulo: [s.n.], 2004.

DEAN, R. G.; DALRYMPLE, R. A. Water wave mechanics for engineers and scientists. New Jersey: Prentice-Hall, Inc., 1984.

FOLEY, J. D.; DAM, A. V. Fundamentals of Interactive Computer Graphics. Massachusetts: Addison-Wesley, 1981.

GALLEGO-JUAREZ, J. A. Piezoelectric ceramics and ultrasonic transducers. J. Phys. E. Sci. Instr, v. 22, p. 804-816, 1989.

GROSSO, V. A. del; MADER, C. W. Speed of sound in pure water. Journal of the Acoustical Society of America, v. 52, n. 5, p. 1442-1446, 1972.

HARRIS, N. R.; HILL, M.; TUNER, J. D. Practical aspects of modal propagation through water filled pipes. Ultrasonics, v. 35, n. 1, p. 73-78, 1995.

HAUPTMANN, P.; HOPPE, N.; PüTTMER, A. Application of ultrasonic sensors in the process industry. Measurement Science and Technology, v. 13, p. 73-83, 2002.

ISAACSON, M. Measurement of regular wave reflection. Journal of Waterway, Port, Coastal and Ocean Engineering, v. 117, n. 6, p. 553-569, 2000.

ITTC. The loads and responses committee final report and recommendations to the 22nd ittc. ITTC - International Towing Tank Conference, Seoul \& Shanghai., 1999.

KINSLER, L. E.; FREY, A. R.; COPPENS, A. B.; SANDERS, J. V. Fundamentals of acoustics. Third. New York: John Wiley \& Sons, 1982. 
LEMéHAUTé, B. An introduction to hydrodynamics \& water waves. New York: Springer-Verlag, 1976. ISBN 0-387-07232-2.

MAEDA, K.; HOSOTANI, N.; TAMURA, K.; ANDO, H. Wave making properties of circular basin. International Symposium on Underwater Technology, p. 349-354, 2004.

MARTINS, J. A. de A. Análise de ondas em tanque de dimensões reduzidas com vistas à engenharia oceânica. 188 p. Tese (Doutorado) - Escola Politécnica da Universidade de São Paulo, São Paulo, 2003.

MELLO, P. C. de. Um aparato para redução da reflexão de ondas em praia parabólica. 117 p. Dissertação (Mestrado) - COPPE, Departamento de Engenharia Naval e Oceânica, Universidade Federal do Rio de Janeiro, Rio de Janeiro, 2006.

NAITO, S. Wave generation and absorption. theory and application. Proceedings of the 16th International Society of Offshore and Polar Engineering Conference, California, USA, p. 1-9, 2006.

NAITO, S.; NAKAMURA, T.; SAKASHITA, H.; TOMITA, K. A new configuration of wave basin and a control of wave generation and absorption-the case when an advancing ship comes across the given waves. Proceedings of the 4th Pacific/Asia Offshore Mechanics Symposium, v. 226, p. 207-212, 1996.

NAOE. Advanced Multiple Organized Experimental BAsin (AMO$E B A$ ). [s.n.], 2000. Disponível em: <http://www.naoe.eng.osakau.ac.jp/naoe/naoe1/equipments/amoeba/eamoeba.html>. Acesso em: 29 apr. 2005.

NOHARA, B. T. A survey of the generation of ocean waves in a test basin. Journal of the Brazilian Society of Mechanical Sciences, v. 22, n. 2, p. 303-315, 2000.

NOHARA, B. T.; YAMAMOTO, I.; MATSUURA, M. The organized motion control of multi-directional wave maker. Proceedings of the 4th International Workshop on Advanced Motion Control, v. 2, p. 470-475, 1996.

OGATA, K. Engenharia de Controle Moderno. Terceira. Rio de Janeiro: Prentice-Hall do Brasil, 1998.

REDWOOD, M. Ultrasonic waveguides - a physical approach. Ultrasonics, v. 1, n. 2 , p. 993-105, 1963.

SCHäFFER, H. A.; KLOPMAN, G. Review of multidirectional active wave absorption methods. Journal of Waterway, Port, Coastal and Ocean Engineering, v. 126, n. 2, p. 88-97, 2000.

SOUZA, C. A. G. F. de; MORISHITA, H. M. Evaluation of a flap type wave generator. 17th International Congress of Mechanical Engineering COBEM 2003, São Paulo, November 2003.

TAMURA, K. The Deep-Sea Basin in National Maritme Research Institute. Japan: [s.n.], 2006. Disponível em: <http://www.nmri.go.jp/ocean/DeepSeaBasen/indexe.html>. Acesso em: 05 sep. 2006.

THOMSON, W. T. Theory of vibration with aplications. Fourth. London: Chapman \& Hall, 1993. 
TPN. Tanque de Provas Numérico. [s.n.], 2004. Disponível em:

<http://tpn.usp.br/site/>. Acesso em: 25 fev. 2004.

WILNER, L. B. Variable capacitance liquid level sensors. Review of Scientific Instruments, v. 31, n. 5, p. 481-581, 1960.

YASKAWA. Sigma II Series Servo System User's Manual. USA: [s.n.], 2005. Disponível em: <http://www.yaskawa.com>. Acesso em: 18 jan. 2006. 


\section{Apêndice A - Método experimental para estudo da reflexão}

Nesta seção é descrito o método experimental utilizado para se realizar a medição do coeficiente de reflexão $\mathrm{Cr}$ de ondas regulares em um canal. O algoritmo utilizado é o método de Mansard \& Funke que foi apresentado por Isaacson (2000) e implementado por Mello (2006).

O arranjo experimental é apresentado na figura A.1. São utilizados três sensores de altura de onda posicionados em linha, no sentido da propagação da onda. A distância do gerador de ondas até o primeiro sensor $x_{1}$ tem importância secundária para o método, diferentemente das distâncias relativas entre os sensores $\lambda_{2}$ e $\lambda_{3}$ que têm grande relevância.

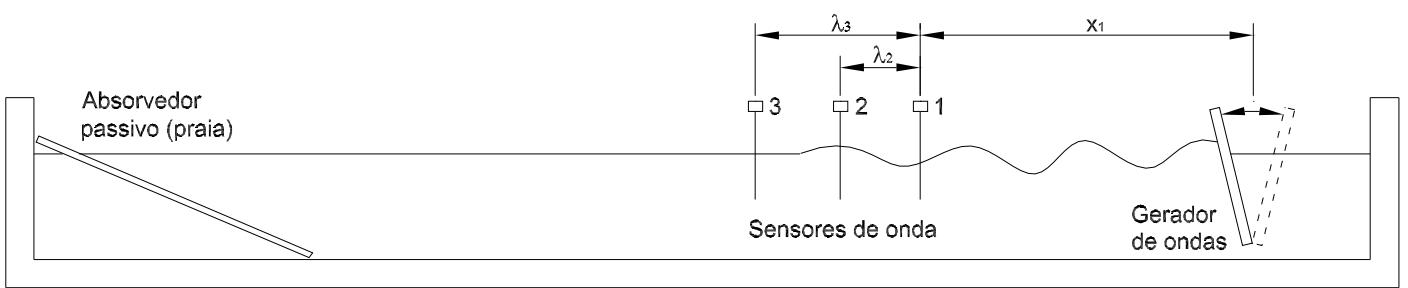

Figura A.1: Arranjo experimental para medição de reflexão de ondas.

A superfície livre é considerada como sendo a superposição de uma onda senoidal incidente e uma onda senoidal refletida. Desta forma, a superfície livre em um ponto arbitrário no tanque é descrita por:

$$
\eta=a_{i} \cos (k x-\omega t)+a_{r} \cos (k x+\omega t-\beta)
$$

onde $a_{i}$ e $a_{r}$ são respectivamente as amplitudes das ondas incidente e refletida e $\beta$ é a fase entre a onda incidente e a refletida.

Aplicando a equação A.1 para o n-ésimo sensor, tem-se:

$$
\eta_{n}=a_{i} \cos \left(k x_{n}-\omega t\right)+a_{r} \cos \left(k x_{n}+\omega t-\beta\right)
$$


A equação $A .1$ pode ser reescrita como:

$$
\eta=A^{\prime} \cos \left(\omega t-\phi^{\prime}\right)
$$

onde:

$$
A^{\prime 2}=a_{i}^{2}+a_{r}^{2}+2 a_{i} a_{r} \cos (2 k x-\beta)
$$

Aplicando as distâncias para o n-ésimo sensor, tem-se:

$$
\begin{aligned}
\eta_{n} & =A_{n}^{\prime} \cos \left(\omega t-\phi_{n}^{\prime}\right) \\
A_{n}^{\prime 2} & =a_{i}^{2}+a_{r}^{2}+2 a_{i} a_{r} \cos \left[2 k\left(x_{1}+\lambda_{n}\right)-\beta\right]
\end{aligned}
$$

A medição real de um sensor de altura de onda pode ser ser descrito como:

$$
\eta_{n}^{(m)}=A_{n} \cos \left(\omega t-\phi_{1}-\delta_{n}\right)
$$

onde, $A_{n}$ é a amplitude medida no n-ésimo sensor, $\phi_{1}$ é a fase medida no primeiro sensor e $\delta_{n}$ é a fase medida no n-ésimo sensor relativa ao primeiro, de forma que $\delta_{n}=\phi_{n}-\phi_{1}$, com $\delta_{1}=0$.

Para simplificar a algebra, a equação A.2 que descreve o movimento da superfície livre em termos de onda incidente e refletida, será reescrita na forma complexa, de maneira que a parte real da expressão complexa corresponde ao fenômeno físico descrito:

$$
\eta_{n}=\left[a_{i} e^{i\left(k x_{1}+k \lambda_{n}\right)}+a_{r} e^{-i\left(k x_{1}+k \lambda_{n}-\beta\right)}\right] e^{-i \omega t}
$$

Da mesma forma, a onda medida pelos sensores (equação A.7) pode ser descrita na forma complexa como:

$$
\eta_{n}^{(m)}=A_{n} e^{i\left(\phi_{1}+\delta_{n}\right)} e^{(-i \omega t)}
$$

A partir das equações A.8 e A.9 pode-se realizar a estimação da onda refletida baseado na técnica dos mínimos quadrados. Os sensores provêm cinco variáveis 
medidas: $A_{1}, A_{2}, A_{3}, \delta_{2}$ e $\delta_{3}$, a partir das quais três variáveis devem ser estimadas: $a_{i}, C r$ e $\beta$. Reescrevendo as equações A.8 e A.9 nos termos das amplitudes complexas, tem-se:

$$
\begin{aligned}
\eta_{n} & =\left[b_{i} e^{i \Delta_{n}}+b_{r} e^{-i \Delta_{n}}\right] e^{-i \omega t} \\
\eta_{n}^{(m)} & =B_{n} e^{(-i \omega t)}
\end{aligned}
$$

onde:

$$
\begin{aligned}
b_{i} & =a_{i} e^{i k x_{1}} \\
b_{r} & =a_{r} e^{-i\left(k x_{1}-\beta\right)} \\
B_{n} & =A_{n} e^{i\left(\phi_{1}+\delta_{n}\right)} \\
\Delta_{n} & =k \lambda_{n}
\end{aligned}
$$

A soma dos quadrados dos erros entre as amplitudes complexas teórica e medida pode ser expressa por:

$$
E^{2}=\sum_{n=1}^{3}\left[b_{i} e^{i \Delta_{n}}+b_{r} e^{-i \Delta_{n}}-B_{n}\right]^{2}
$$

O erro quadrático é minimizado quando suas derivadas com relação às variáveis complexas de interesse $b_{i}$ e $b_{r}$ são iguais a zero:

$$
\begin{gathered}
\frac{\partial E^{2}}{\partial b_{i}}=\sum_{n=1}^{3} e^{i \Delta_{n}}\left(b_{i} e^{i \Delta_{n}}+b_{r} e^{-i \Delta_{n}}-B_{n}\right)=0 \\
\frac{\partial E^{2}}{\partial b_{r}}=\sum_{n=1}^{3} e^{-i \Delta_{n}}\left(b_{i} e^{i \Delta_{n}}+b_{r} e^{-i \Delta_{n}}-B_{n}\right)=0
\end{gathered}
$$

A solução deste sistema é dada pelos termos a seguir:

$$
\begin{aligned}
a_{I} & =\left|X_{I}\right| \\
a_{R} & =\left|X_{R}\right| \\
\beta & =2 k x_{1}-\chi \pm 2 \pi m
\end{aligned}
$$


onde:

$$
\begin{aligned}
X_{I} & =\frac{s_{2} s_{3}-3 s_{4}}{s_{5}} \\
X_{R} & =\frac{s_{1} s_{4}-3 s_{3}}{s_{5}} \\
\chi & =\arg \left(X_{I}\right)-\arg \left(X_{R}\right)
\end{aligned}
$$

onde:

$$
\begin{aligned}
& s_{1}=\sum_{n=1}^{3} \exp \left(i 2 \Delta_{n}\right) \\
& s_{2}=\sum_{n=1}^{3} \exp \left(-i 2 \Delta_{n}\right) \\
& s_{3}=\sum_{n=1}^{3} A_{n} \exp \left[i\left(\delta_{n}+\Delta_{n}\right)\right] \\
& s_{4}=\sum_{n=1}^{3} A_{n} \exp \left[i\left(\delta_{n}-\Delta_{n}\right)\right] \\
& s_{5}=s_{1} s_{2}-9
\end{aligned}
$$

E finalmente o coeficiente de reflexão $C_{r}$ é calculado através de:

$$
C r=\frac{a_{r}}{a_{i}}
$$

A convergência do método é comprometida em pontos singulares das equações A.22 e A.23, ou seja, quando $s_{5}=0$. Isto ocorre para $\Delta_{n}=0, \pi, 2 \pi, \ldots$, quando o espaçamento dos sensores é igual. Quando os sensores têm espaçamentos diferentes, isso acontece toda vez que $\Delta_{2}=0, \pi, 2 \pi, \ldots$ e $\Delta_{3}=0, \pi, 2 \pi, \ldots$ ocorrem simultaneamente.

Na prática, a convergência do método é garantida quando os sensores são posicionados em pontos fora dos mútiplos de meio comprimento de onda $\lambda / 2$ com uma tolerância de $5 \%$ de $\lambda$, como por exemplo:

$$
0,05 \lambda<\lambda_{n}<0,45 \lambda
$$




\title{
Apêndice B - Dados obtidos no ensaio de caracterização do gerador de ondas
}

\author{
A seguir são listados os dados obtidos no ensaio de caracterização do gerador \\ de ondas, a descrição deste ensaio se encontra no capítulo 6. A análise foi realizada \\ no domínio da freqüência através do método da densidade espectral de potência \\ cruzada. No qual, os valores obtidos de módulo e fase, são uma comparação do \\ sensor em questão com o sinal de referência.
}


Tabela B.1: Ensaio para determinação do desempenho do gerador de ondas. Módulo dos sensores capacitivos.

\begin{tabular}{ccccc}
\hline $\begin{array}{c}\text { Número } \\
\text { do ensaio }\end{array}$ & $\begin{array}{c}\text { freqüência } \\
(\mathrm{Hz})\end{array}$ & $\begin{array}{c}\text { Sensor } 1 \\
\text { módulo }\end{array}$ & $\begin{array}{c}\text { Sensor } 2 \\
\text { módulo }\end{array}$ & $\begin{array}{c}\text { Sensor } 3 \\
\text { módulo }\end{array}$ \\
\hline 1 & 0,50 & 0,4408 & 0,4433 & 0,4414 \\
2 & 0,50 & 0,4419 & 0,4436 & 0,4405 \\
3 & 0,50 & 0,4319 & 0,4296 & 0,4269 \\
4 & 0,75 & 0,9353 & 0,9429 & 0,9313 \\
5 & 0,75 & 0,8997 & 0,9079 & 0,8889 \\
6 & 0,75 & 0,8280 & 0,8662 & 0,8802 \\
7 & 1,00 & 1,2294 & 1,2201 & 1,2152 \\
8 & 1,00 & 1,2292 & 1,2243 & 1,2334 \\
9 & 1,00 & 1,1920 & 1,1990 & 1,1941 \\
10 & 1,25 & 1,4135 & 1,4168 & 1,4196 \\
11 & 1,25 & 1,4062 & 1,4019 & 1,4149 \\
12 & 1,25 & 1,3667 & 1,3654 & 1,3846 \\
13 & 1,50 & 1,6211 & 1,6210 & 1,5494 \\
14 & 1,50 & 1,5713 & 1,5707 & 1,5418 \\
15 & 1,50 & 1,5144 & 1,5285 & 1,5093 \\
16 & 1,75 & 1,7527 & 1,7549 & 1,6870 \\
17 & 1,75 & 1,7098 & 1,7206 & 1,7011 \\
18 & 1,75 & 1,6627 & 1,6856 & 1,7060 \\
19 & 2,00 & 1,6311 & 1,6072 & 1,6432 \\
20 & 2,00 & 1,5898 & 1,5789 & 1,6538 \\
21 & 2,00 & 1,5911 & 1,5829 & 1,6818 \\
22 & 2,25 & 1,7181 & 1,6797 & 1,6738 \\
23 & 2,25 & 1,5926 & 1,5956 & 1,6625 \\
24 & 2,25 & 1,5636 & 1,6296 & 1,7452 \\
25 & 2,50 & 2,2678 & 2,1612 & 2,0545 \\
26 & 2,50 & 1,7698 & 1,6107 & 1,5888 \\
27 & 2,50 & 1,4012 & 1,4125 & 1,7031 \\
28 & 2,75 & 2,2312 & 2,1754 & 2,0170 \\
29 & 2,75 & 1,6693 & 1,6061 & 1,5388 \\
30 & 2,75 & 1,3674 & 1,4396 & 1,4748 \\
31 & 2,90 & 1,8754 & 1,8161 & 1,8545 \\
32 & 2,90 & 1,4101 & 1,2606 & 1,3807 \\
33 & 2,90 & 1,4534 & 1,4113 & 1,5499 \\
34 & 1,25 & 1,3781 & 1,3861 & 1,4130 \\
35 & 2,00 & 1,5707 & 1,5390 & 1,6123 \\
36 & 2,25 & 1,5220 & 1,5125 & 1,6087 \\
\hline & & & &
\end{tabular}


Tabela B.2: Ensaio para determinação do desempenho do gerador de ondas. Módulo e fase dos sensores por ultra-som.

\begin{tabular}{ccrcr}
\hline Número & \multicolumn{2}{c}{ Sensor 2} & \multicolumn{2}{c}{ Sensor 3} \\
do ensaio & módulo & \multicolumn{1}{c}{ fase } & módulo & \multicolumn{1}{c}{ fase } \\
\hline 1 & 0,5067 & 102,79 & 0,4997 & 102,83 \\
2 & 0,5067 & 102,35 & 0,5043 & 102,26 \\
3 & 0,5142 & 104,43 & 0,5084 & 103,27 \\
4 & 1,0351 & 85,57 & 1,0339 & 85,87 \\
5 & 1,0250 & 87,00 & 1,0216 & 87,25 \\
6 & 1,0319 & 88,13 & 1,0347 & 88,47 \\
7 & 1,3024 & 75,36 & 1,2916 & 74,34 \\
8 & 1,3052 & 74,41 & 1,3025 & 73,71 \\
9 & 1,3054 & 73,05 & 1,3014 & 72,47 \\
10 & 1,7497 & 65,29 & 1,7285 & 64,89 \\
11 & 1,6726 & 65,85 & 1,6574 & 65,41 \\
12 & 1,6499 & 63,50 & 1,6552 & 63,13 \\
13 & 1,9191 & 57,99 & 1,8509 & 54,27 \\
14 & 1,8568 & 58,70 & 1,8787 & 54,51 \\
15 & 1,8222 & 58,21 & 1,8645 & 52,07 \\
16 & 2,1477 & 48,26 & 2,1207 & 49,23 \\
17 & 2,0920 & 49,35 & 2,1009 & 49,78 \\
18 & 2,1065 & 49,80 & 2,0958 & 50,09 \\
19 & 2,3454 & 42,47 & 2,4022 & 41,82 \\
20 & 2,2641 & 43,12 & 2,4062 & 41,57 \\
21 & 2,2394 & 43,22 & 2,3806 & 40,43 \\
22 & 2,6441 & 39,15 & 2,6114 & 38,15 \\
23 & 2,5988 & 40,44 & 2,5892 & 39,00 \\
24 & 2,6007 & 38,91 & 2,5897 & 38,79 \\
25 & 3,3962 & 28,04 & 3,3257 & 26,34 \\
26 & 3,3177 & 28,81 & 3,3198 & 26,59 \\
27 & 3,1754 & 24,31 & 3,1455 & 24,72 \\
28 & 3,5645 & 18,56 & 3,3028 & 18,18 \\
29 & 3,6168 & 19,81 & 3,4672 & 18,65 \\
30 & 4,1379 & 7,96 & 4,1839 & 7,57 \\
31 & 3,9555 & 17,76 & 3,7951 & 21,48 \\
32 & 3,9664 & 14,95 & 3,7618 & 24,13 \\
33 & 3,8363 & 13,74 & 4,0472 & 21,32 \\
34 & 1,7675 & 66,02 & 1,7630 & 65,78 \\
35 & 2,2134 & 47,00 & 2,5594 & 38,39 \\
36 & 2,6027 & 39,74 & 2,6201 & 38,35 \\
\hline & & & &
\end{tabular}


Tabela B.3: Ensaio para determinação do desempenho do gerador de ondas. Módulo e fase dos motores.

\begin{tabular}{|c|c|c|c|c|c|c|c|c|}
\hline \multirow{2}{*}{$\begin{array}{l}\text { Número } \\
\text { do ensaio }\end{array}$} & \multicolumn{2}{|c|}{ Motor 1} & \multicolumn{2}{|c|}{ Motor 2} & \multicolumn{2}{|c|}{ Motor 3} & \multicolumn{2}{|c|}{ Motor 4} \\
\hline & módulo & fase & módulo & fase & módulo & fase & módulo & fase \\
\hline 1 & 0,9998 & $-2,25$ & 0,9999 & $-2,25$ & 0,9997 & $-2,25$ & 0,9999 & $-2,25$ \\
\hline 2 & 0,9995 & $-2,25$ & 0,9995 & $-2,25$ & 0,9995 & $-2,25$ & 0,9994 & $-2,25$ \\
\hline 3 & 0,9992 & $-2,25$ & 0,9992 & $-2,25$ & 0,9992 & $-2,25$ & 0,9992 & $-2,25$ \\
\hline 4 & 1,0002 & $-3,41$ & 0,9999 & $-3,41$ & 1,0006 & $-3,41$ & 1,0001 & $-3,39$ \\
\hline 5 & 0,9988 & $-3,38$ & 0,9987 & $-3,39$ & 0,9988 & $-3,39$ & 0,9988 & $-3,39$ \\
\hline 6 & 0,9986 & $-3,38$ & 0,9984 & $-3,38$ & 0,9985 & $-3,39$ & 0,9985 & $-3,39$ \\
\hline 7 & 1,0013 & $-4,58$ & 1,0012 & $-4,58$ & 1,0011 & $-4,56$ & 1,0009 & $-4,61$ \\
\hline 8 & 0,9983 & $-4,53$ & 0,9984 & $-4,52$ & 0,9982 & $-4,53$ & 0,9982 & $-4,53$ \\
\hline 9 & 9978 & $-4,52$ & 0,9980 & $-4,52$ & 0,9979 & $-4,52$ & 0,9979 & $-4,53$ \\
\hline 10 & 1,0227 & $-6,50$ & 1,0157 & $-6,23$ & 1,0197 & $-6,26$ & 1,0165 & $-6,14$ \\
\hline 11 & 0,9977 & $-5,68$ & 0,9978 & $-5,66$ & 0,9974 & $-5,68$ & 0,9979 & $-5,70$ \\
\hline 12 & 0,9970 & $-5,66$ & 0,9969 & $-5,66$ & 0,9969 & $-5,66$ & 0,9972 & $-5,66$ \\
\hline 13 & 0024 & $-7,03$ & 1,0038 & $-7,32$ & 1,0053 & $-7,13$ & 1,0013 & $-6,87$ \\
\hline 14 & 967 & $-6,83$ & 0,9965 & $-6,84$ & 0,9971 & $-6,84$ & 0,9973 & $-6,86$ \\
\hline 15 & 0,9958 & $-6,81$ & 0,9959 & $-6,82$ & 0,9958 & $-6,81$ & 0,9959 & $-6,81$ \\
\hline 16 & 023 & $-8,27$ & 1,0044 & $-8,73$ & 1,0074 & $-8,36$ & 050 & $-8,15$ \\
\hline 17 & 0,9962 & $-8,03$ & 0,9959 & $-7,98$ & 0,9968 & $-8,02$ & 0,9967 & $-8,06$ \\
\hline 18 & 9943 & $-7,96$ & 0,99 & $-7,98$ & 0,9 & $-7,97$ & & $-7,97$ \\
\hline 19 & 050 & $-9,69$ & 1,0054 & $-9,88$ & 1,0055 & $-9,72$ & 084 & $-9,50$ \\
\hline 20 & 9958 & $-9,23$ & 0,9952 & $-9,29$ & 0,9972 & $-9,27$ & 0,9941 & $-9,21$ \\
\hline 21 & 0,9924 & $-9,12$ & 0,9930 & $-9,15$ & 0,9927 & $-9,14$ & 0,9935 & $-9,15$ \\
\hline 22 & 1,0028 & $-10,91$ & 1,0014 & $-11,14$ & 1,0066 & $-11,12$ & 0,9949 & $-10,60$ \\
\hline 23 & 0,9948 & $-10,49$ & 0,9939 & $-10,49$ & 0,9950 & $-10,48$ & 0,9955 & $-10,55$ \\
\hline 24 & 0,9915 & $-10,33$ & 0,9909 & $-10,35$ & 0,9917 & $-10,32$ & 0,9919 & $-10,31$ \\
\hline 25 & 1,0116 & $-12,40$ & 1,0135 & $-12,53$ & 1,0245 & $-12,82$ & 1,0104 & $-12,43$ \\
\hline 26 & 0,9913 & $-11,78$ & 0,9931 & $-11,75$ & 0,9931 & $-11,61$ & 0,9924 & $-11,59$ \\
\hline 27 & 0,9897 & $-11,51$ & 0,9893 & $-11,55$ & 0,9912 & $-11,52$ & 0,9903 & $-11,52$ \\
\hline 28 & 1,0058 & $-14,20$ & 1,0134 & $-13,99$ & 1,0139 & $-14,48$ & 0,9981 & $-13,24$ \\
\hline 29 & 0,9934 & $-12,99$ & 0,9941 & $-12,95$ & 0,9941 & $-13,01$ & 0,9930 & $-13,03$ \\
\hline 30 & & $-12,71$ & 0,9873 & $-12,73$ & 0,9878 & $-12,70$ & 0,9877 & $-12,71$ \\
\hline 31 & 1,0095 & $-14,18$ & 1,0199 & $-15,04$ & 1,0190 & $-15,42$ & 1,0117 & $-14,56$ \\
\hline 32 & 0,9925 & $-13,77$ & 0,9921 & $-13,61$ & 0,9945 & $-13,86$ & 0,9928 & $-13,67$ \\
\hline 33 & 0,9881 & $-13,43$ & 0,9866 & $-13,41$ & 0,9879 & $-13,47$ & 0,9882 & $-13,43$ \\
\hline 34 & 0,9996 & $-5,73$ & 1,0000 & $-5,76$ & 0,9978 & $-5,77$ & 0,9989 & $-5,74$ \\
\hline 35 & 0,9916 & $-9,11$ & 0,9925 & $-9,11$ & 0,9913 & $-9,12$ & 0,9915 & $-9,13$ \\
\hline 36 & 0,9945 & $-10,47$ & 0,9948 & $-10,47$ & 0,9944 & $-10,41$ & 0,9939 & $-10,47$ \\
\hline
\end{tabular}

